\title{
Synthetic Efforts Towards the Macrolactone Core of Leucascandrolide A
}

\author{
Laurent Ferrié, Lucie Boulard, Fabienne Pradaux, Samir Bouzbouz, Sébastien Reymond, Patrice
}

Capdevielle and Janine Cossy*

\section{Supplementary information: NMR spectra}

General....................S2

${ }^{1} \mathrm{H}$ Compound 3............S3

${ }^{13} \mathrm{C}$ Compound 3............S4

${ }^{1} \mathrm{H}$ Compound 4.............S5

${ }^{13} \mathrm{C}$ Compound $4 . . . \ldots \ldots \ldots . . . .56$

${ }^{1} \mathrm{H}$ Intermediate 4-1.........S7

${ }^{13} \mathrm{C}$ Intermediate 4-1....... S8

${ }^{1} \mathrm{H}$ Compound 5............S9

${ }^{13} \mathrm{C}$ Compound 5.........S10

${ }^{1} \mathrm{H}$ Intermediate 5-1.......S11

${ }^{13} \mathrm{C}$ Intermediate 5-1........S12

${ }^{1} \mathrm{H}$ Intermediate 5-2 .......S13

${ }^{13} \mathrm{C}$ Intermediate 5-2.......S14

${ }^{1} \mathrm{H}$ Compound 6...........S15

${ }^{13} \mathrm{C}$ Compound 6...........S16

${ }^{1} \mathrm{H}$ Compound 7............S17

${ }^{13} \mathrm{C}$ Compound 7...........S18

${ }^{1} \mathrm{H}$ Compound 8............S19

${ }^{13} \mathrm{C}$ Compound 8...........S20

${ }^{1} \mathrm{H}$ Compound 9............S21

${ }^{13} \mathrm{C}$ Compound 9..........S22

${ }^{1} \mathrm{H}$ Compound 10...........S23

${ }^{13} \mathrm{C}$ Compound 10..........S24

${ }^{1} \mathrm{H}$ Compound 11..........S25

${ }^{13} \mathrm{C}$ Compound 11...........S26

${ }^{1} \mathrm{H}$ Intermediate 12-1.......S27

${ }^{13} \mathrm{C}$ Intermediate 12-1.....S28

${ }^{1} \mathrm{H}$ Compound 13.........S29

${ }^{13} \mathrm{C}$ Compound 13...........S30

${ }^{1} \mathrm{H}$ Intermediate 13.........S31

${ }^{13} \mathrm{C}$ Intermediate $\mathbf{1 3 - 1 . . . . . S 3 2}$

${ }^{1} \mathrm{H}$ Compound 14..........S33

${ }^{13} \mathrm{C}$ Compound 14..........S34

${ }^{1} \mathrm{H}$ Compound 15..........S35

${ }^{13} \mathrm{C}$ Compound 15..........S36

${ }^{1} \mathrm{H}$ Intermediate 15-1........S37

${ }^{13} \mathrm{C}$ Intermediate 15-1.....S39

${ }^{1} \mathrm{H}$ Intermediate 15-2......S40
${ }^{13} \mathrm{C}$ Intermediate 15-2.....S41

${ }^{1} \mathrm{H}$ Intermediate 15-3......S42

${ }^{13} \mathrm{C}$ Intermediate 15-3.....S43

${ }^{1} \mathrm{H}$ Intermediate 15-4......S44

${ }^{13} \mathrm{C}$ Intermediate 15-4.....S45

${ }^{1} \mathrm{H}$ Compound 16..........S46

${ }^{13} \mathrm{C}$ Compound 16..........S48

${ }^{1} \mathrm{H}$ Compound 17...........S49

${ }^{13} \mathrm{C}$ Compound 17.........S50

${ }^{1} \mathrm{H}$ Intermediate 17-1......S51

${ }^{13} \mathrm{C}$ Intermediate 17-1.....S52

${ }^{1} \mathrm{H}$ Intermediate 17-2......S53

${ }^{13} \mathrm{C}$ Intermediate $\mathbf{1 7 - 2 . . . . . S 5 5}$

${ }^{1} \mathrm{H}$ Intermediate 17-3......S56

${ }^{13} \mathrm{C}$ Intermediate 17-3.....S57

${ }^{1} \mathrm{H}$ Compound 18..........S58

${ }^{13} \mathrm{C}$ Compound 18.........S59

${ }^{1} \mathrm{H}$ Compound 19..........S60

${ }^{13} \mathrm{C}$ Compound 19..........S61

${ }^{1} \mathrm{H}$ Compound 21..........S62

${ }^{1} \mathrm{H}$ Compound 22...........S63

${ }^{13} \mathrm{C}$ Compound 22.........S64

${ }^{1} \mathrm{H}$ Compound 23...........S65

${ }^{1} \mathrm{H}$ Compound 24...........S66

${ }^{13} \mathrm{C}$ Compound 24..........S67

${ }^{1} \mathrm{H}$ Compound 25..........S68

${ }^{13} \mathrm{C}$ Compound 25.........S69

${ }^{1} \mathrm{H}$ Compound 28...........S70

${ }^{13} \mathrm{C}$ Compound 28.........S71

${ }^{1} \mathrm{H}$ Compound 29..........S72

${ }^{13} \mathrm{C}$ Compound 29..........S73

${ }^{1} \mathrm{H}$ Compound 31 ............S74

${ }^{13} \mathrm{C}$ Compound $31 \ldots . . . . . .575$

${ }^{1} \mathrm{H}$ Compound 32...........S76

${ }^{13} \mathrm{C}$ Compound 32.........S77

${ }^{1} \mathrm{H}$ Compound 34..........S78

${ }^{13} \mathrm{C}$ Compound 34.........S79

${ }^{1} \mathrm{H}$ Compound 35..........S80
${ }^{13} \mathrm{C}$ Compound 35.........S81

${ }^{1} \mathrm{H}$ Compound 36..........S82

${ }^{13} \mathrm{C}$ Compound 36..........S83

${ }^{1} \mathrm{H}$ Compound $37 . . . . . . . . . \mathrm{S} 84$

${ }^{13} \mathrm{C}$ Compound 37..........S85

${ }^{1} \mathrm{H}$ Compound 38...........S86

${ }^{13} \mathrm{C}$ Compound 38..........S87

${ }^{1} \mathrm{H}$ Compound 39...........S88

${ }^{13} \mathrm{C}$ Compound 39..........S89

${ }^{1} \mathrm{H}$ Compound 40..........S90

${ }^{13} \mathrm{C}$ Compound 41.........S91

${ }^{1} \mathrm{H}$ Compound cis-42......S82

${ }^{13} \mathrm{C}$ Compound cis-42.....S93

${ }^{1} \mathrm{H}$ macrolide 1.............S94

${ }^{13} \mathrm{C}$ macrolide 1 ............ S95

${ }^{1} \mathrm{H}$ macrolide 48............S96

${ }^{13} \mathrm{C}$ macrolide 48 ...........S97 


\section{GENERAL}

All the reactions were carried out under an argon atmosphere in anhydrous solvents. $\mathrm{CH}_{2} \mathrm{Cl}_{2}$ and toluene were distilled from $\mathrm{CaH}_{2}$. THF and $\mathrm{Et}_{2} \mathrm{O}$ were distilled from sodium/benzophenone. Flash chromatography was performed with Merck Geduran Si60 silica gel (40-63 $\mu \mathrm{M})$. Infrared spectra (IR) were recorded on an IRFT, wave-numbers are indicated in $\mathrm{cm}^{-1} .{ }^{1} \mathrm{H}$ NMR spectra were recorded at 300 or $400 \mathrm{MHz}$ and data are reported as follows: chemical shift from tetramethylsilane with the residual solvent peak as an internal indicator $\left(\mathrm{CDCl}_{3} \delta: 7.26, \mathrm{C}_{6} \mathrm{D}_{6} \delta: 7.16\right)$ multiplicity $(\mathrm{s}=$ singlet, $\mathrm{d}=$ doublet, $\mathrm{t}=$ triplet, $\mathrm{q}=$ quartet, quint $=$ quintet, sext $=$ sextet, $\mathrm{m}=$ multiplet or overlap of non-equivalent resonances), integration. ${ }^{13} \mathrm{C}$ NMR spectra were recorded at 100 or $75 \mathrm{MHz}$ and data are reported as follows: chemical shift from tetramethylsilane with the solvent as an internal indicator, multiplicity with proton $\left(\mathrm{CDCl}_{3} \delta: 77.0, \mathrm{C}_{6} \mathrm{D}_{6} \delta: 128.0, \mathrm{C}_{5} \mathrm{D}_{5} \mathrm{~N} \delta: 135.5\right)$. Mass spectra with electronic impact (MS-EI) were recorded on a GC/MS (70 eV). 


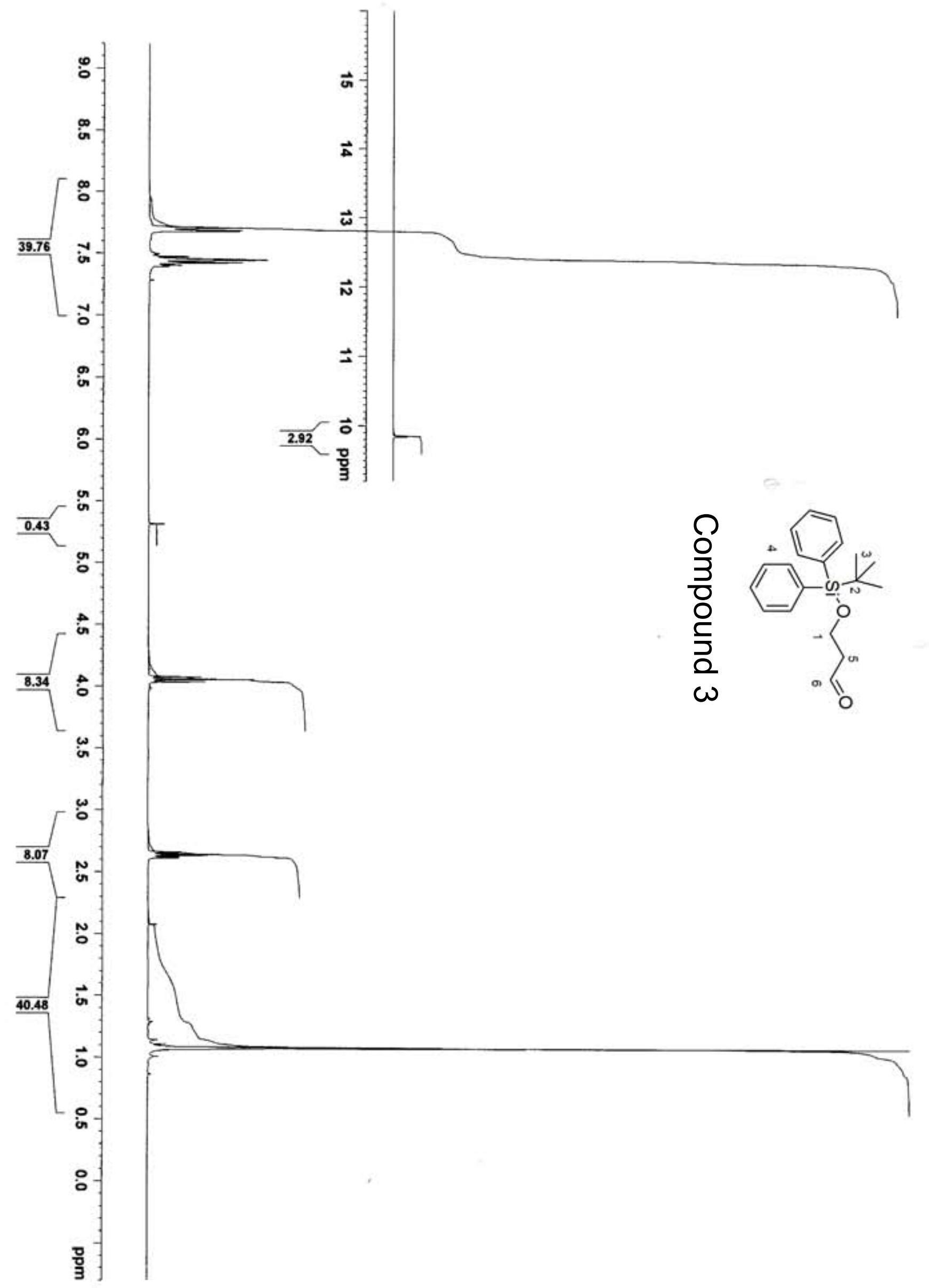

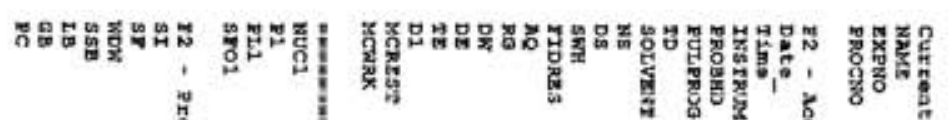

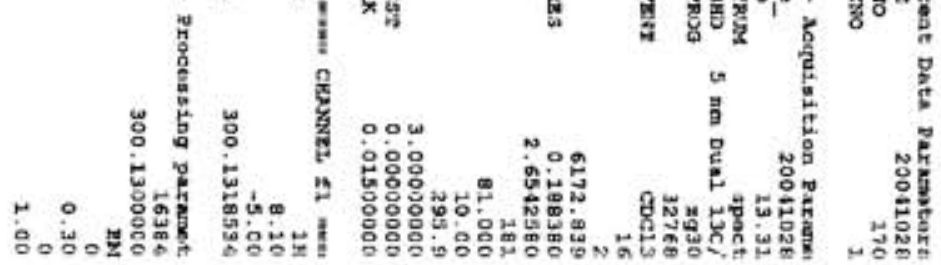




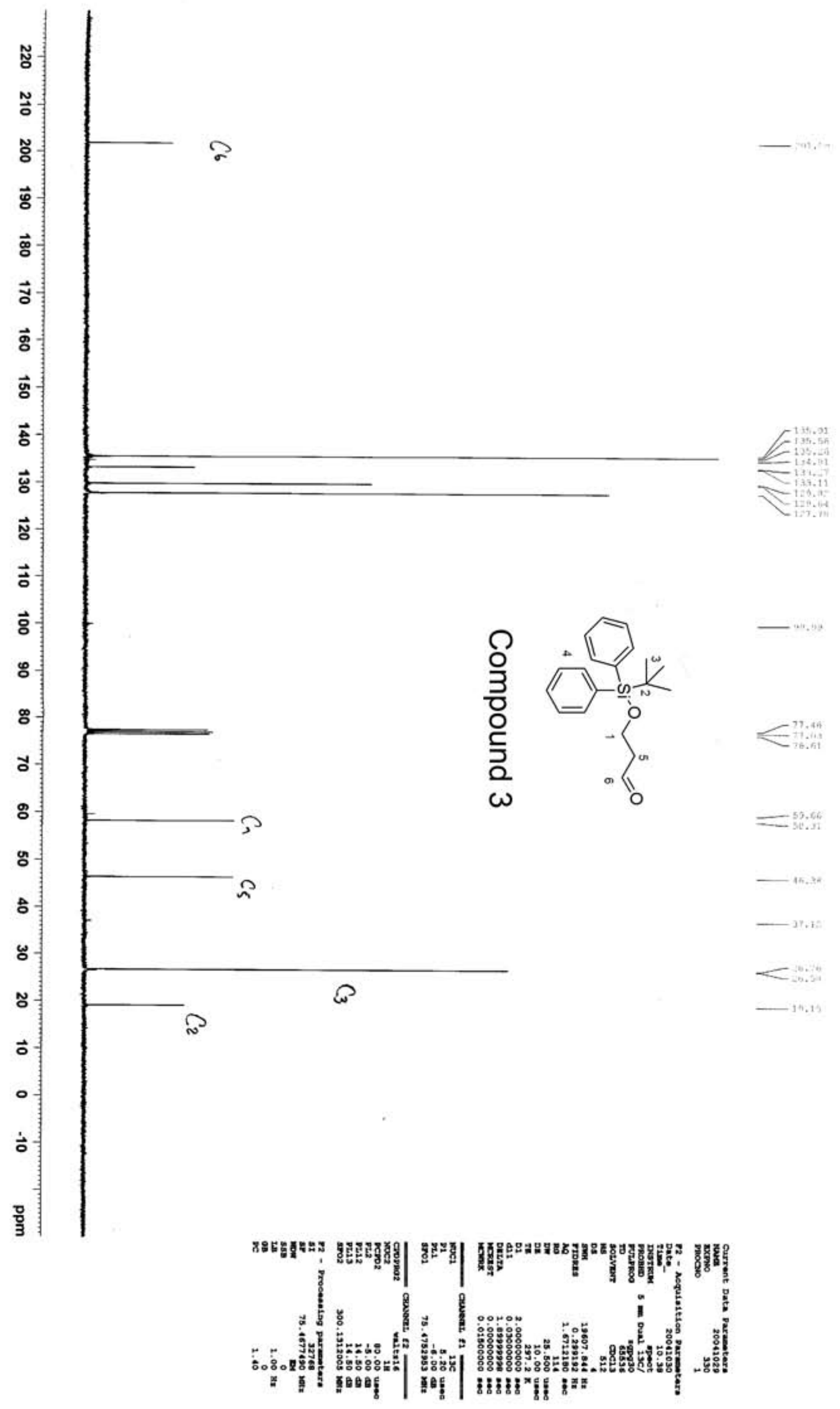




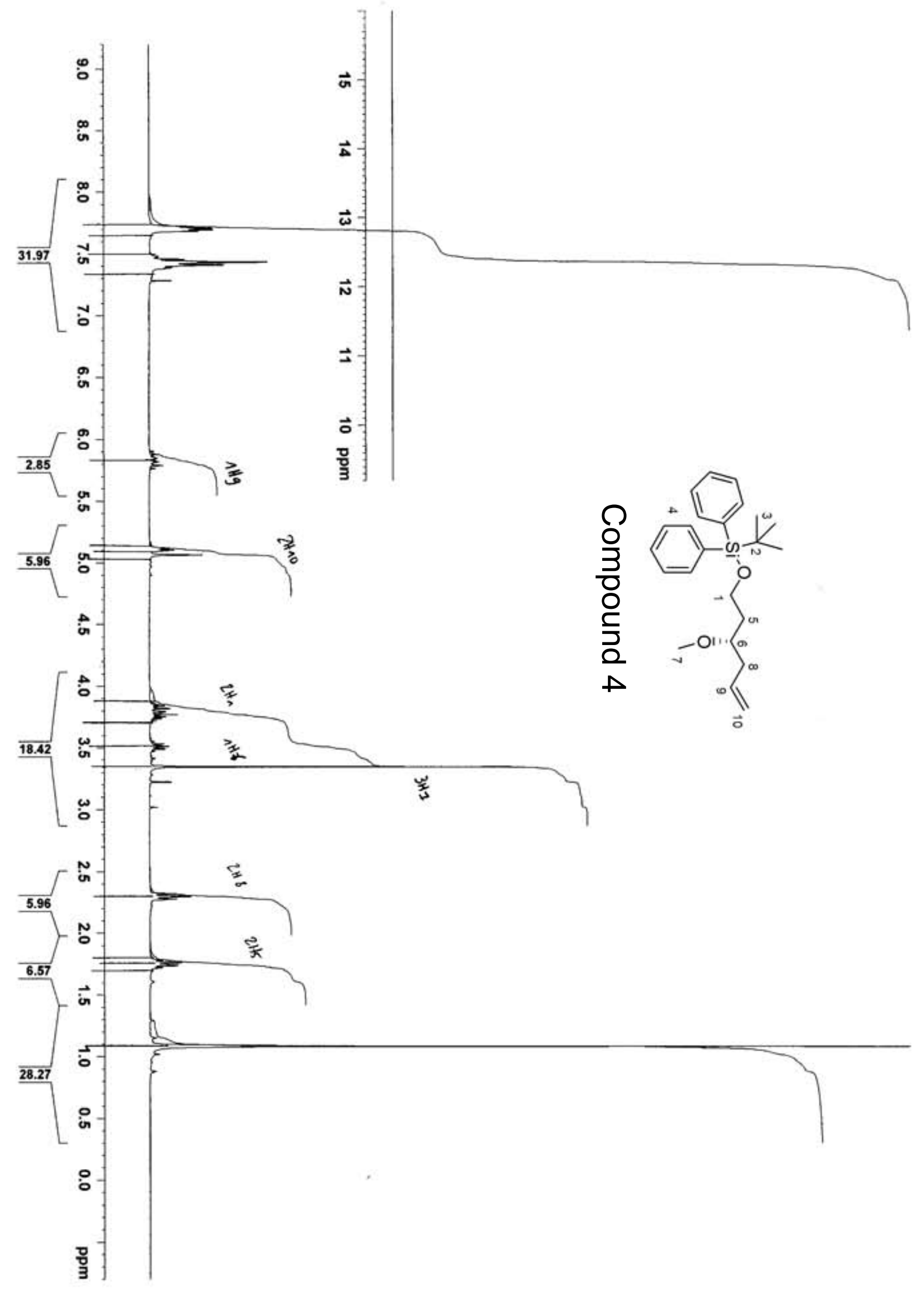



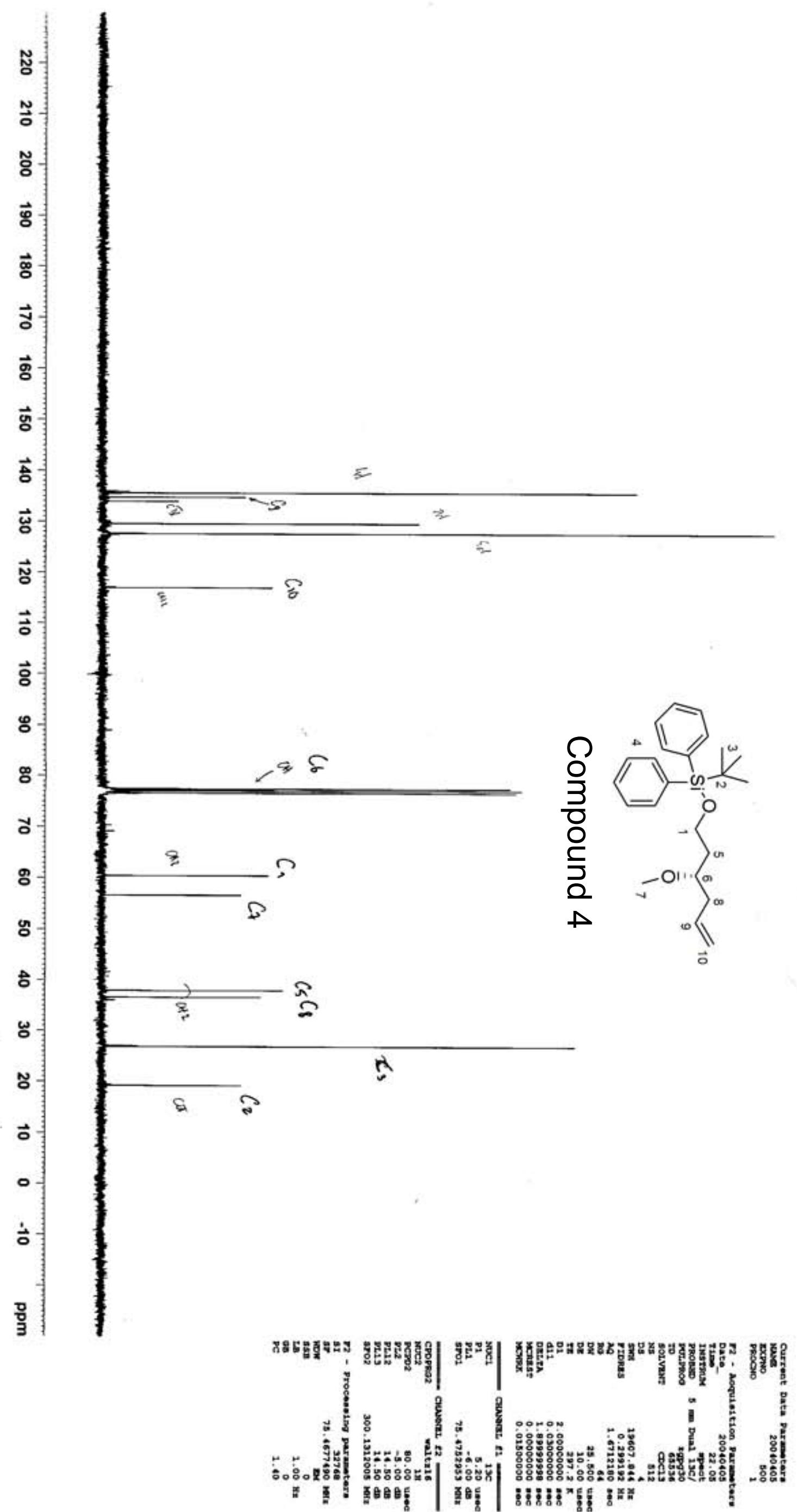


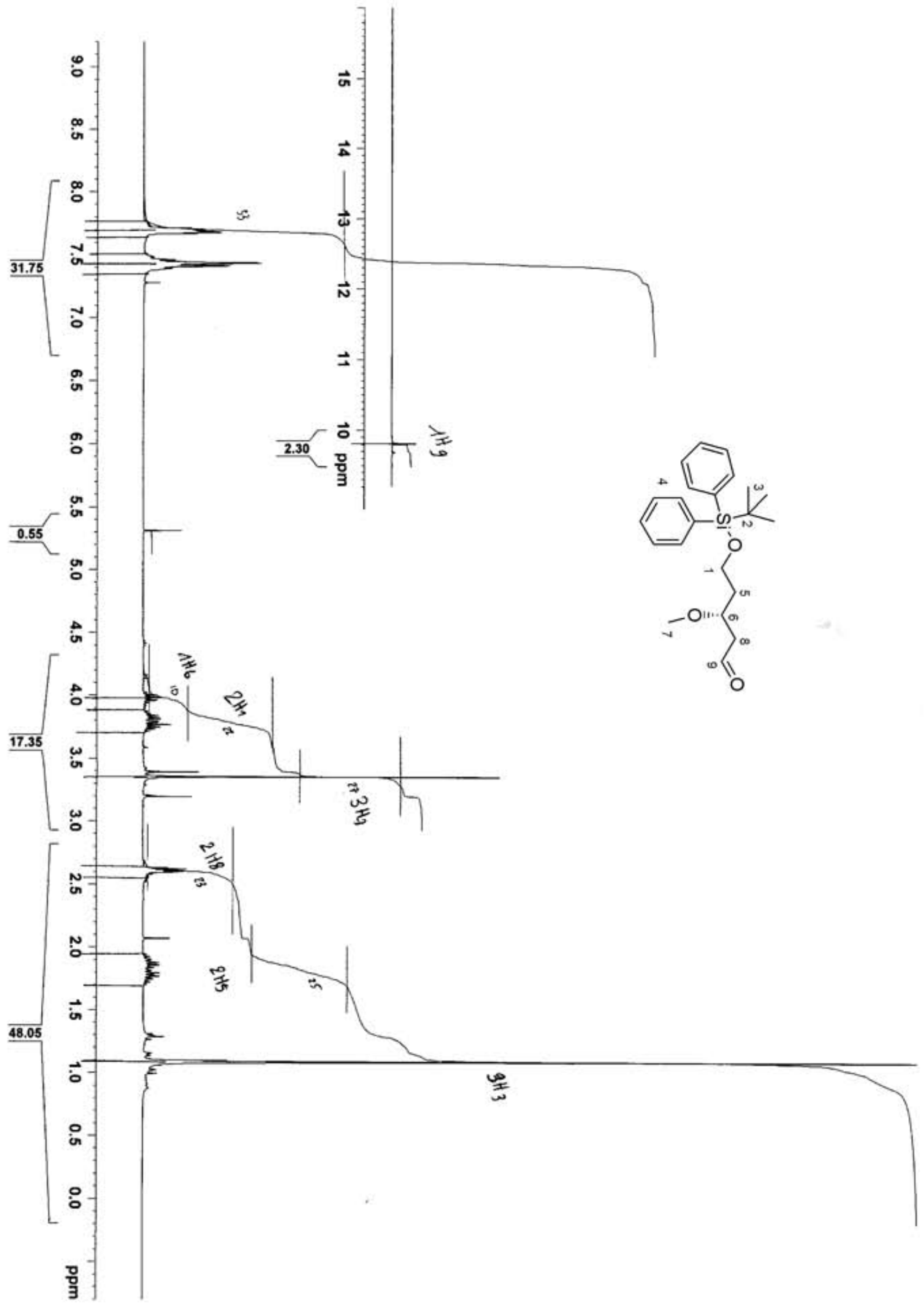




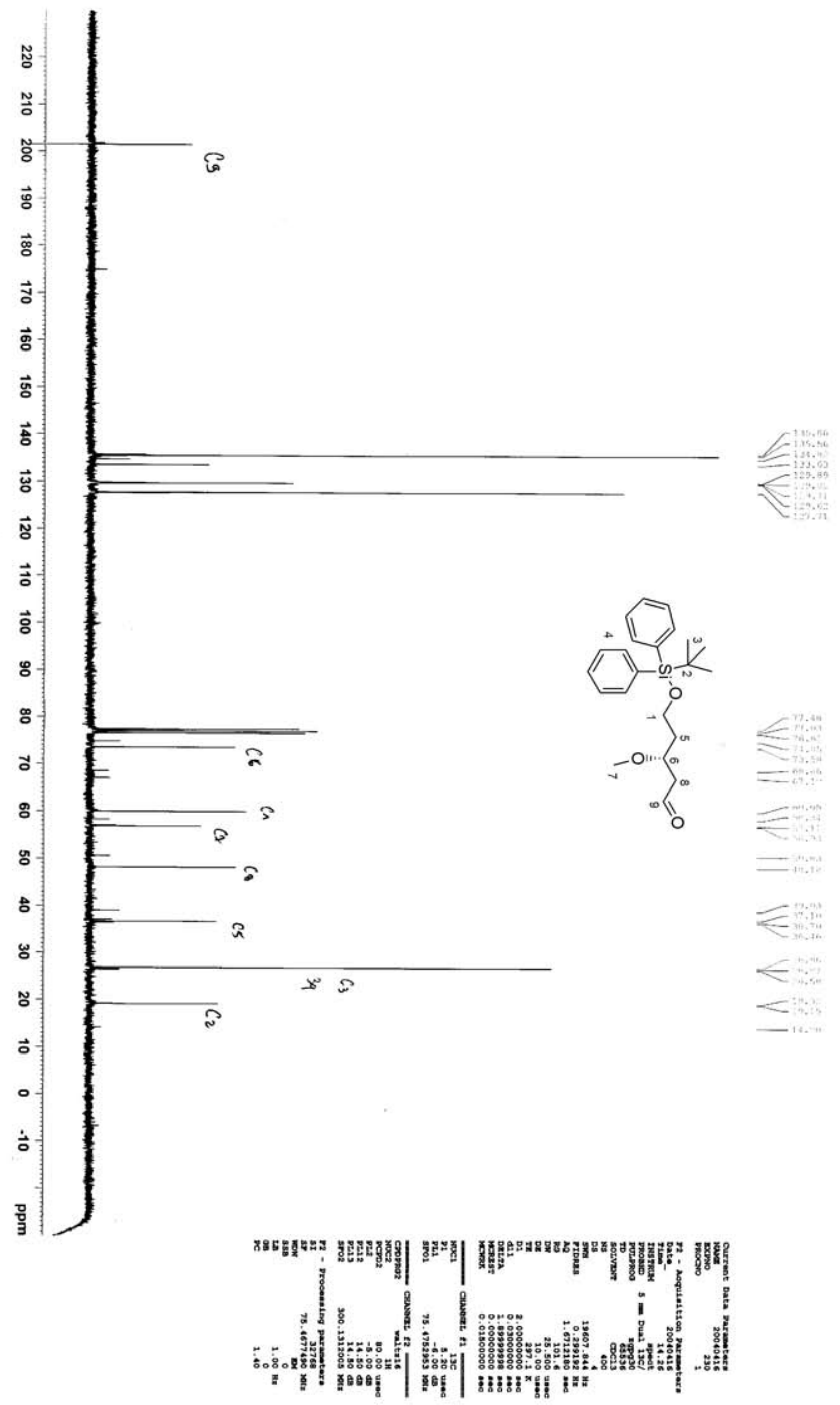



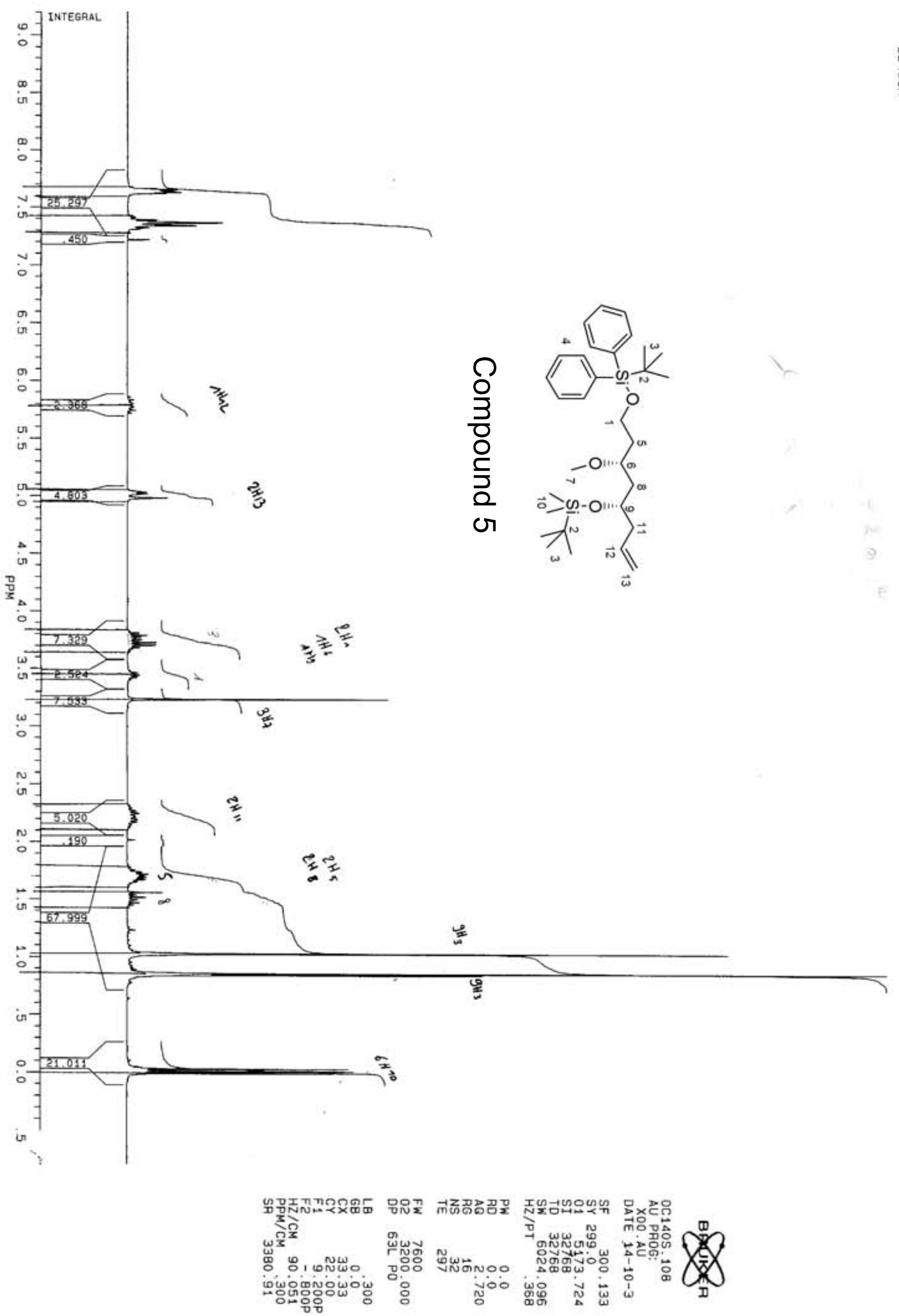


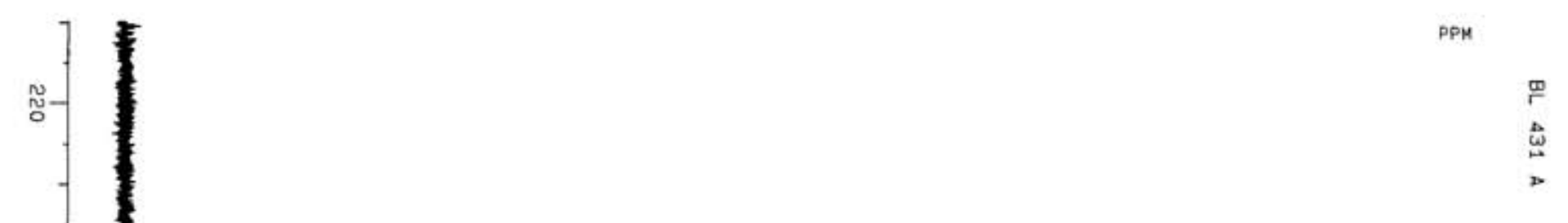

ะั

홍

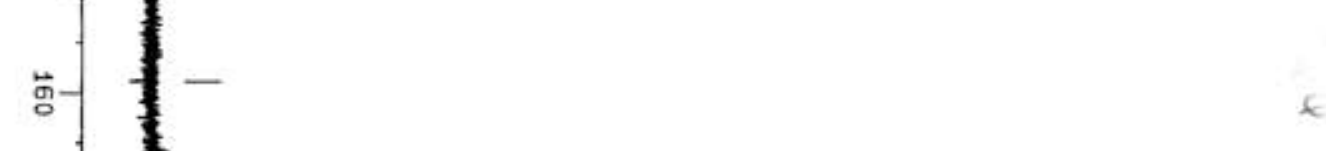

s

$$
\text { . }
$$

.

문

$\sqrt{2}-3$

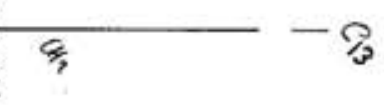

$-$

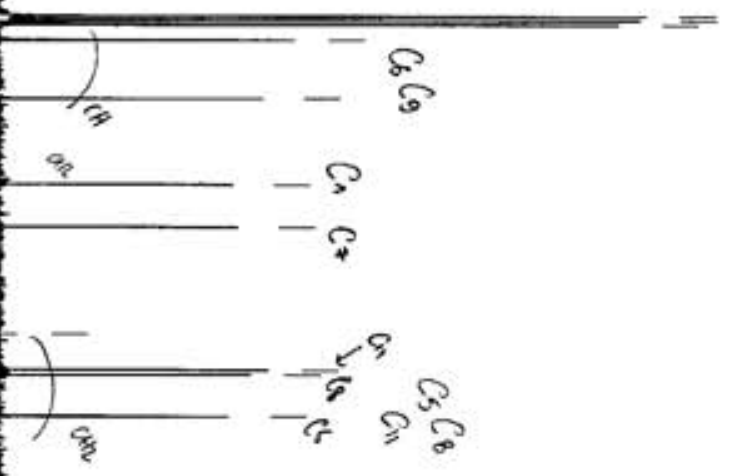

\section{O}
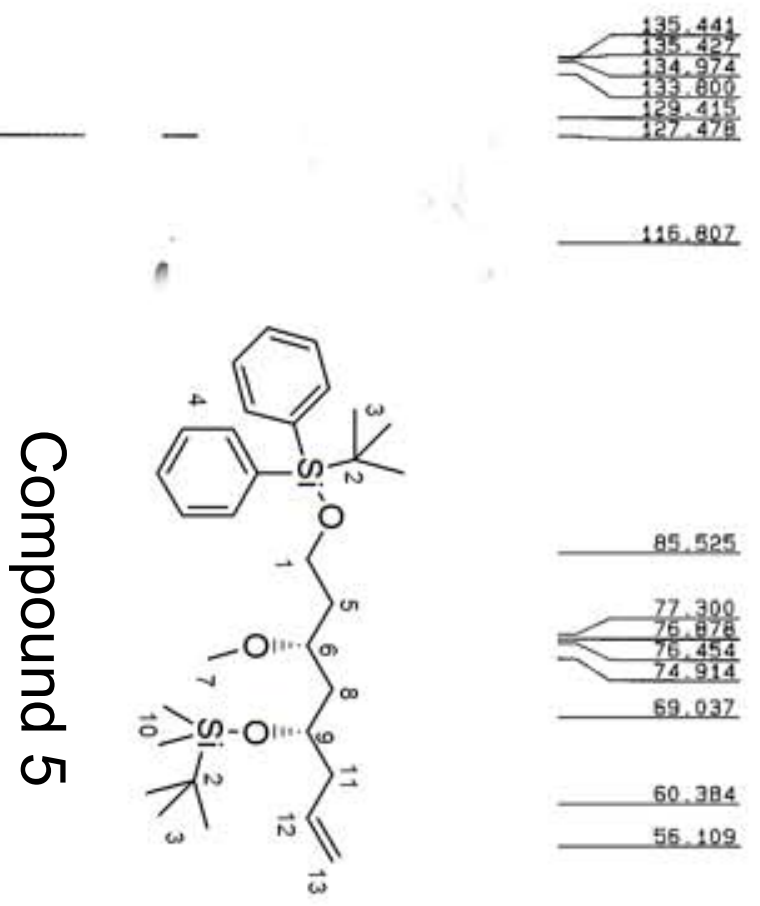

116.807

85.525

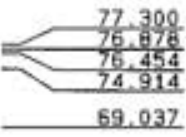

60.384

55.109

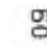
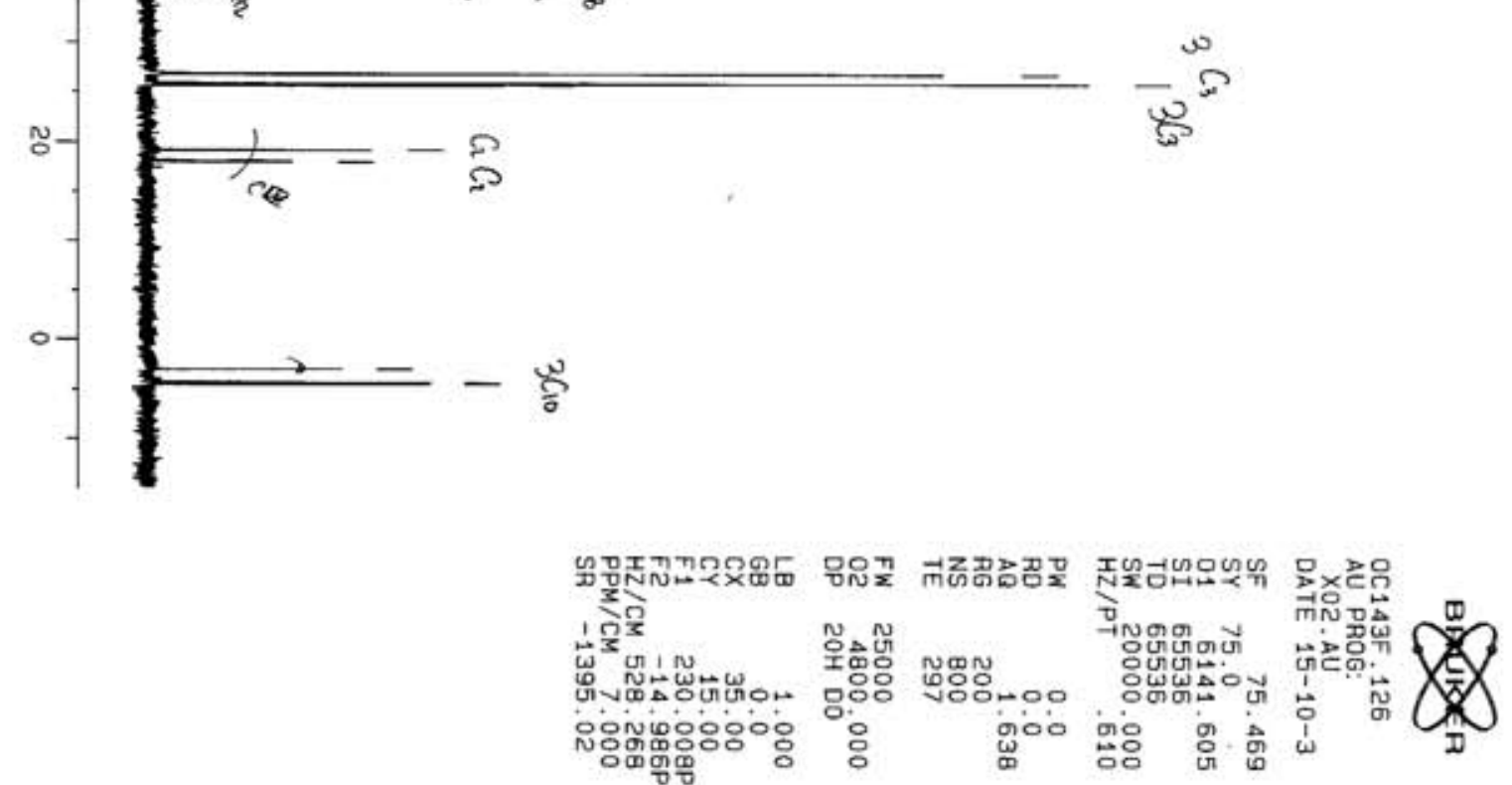

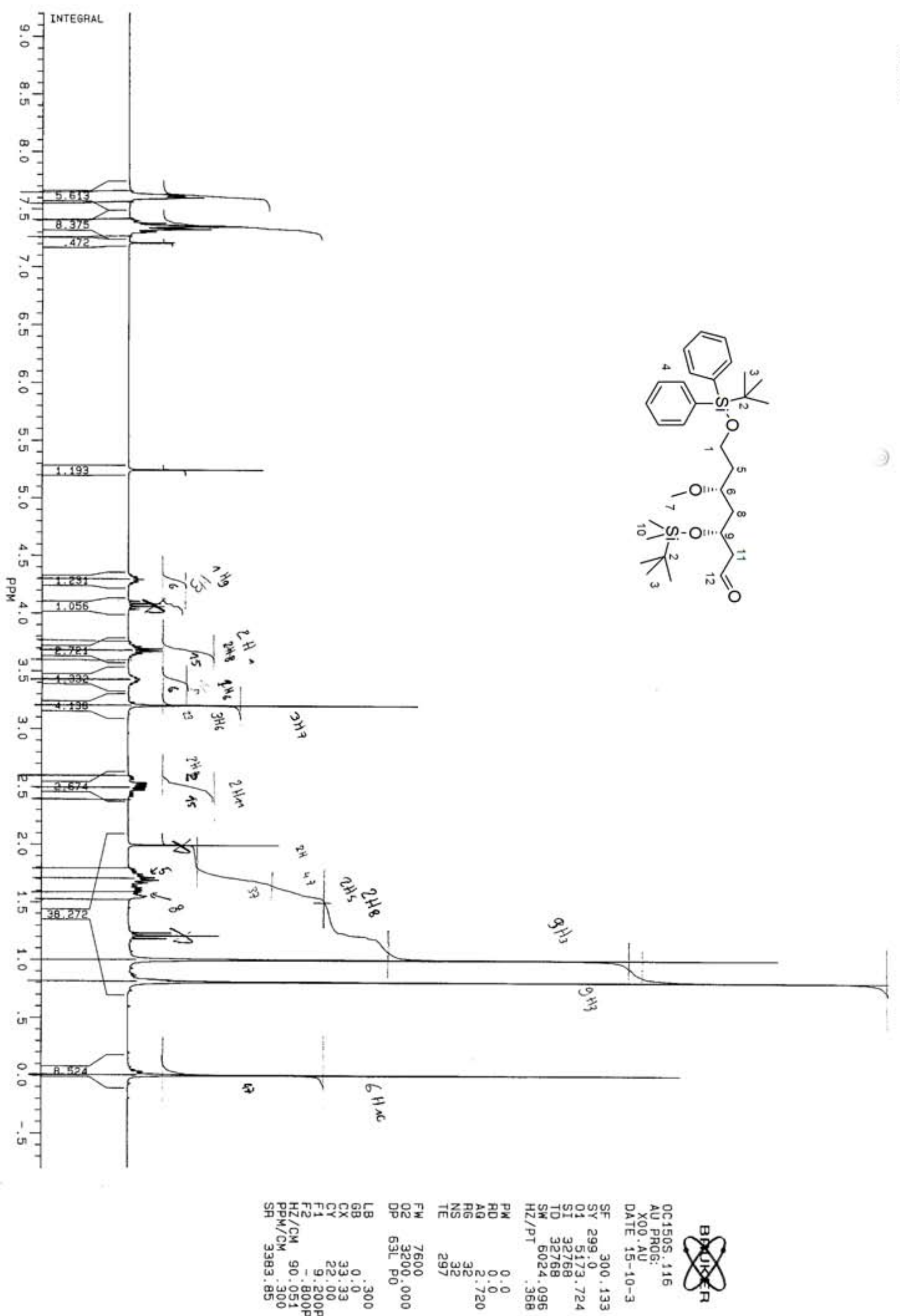

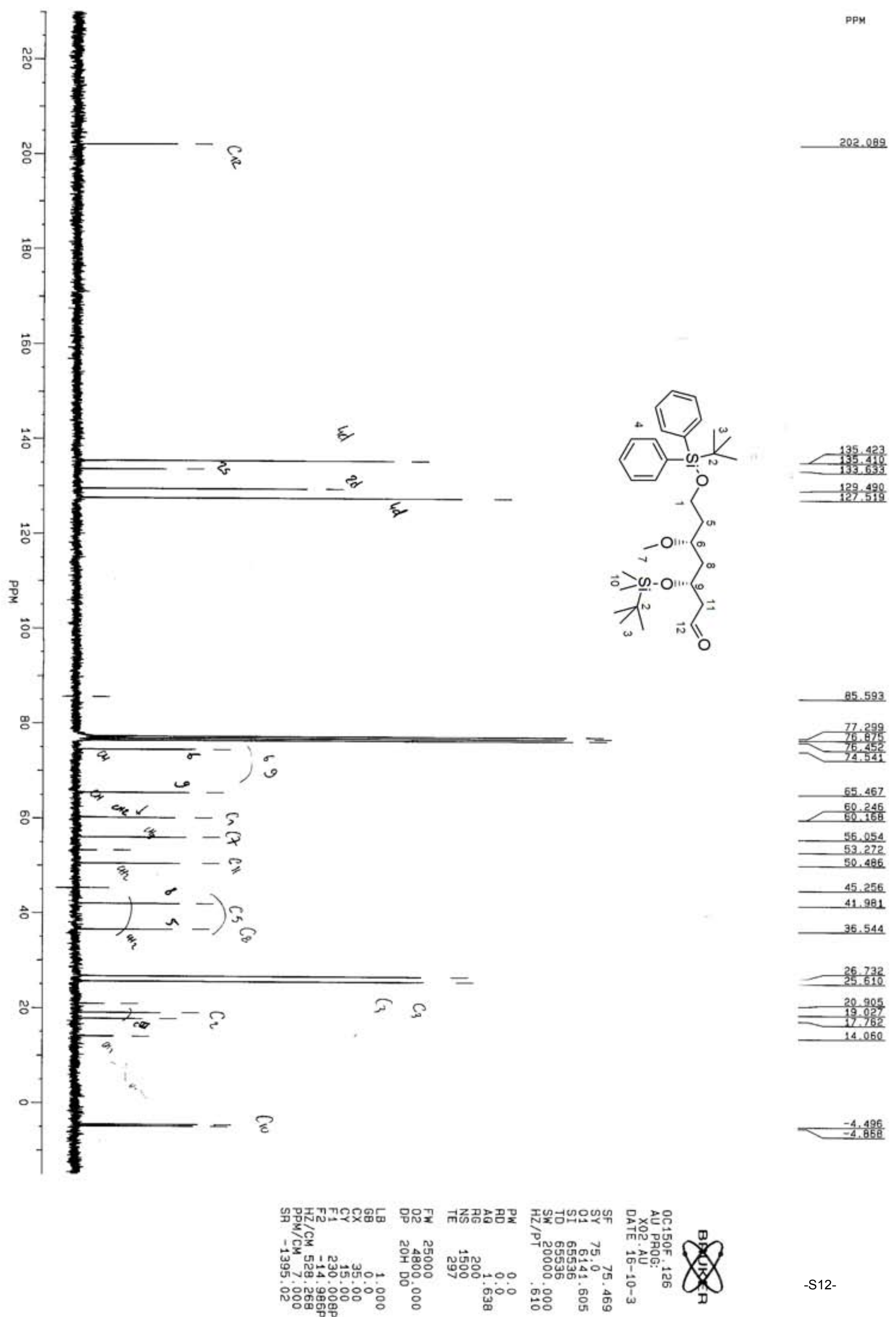

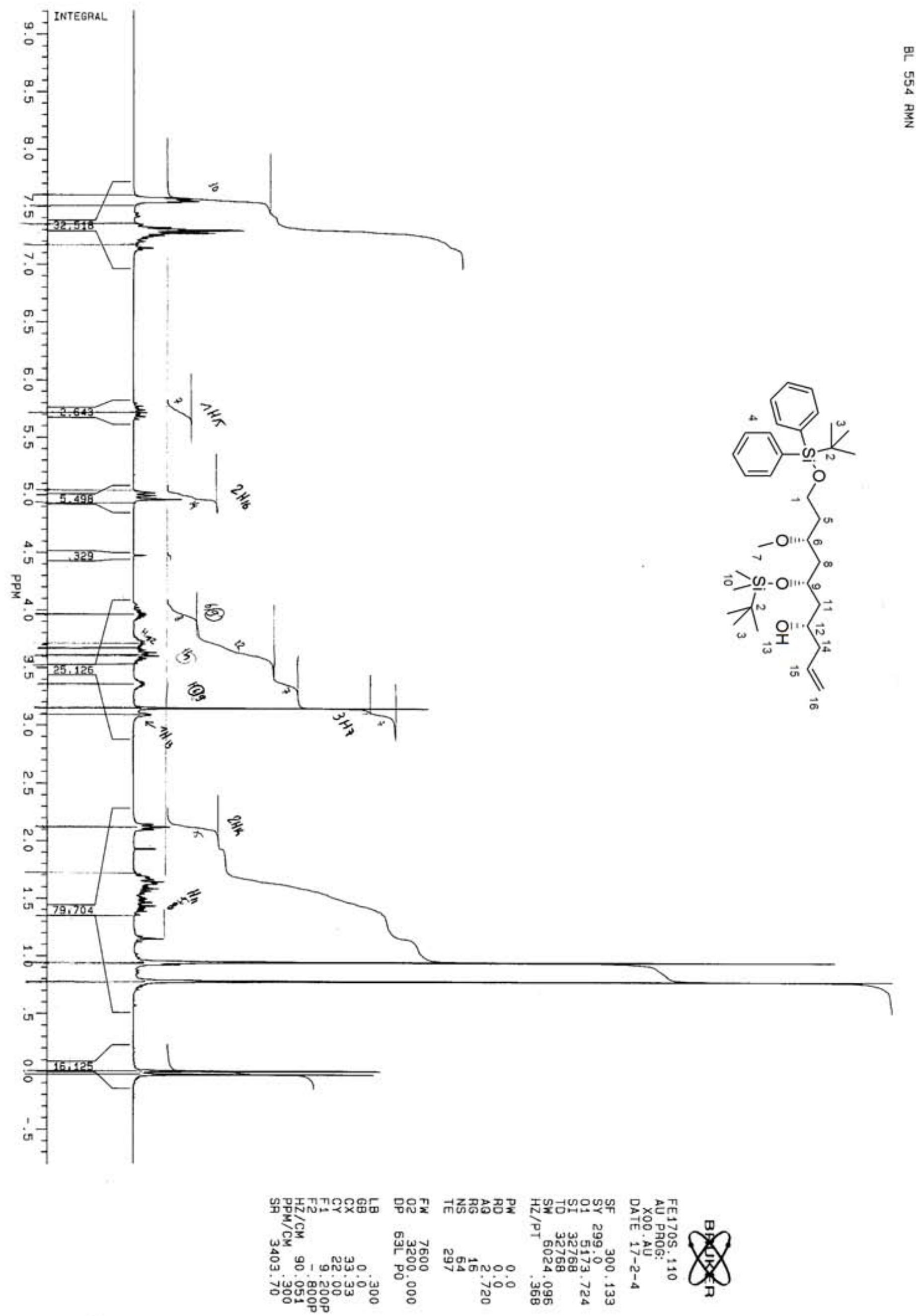

-S13- 


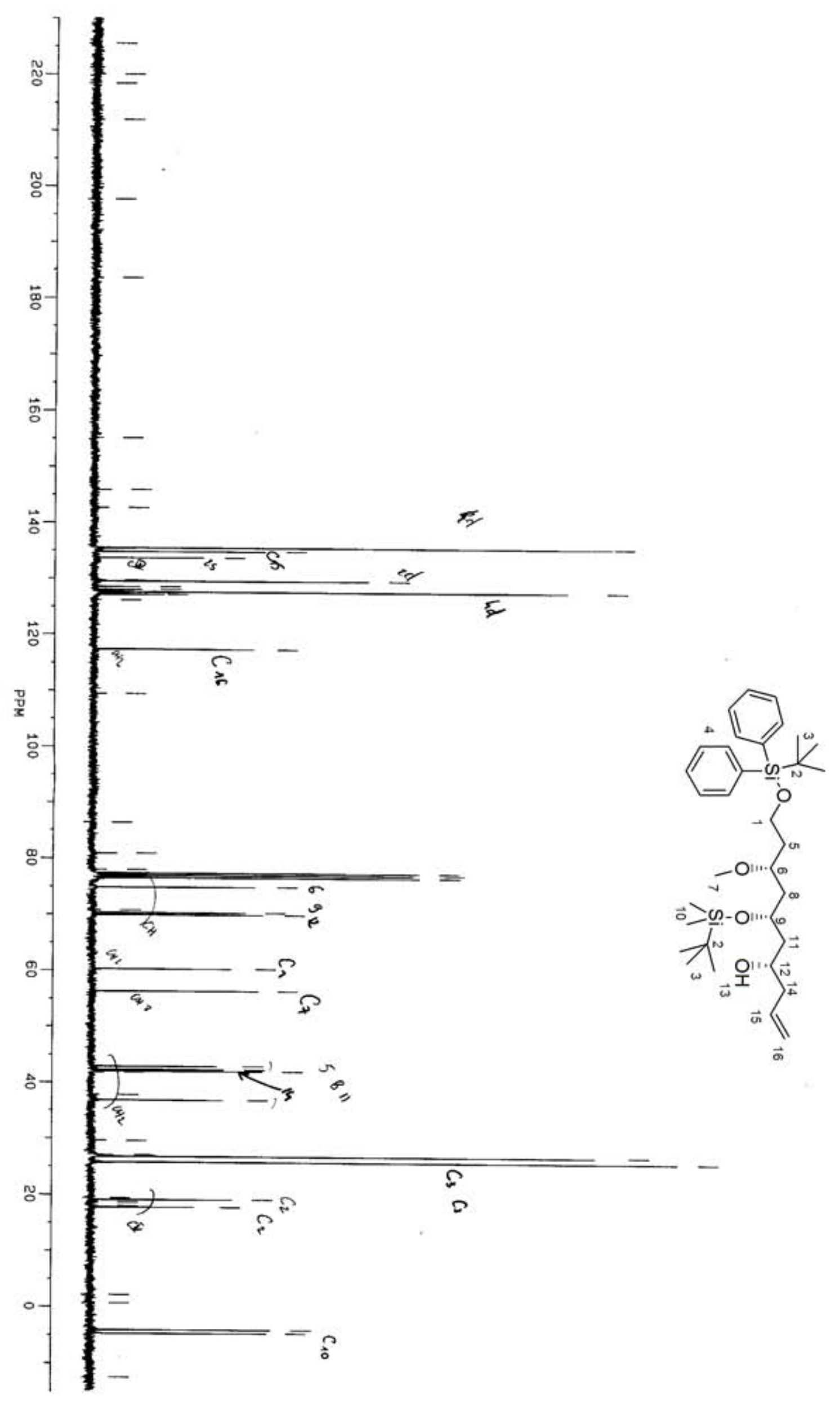

197.545

$-183.593$
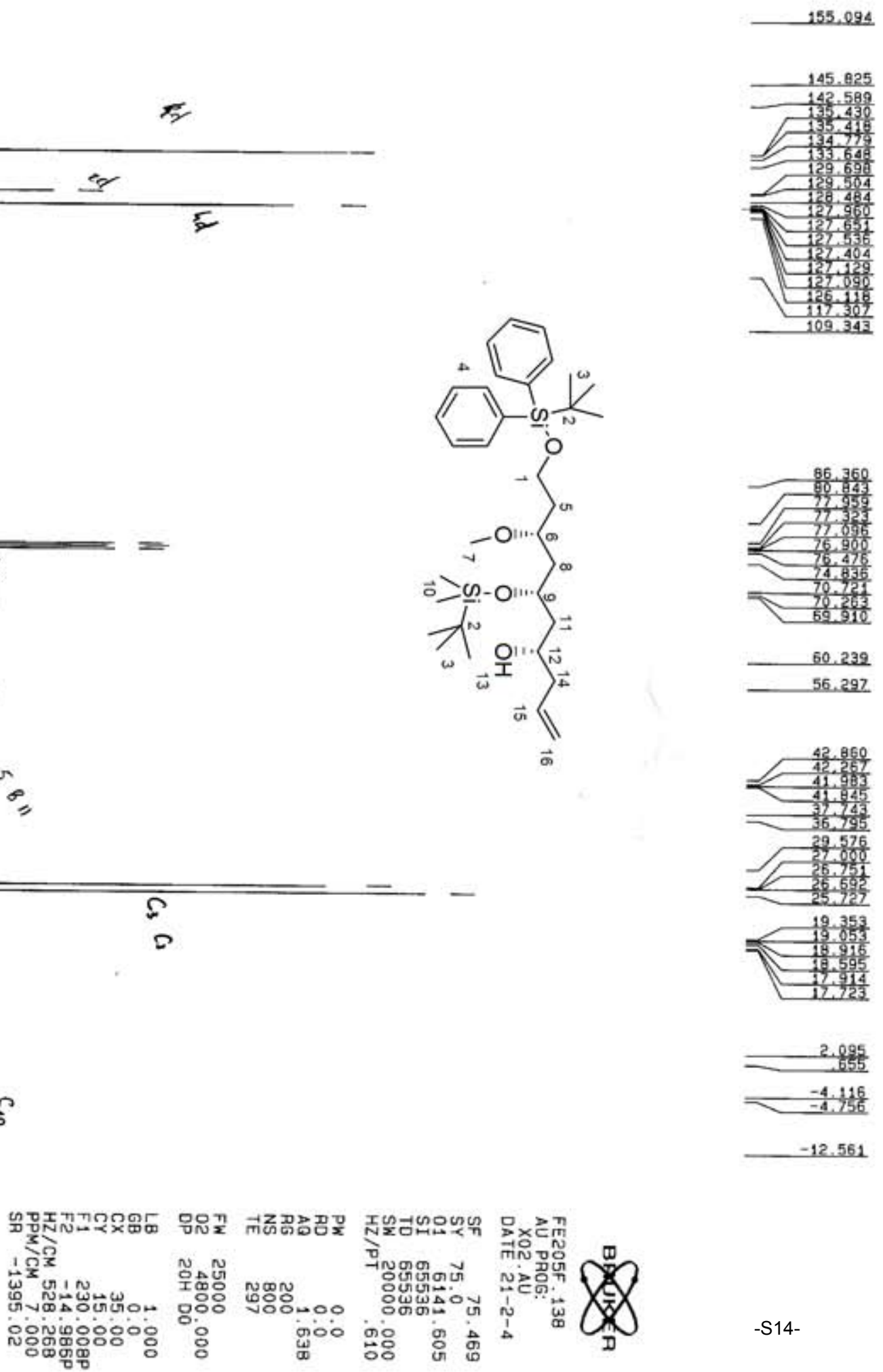


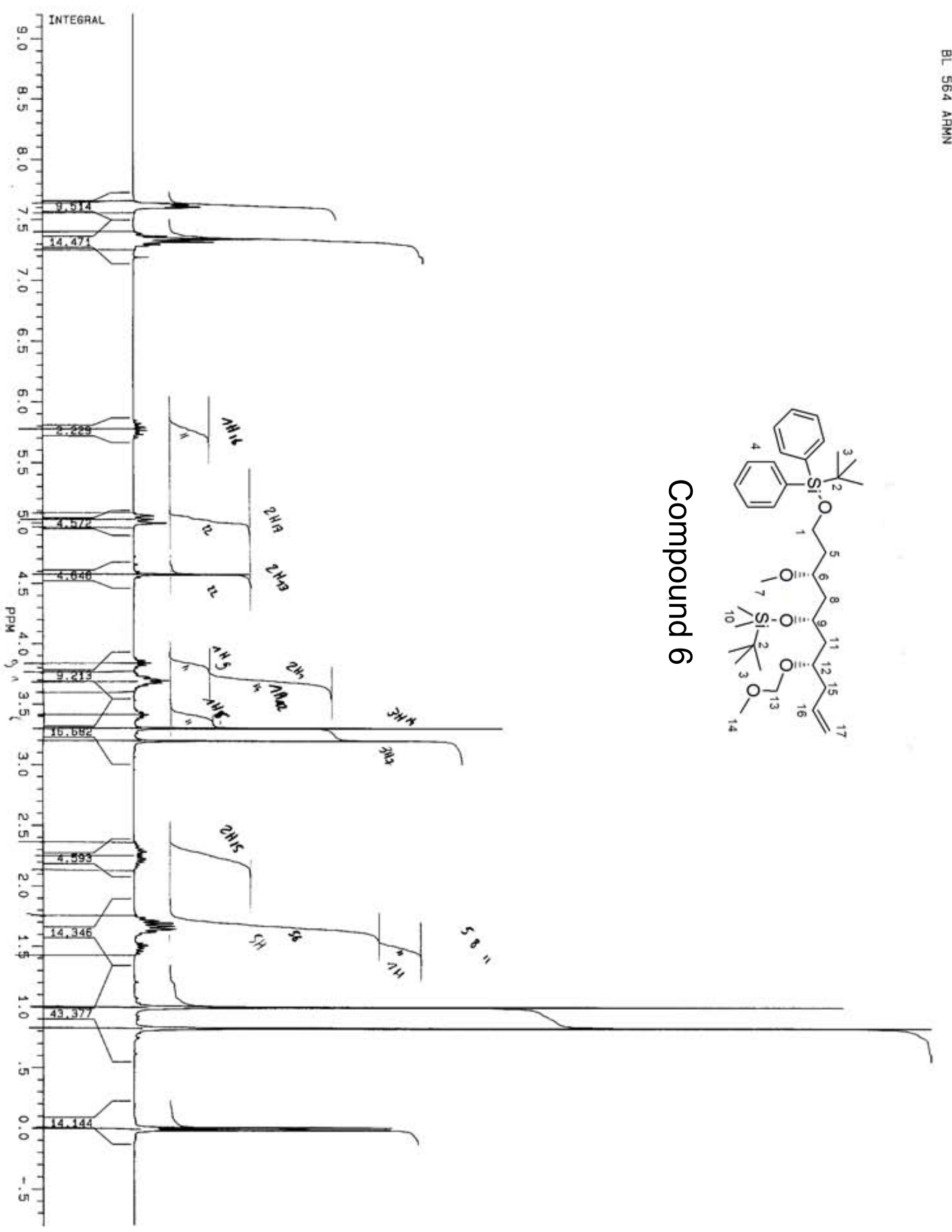

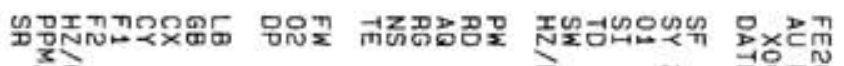

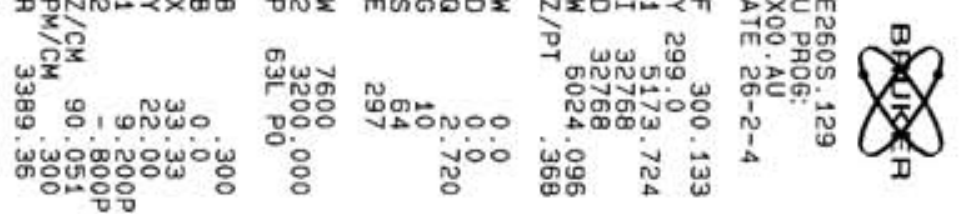




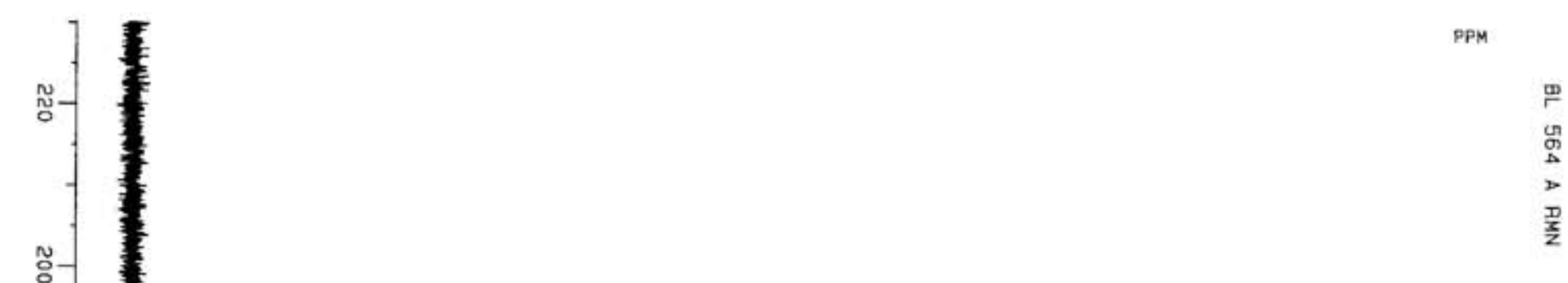

s.

มู

홍

迢

额 $\frac{1}{4}$

家

-

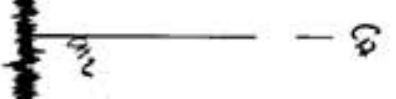

굴

응

$8 / 2-3$

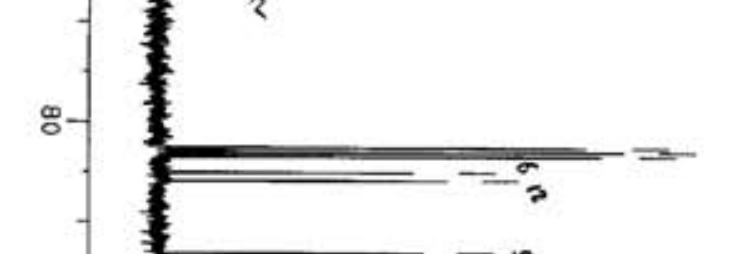

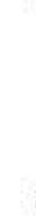

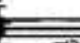

프

- -

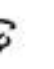

○

$\frac{1}{3}$

20

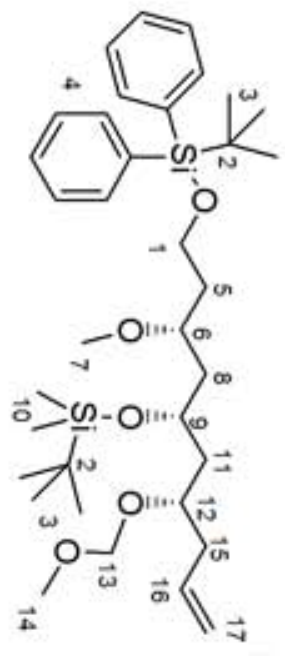

95, 300

$\sigma$

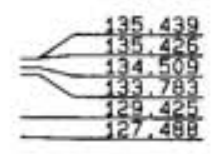

117.093

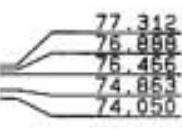

66.778

60.428

$\frac{55.77}{55.415}$
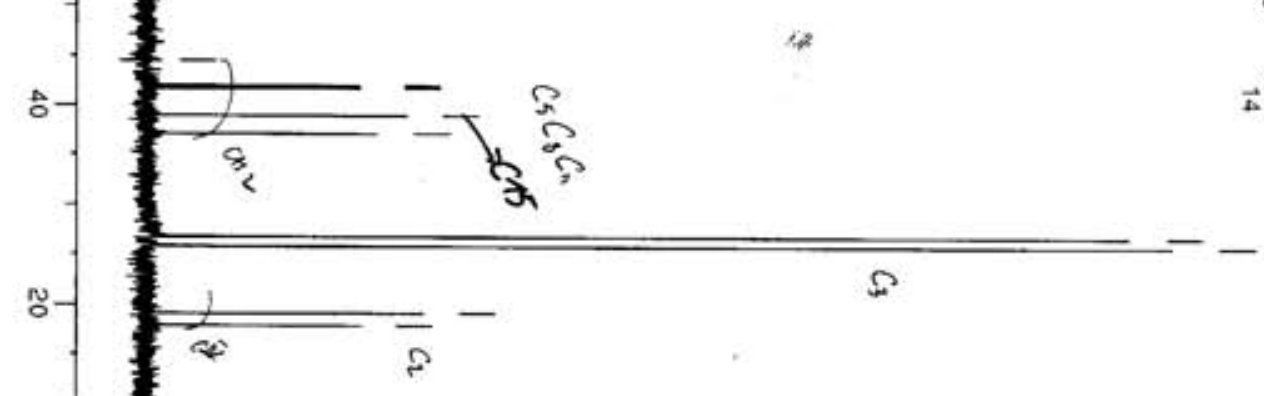

$=\quad \frac{26.754}{25.768}$

$\begin{array}{r}19.047 \\ \hline 12.322\end{array}$

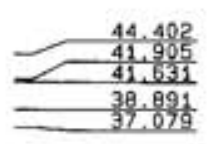

$\frac{-4.3396}{-4.522}$

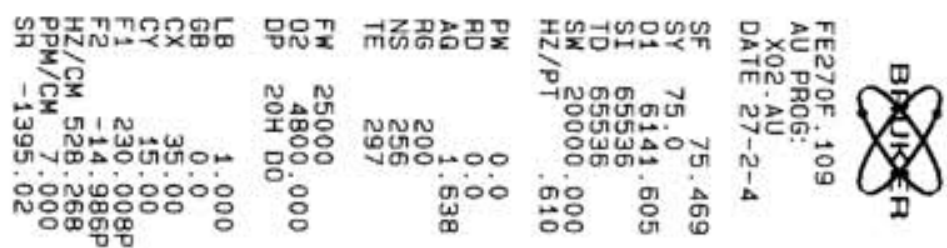




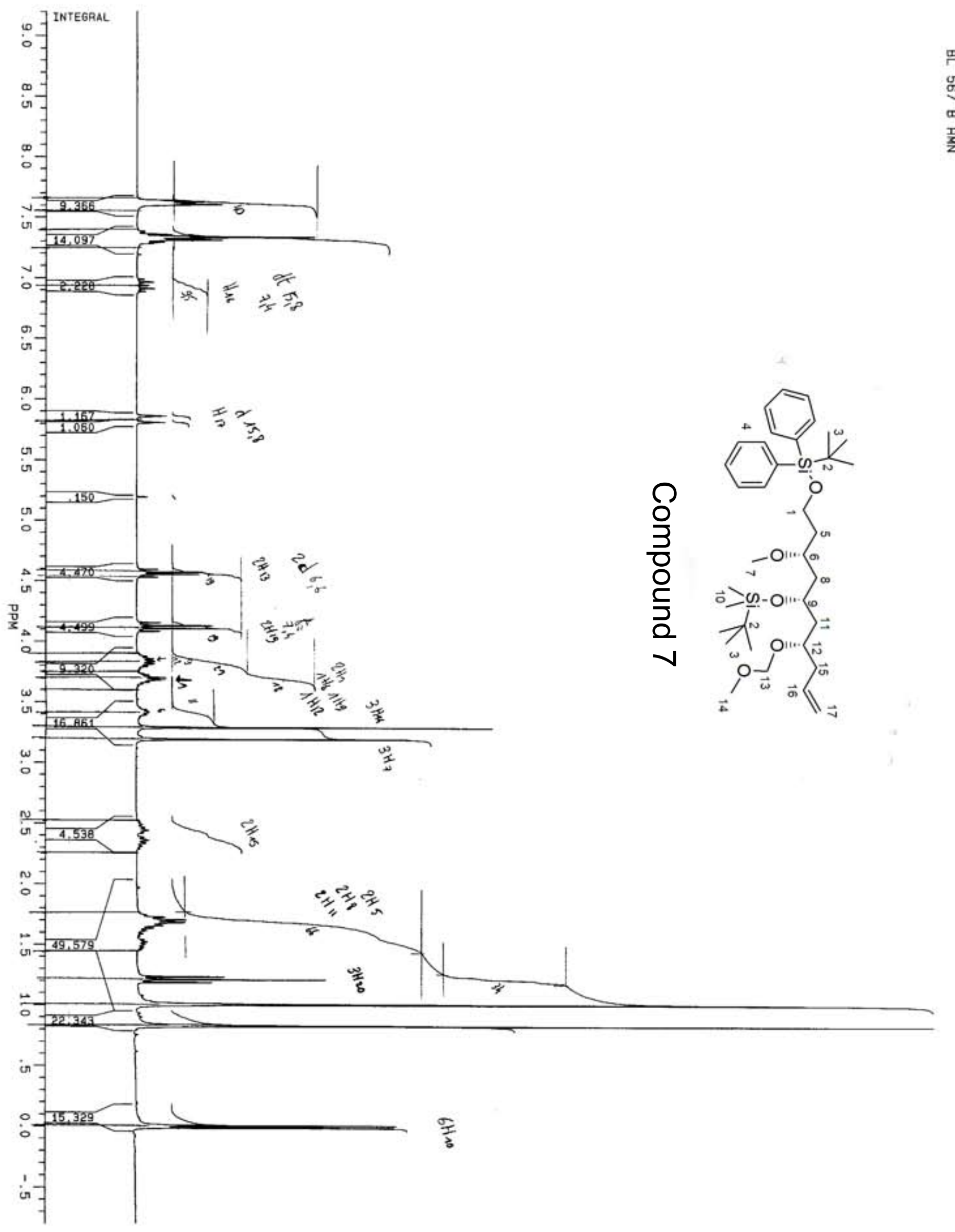

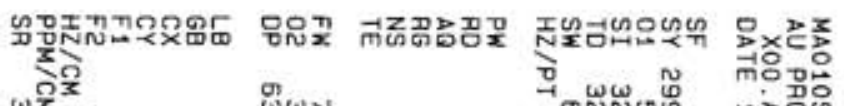

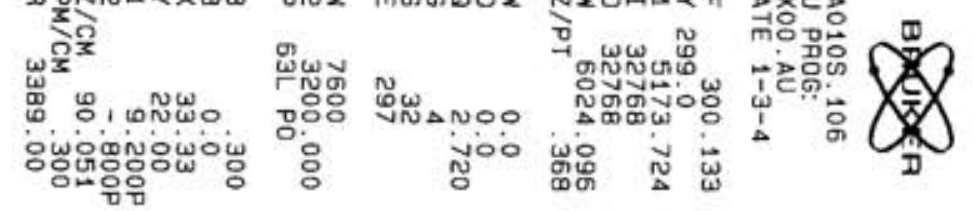




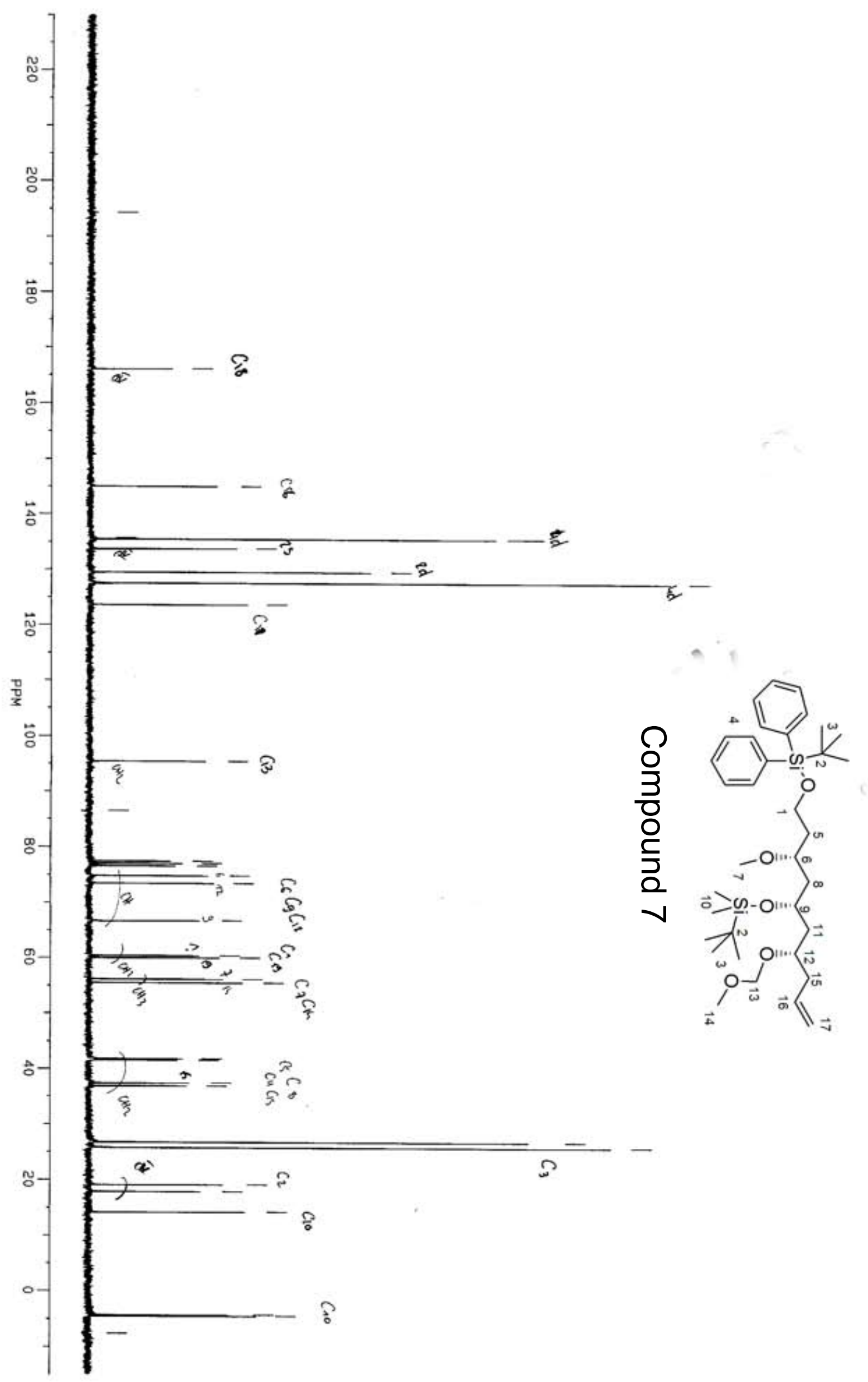



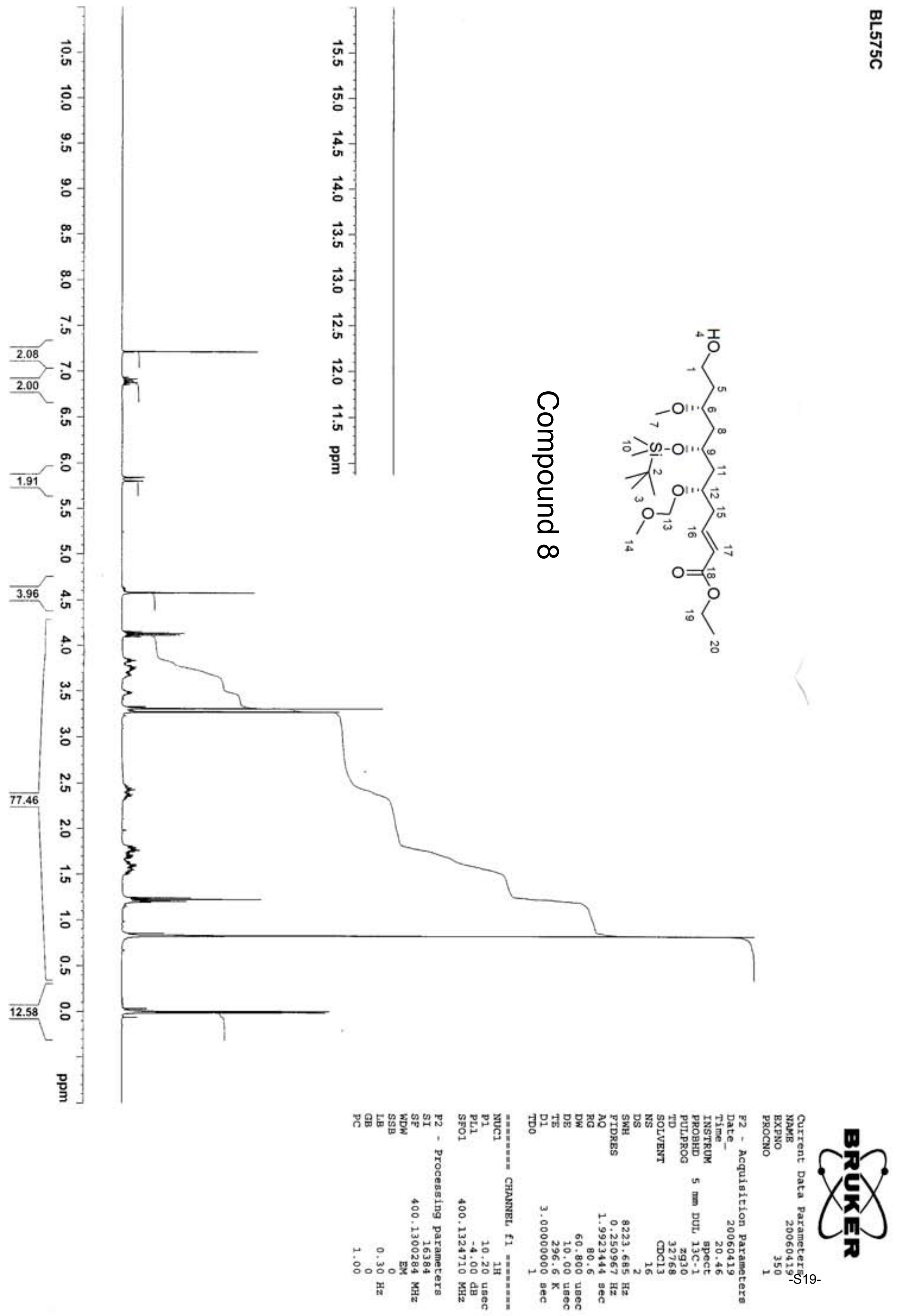


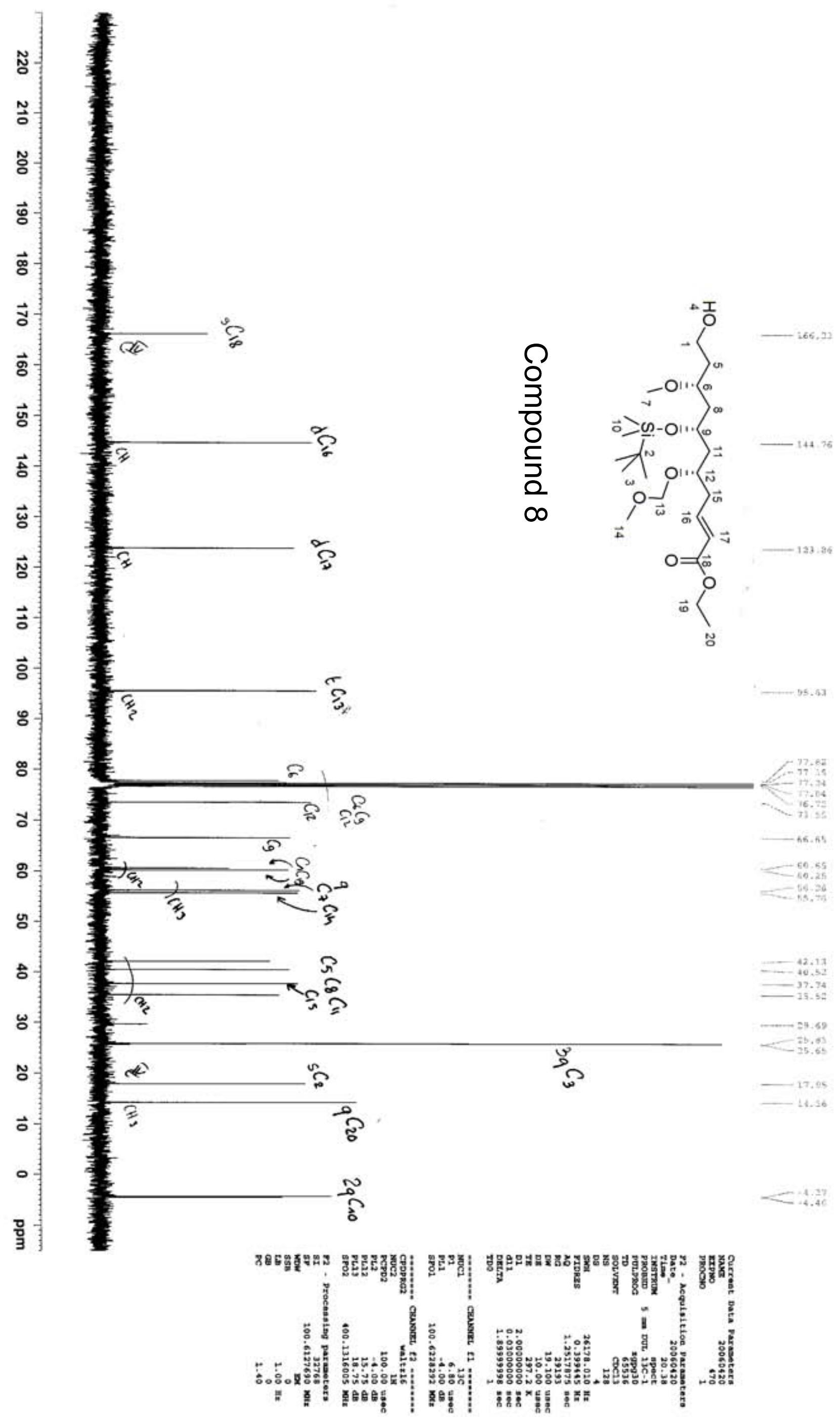




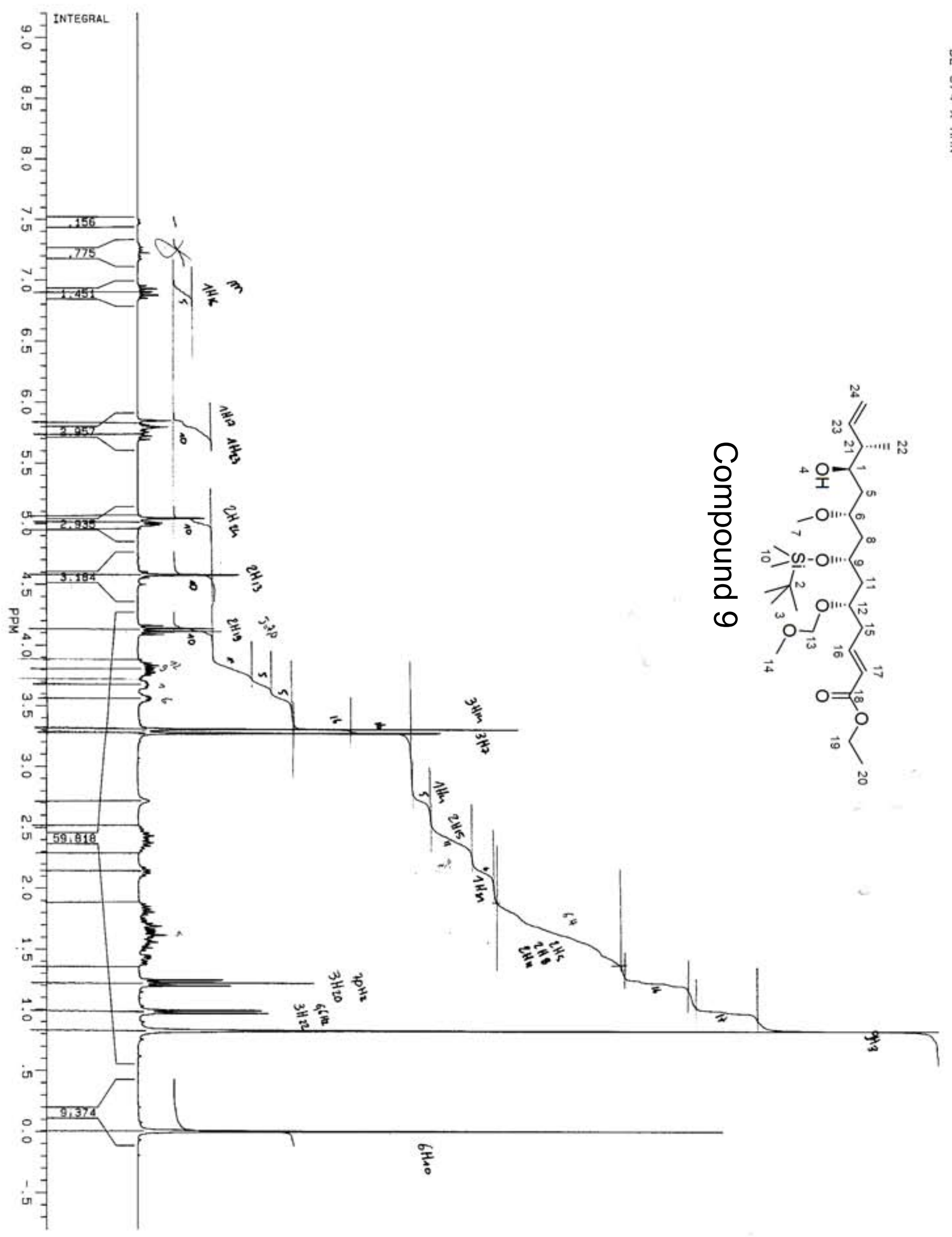

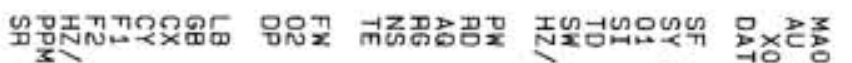

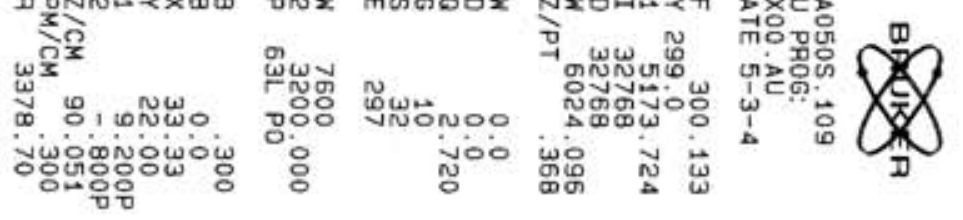




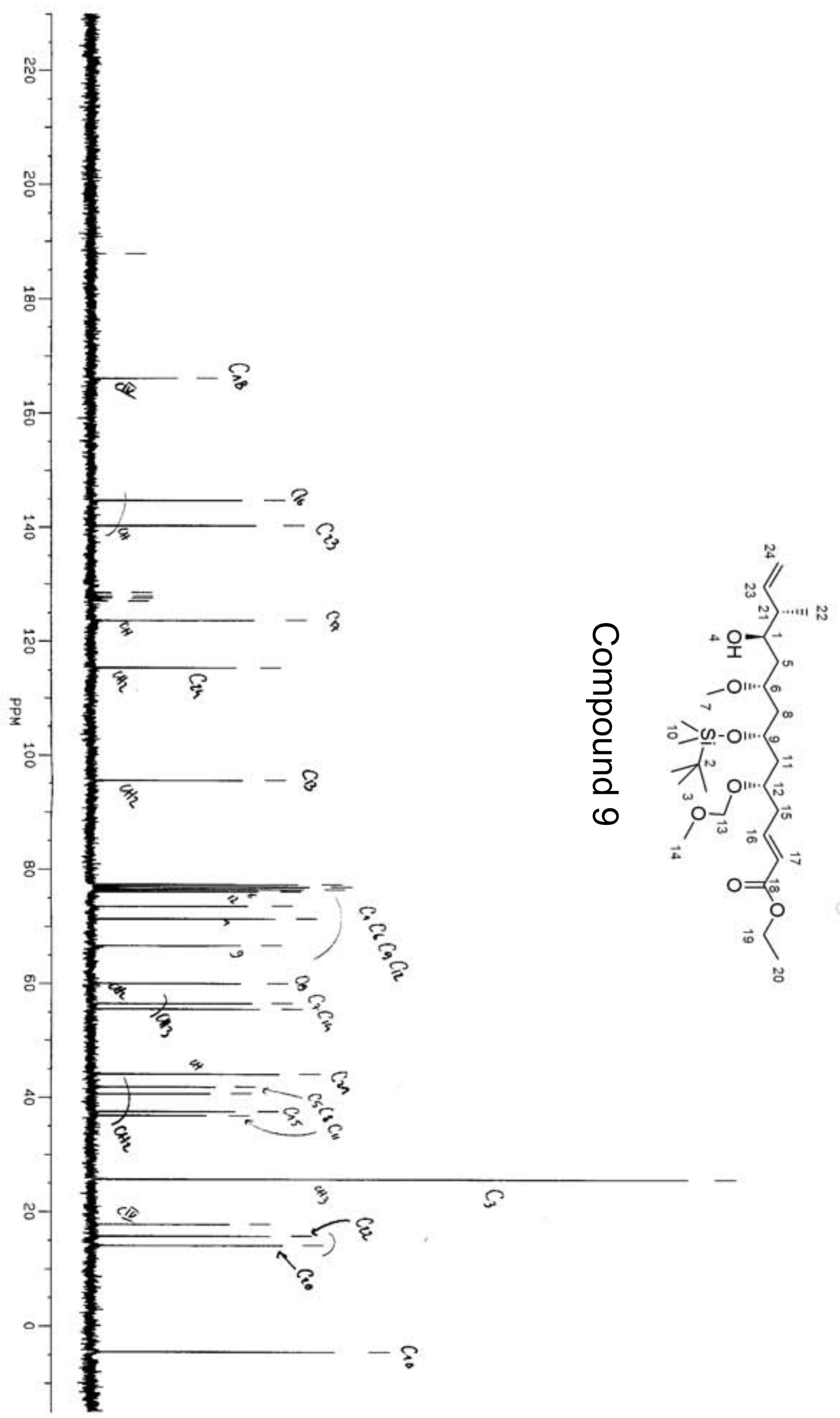




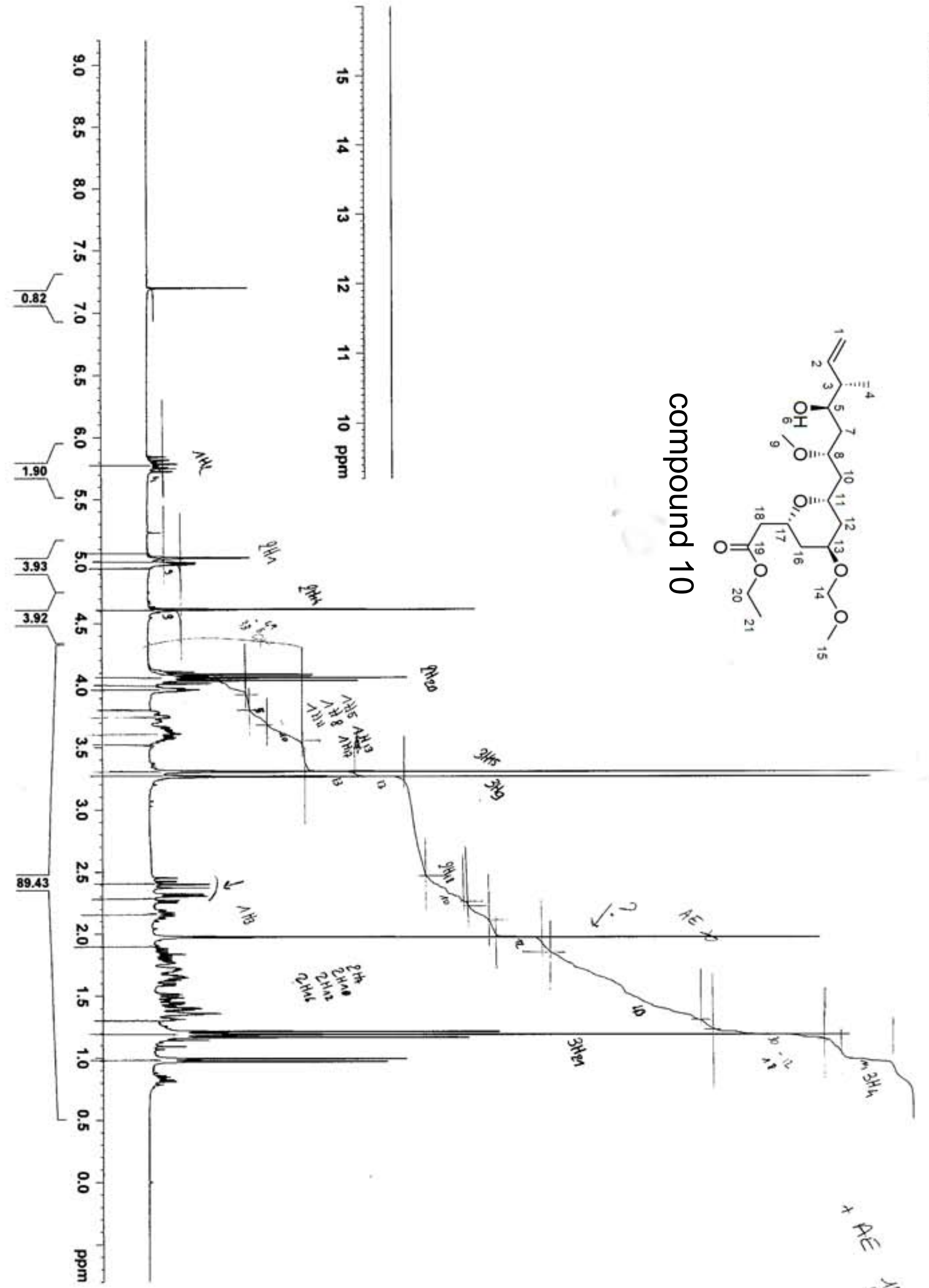




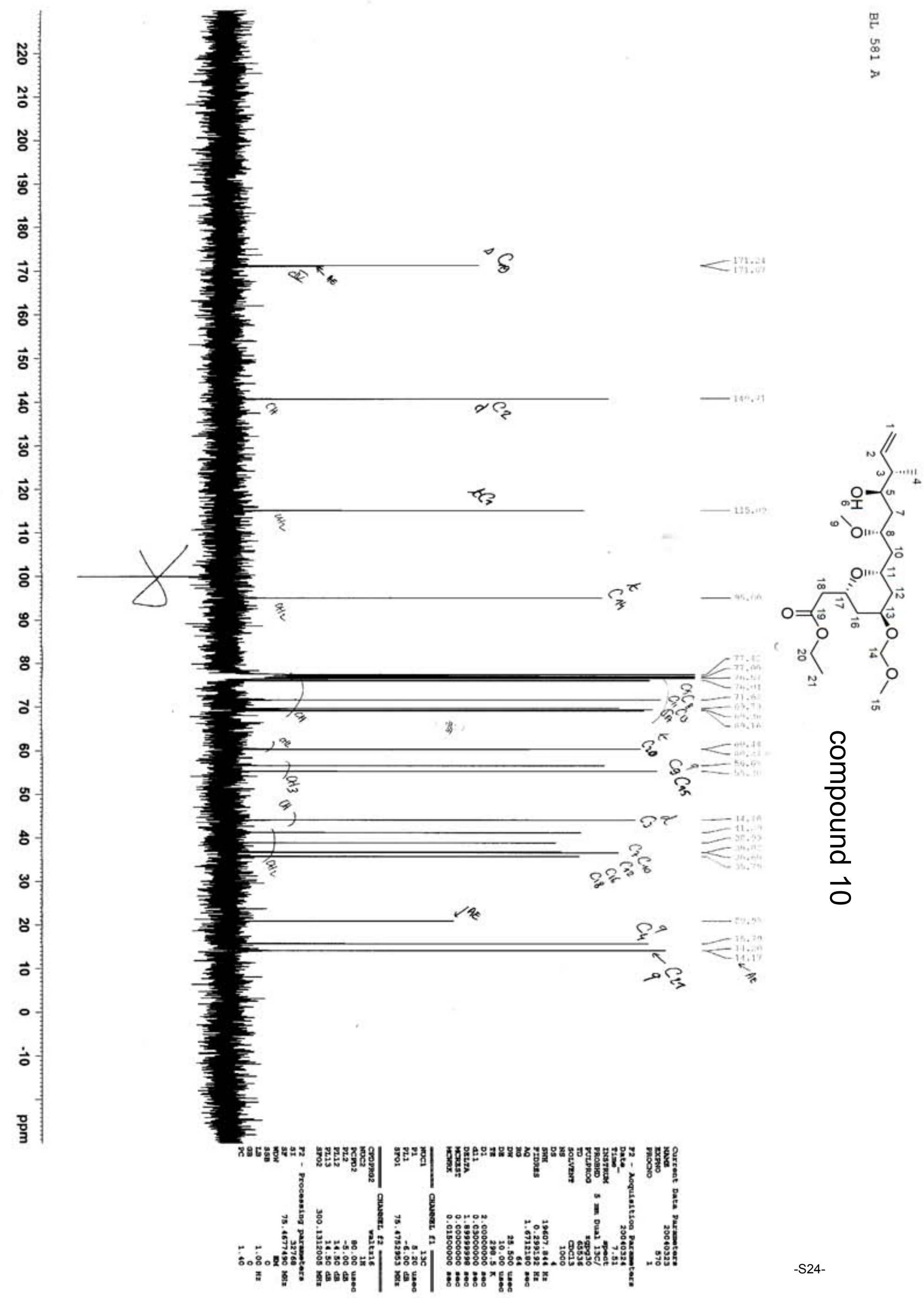




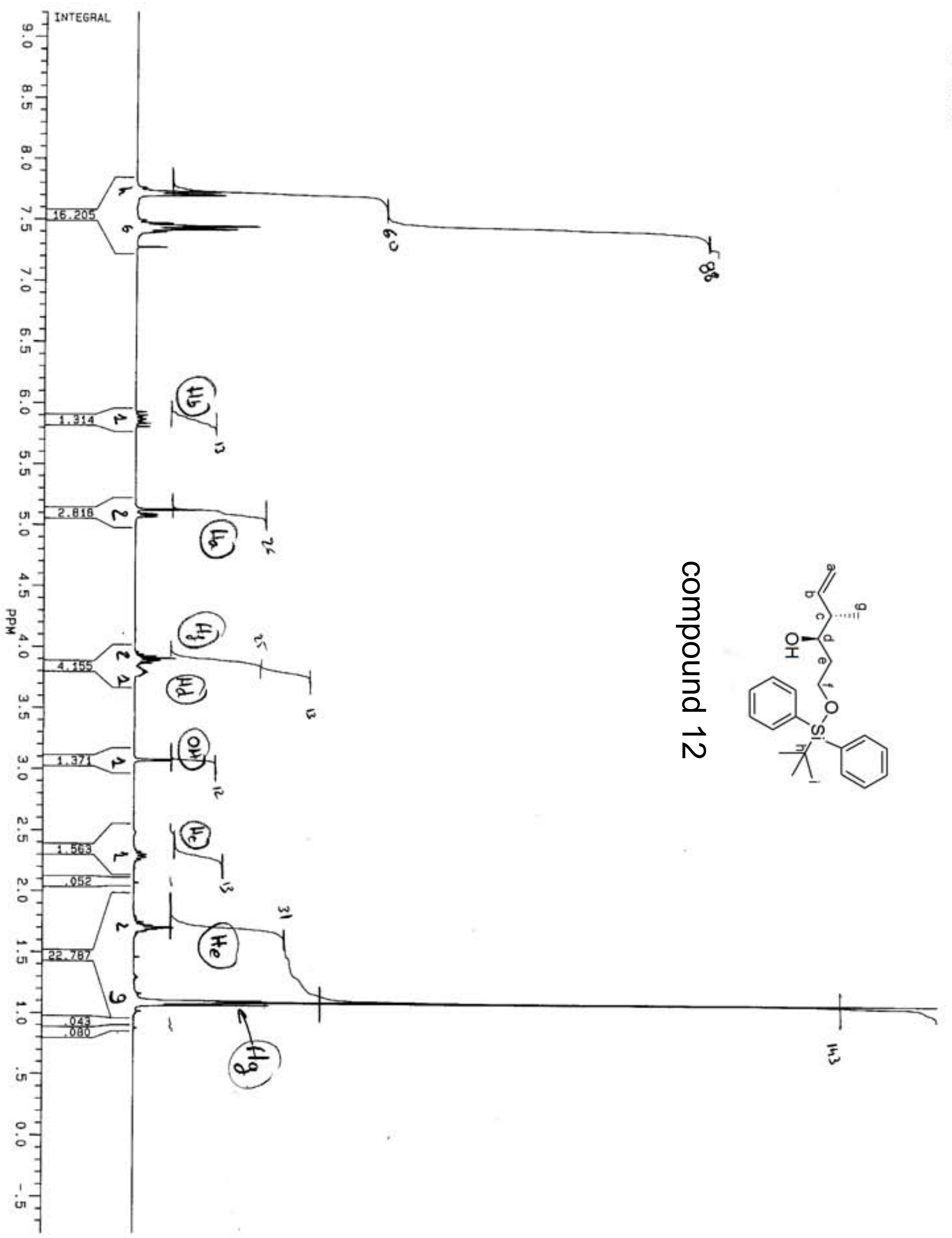

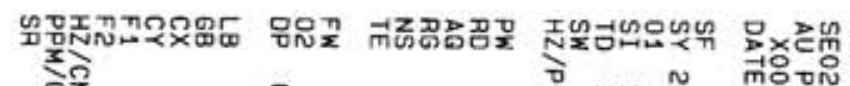

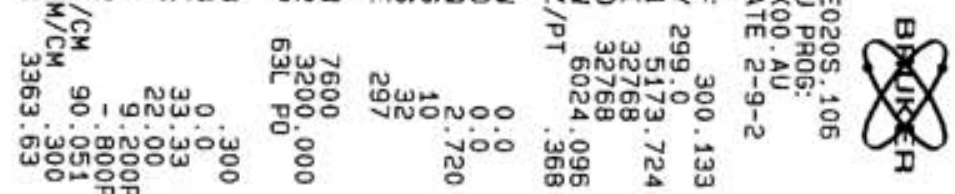



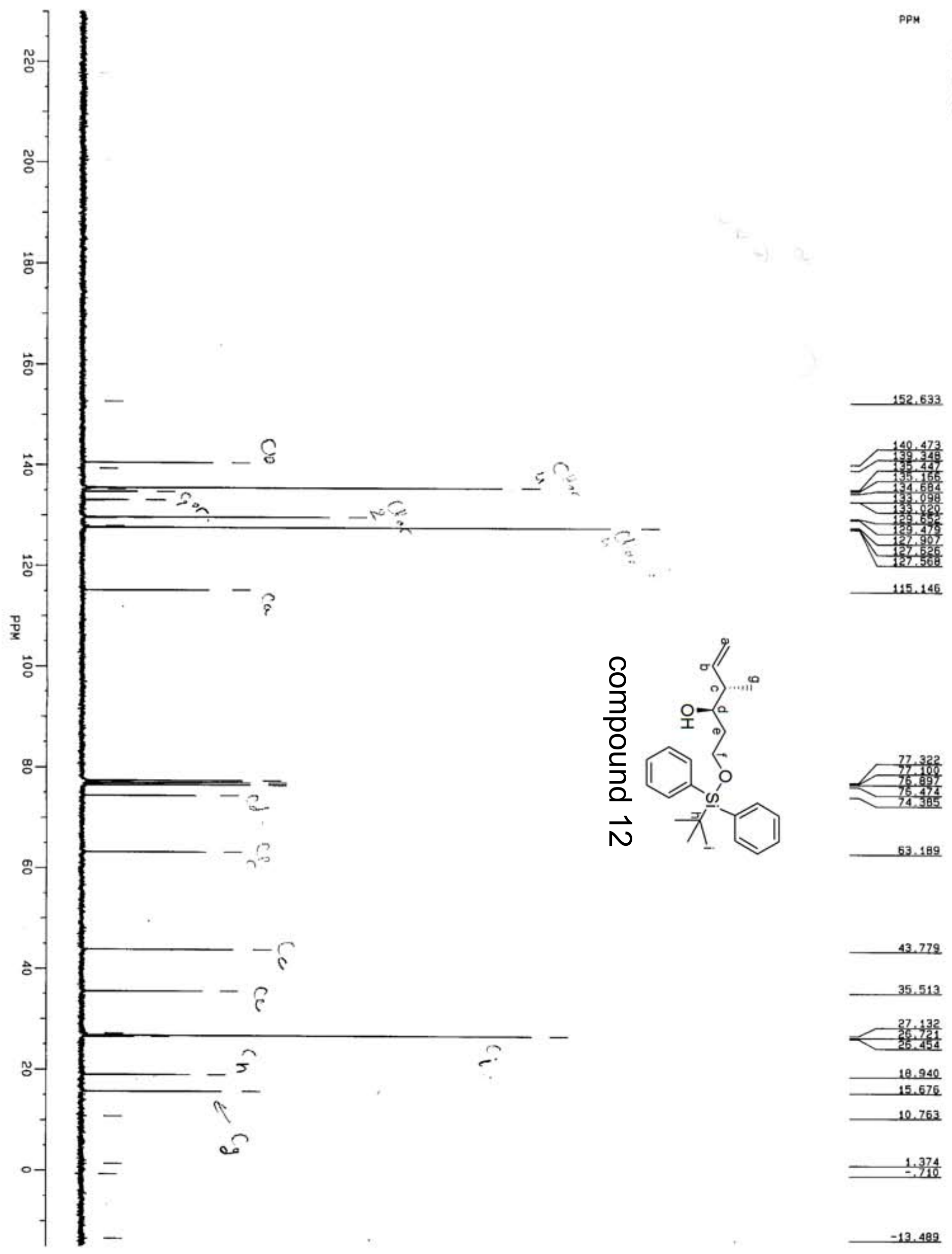

43.779

35.513

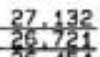

18.940

10.763

$\frac{1.374}{-.310}$

$-13.489$

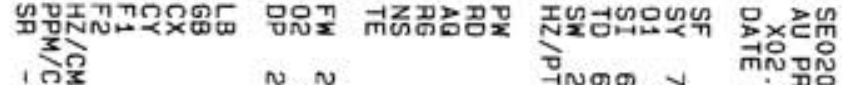

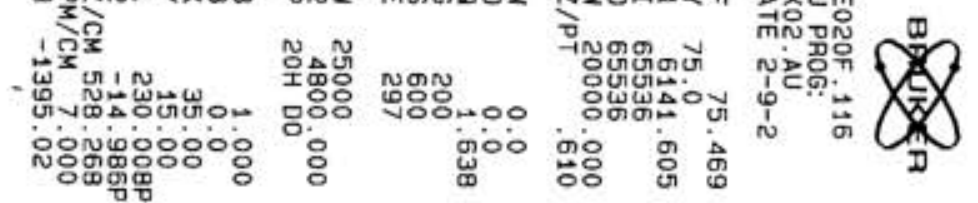



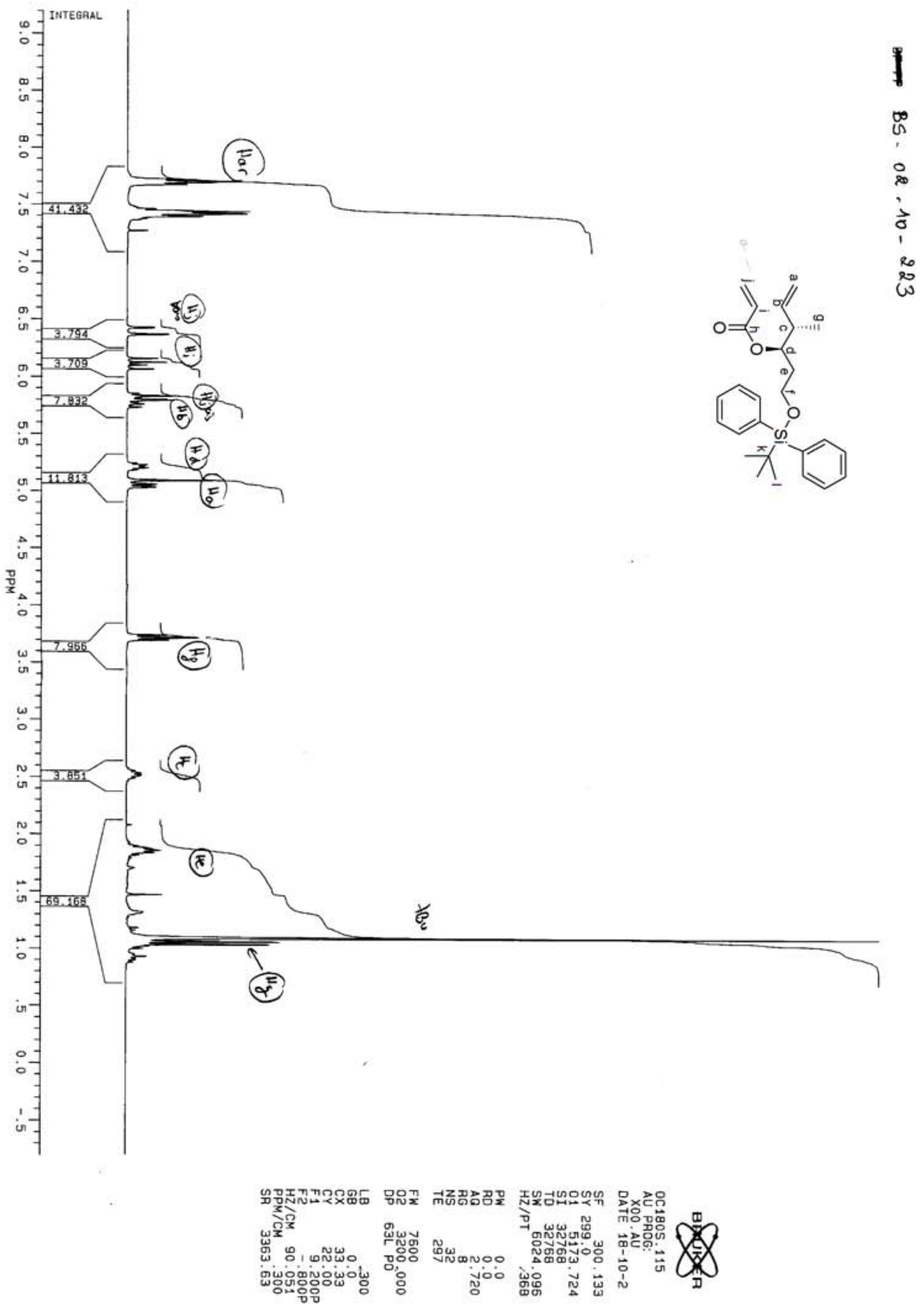


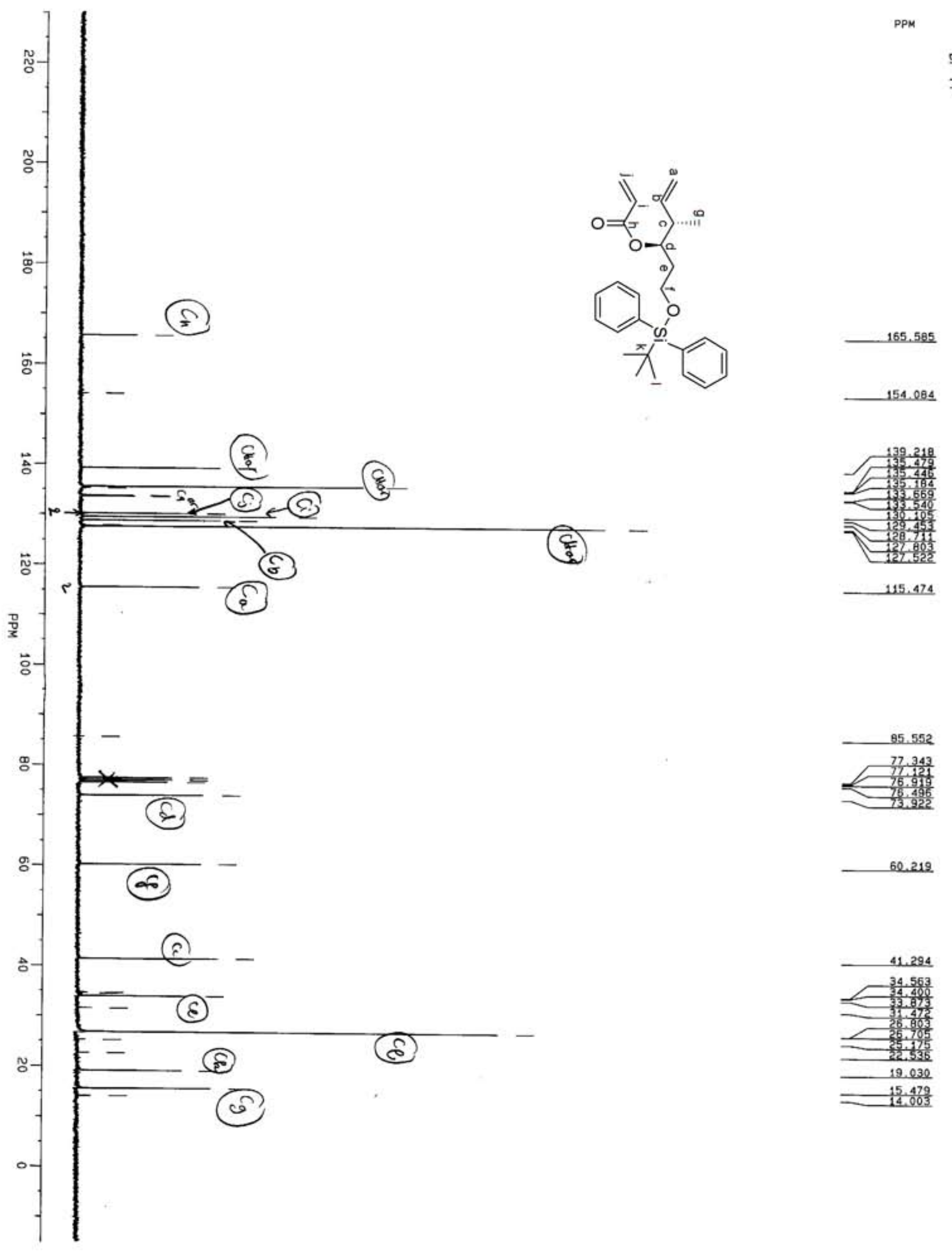

5. 585

4. 084 

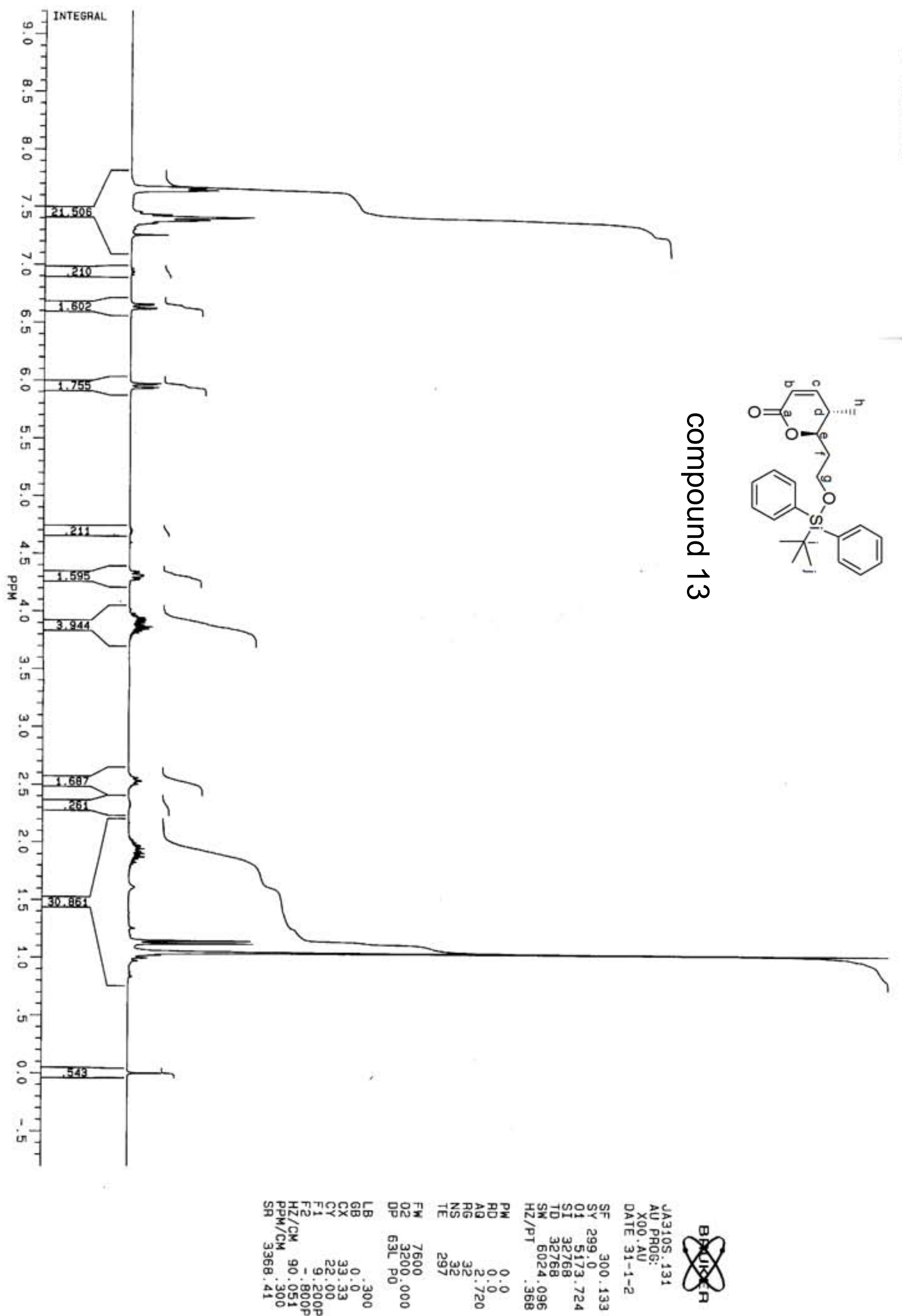

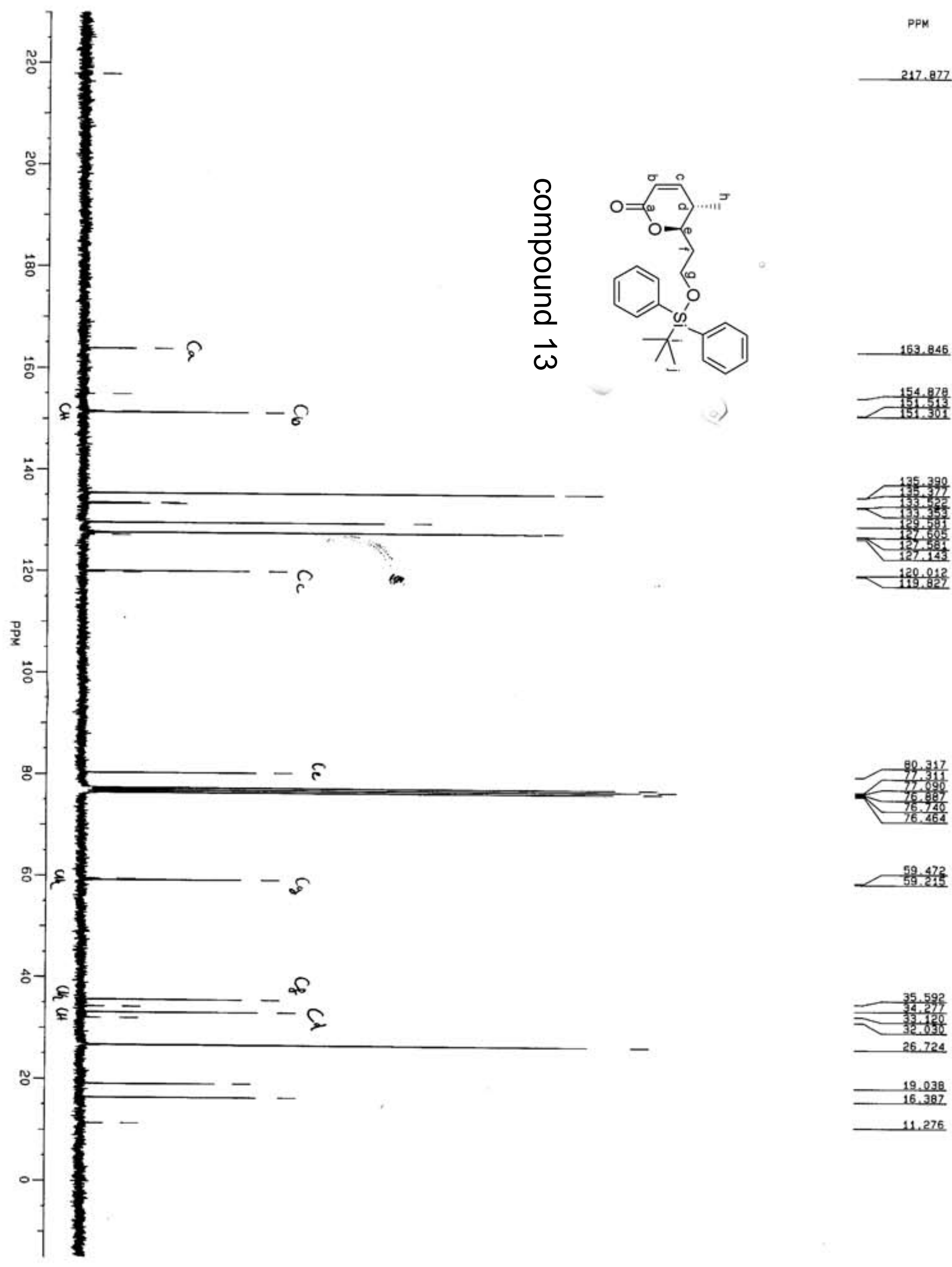

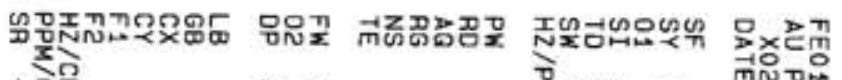

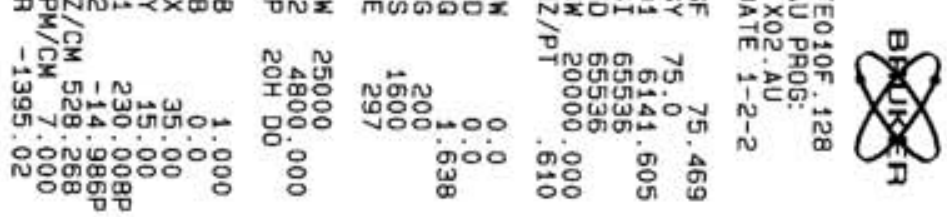




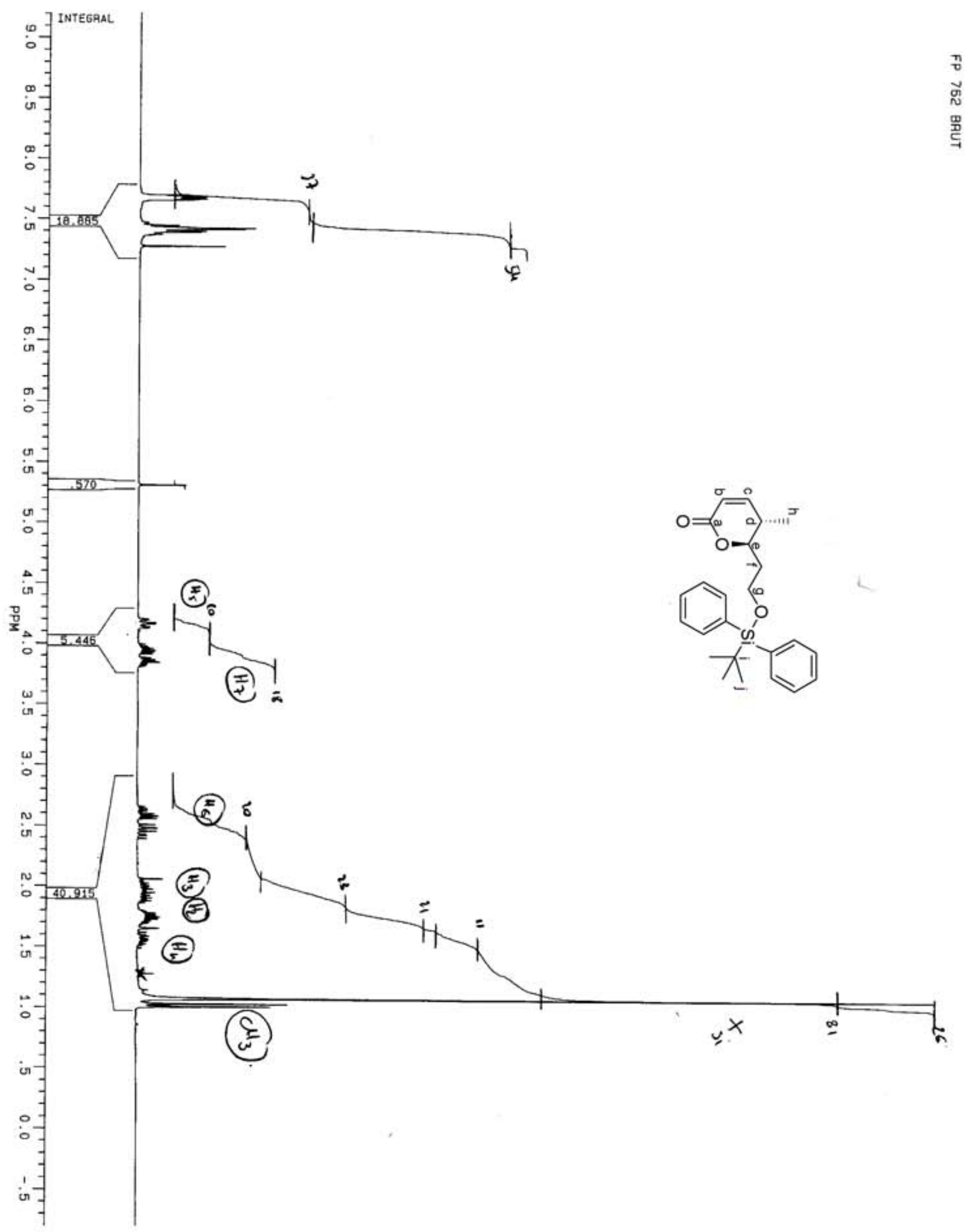

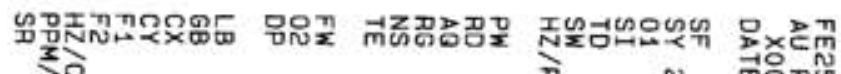

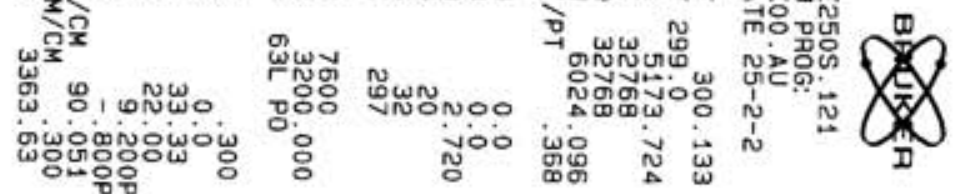



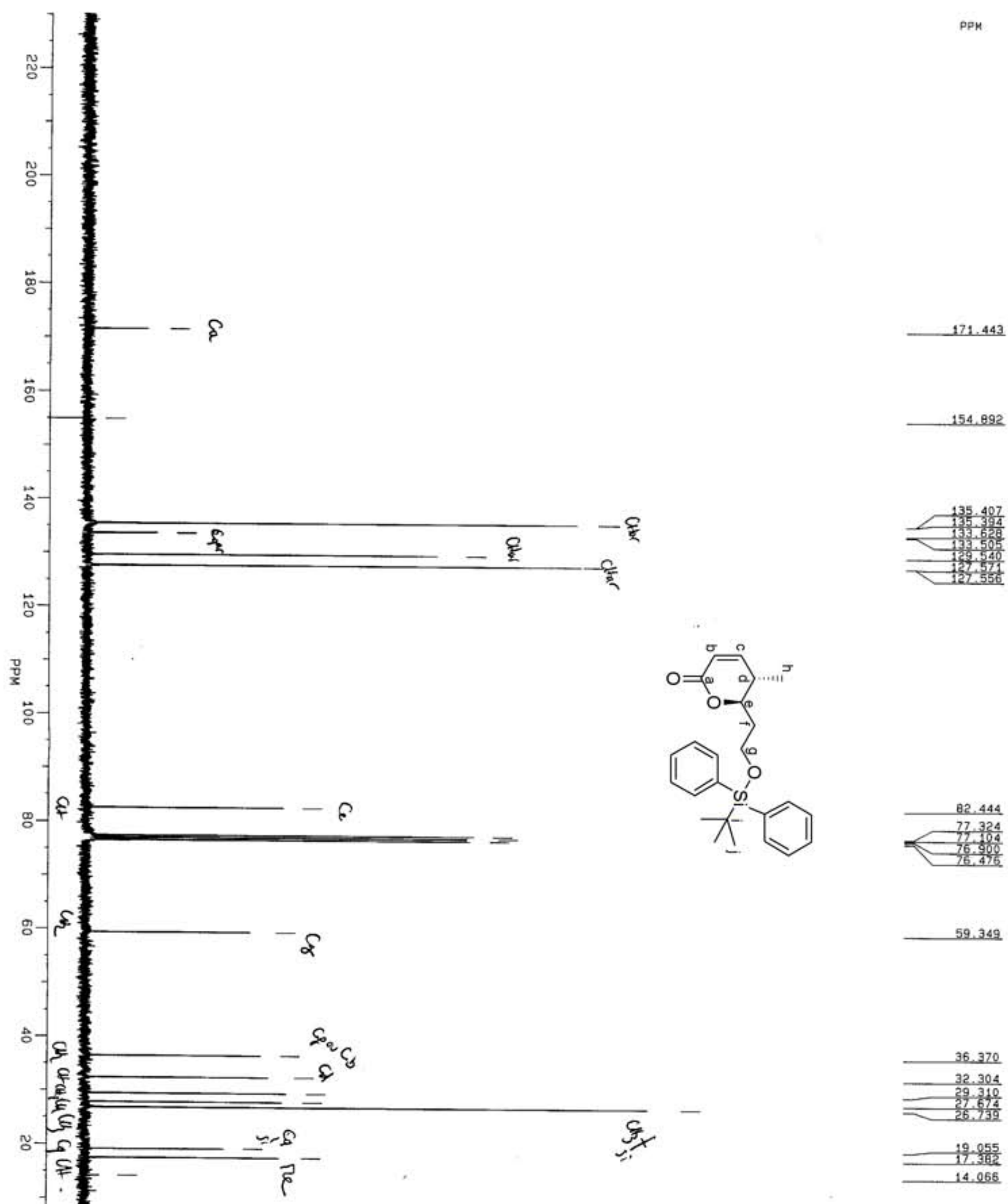

$\frac{12}{12}, 556$ 


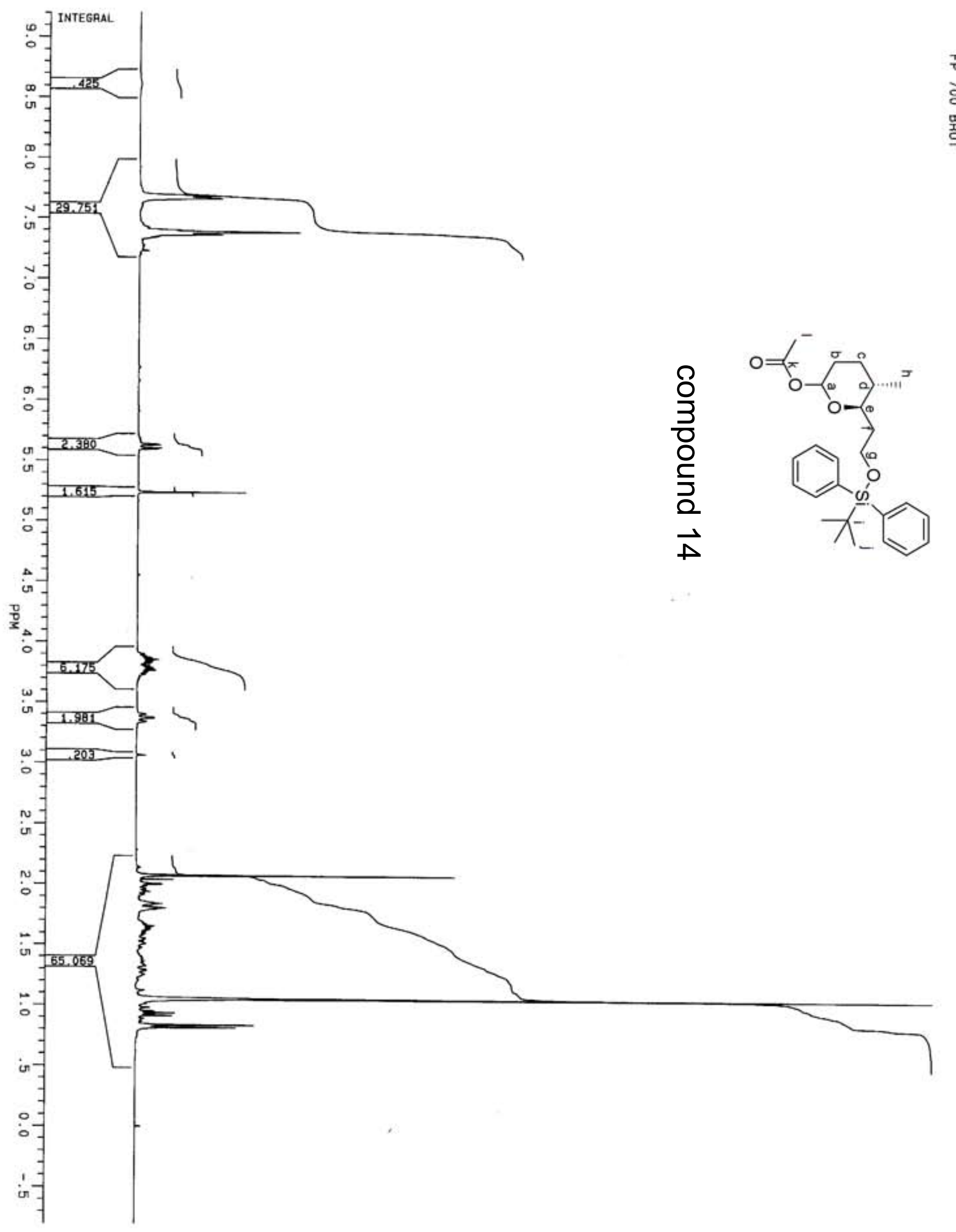

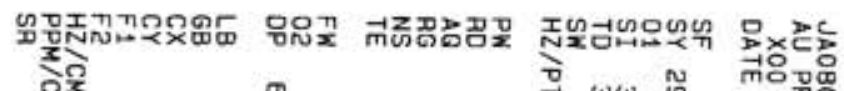

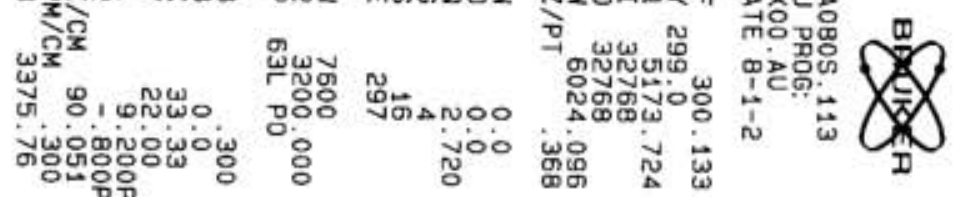



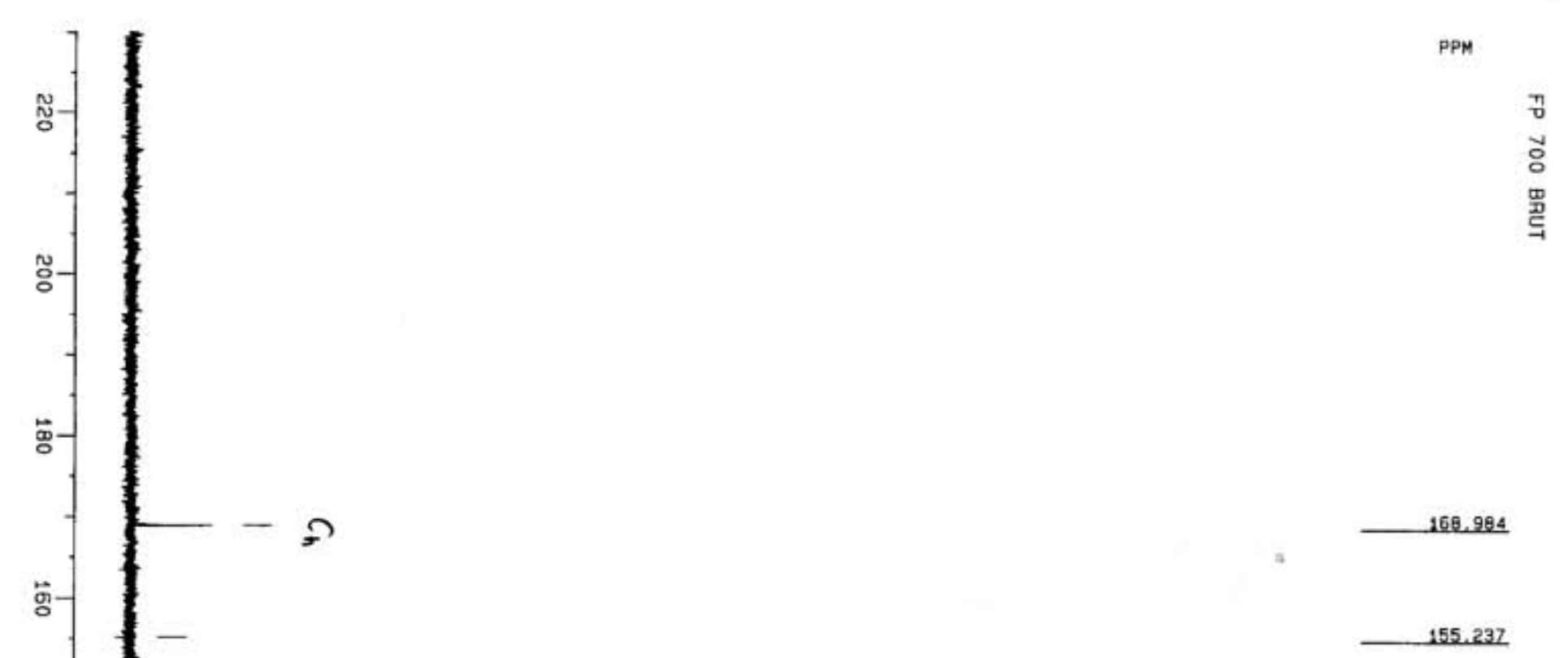

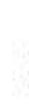

s

.

문

号
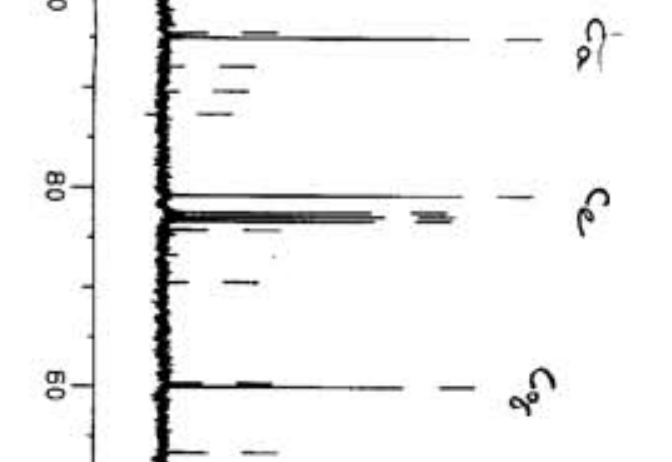

दे
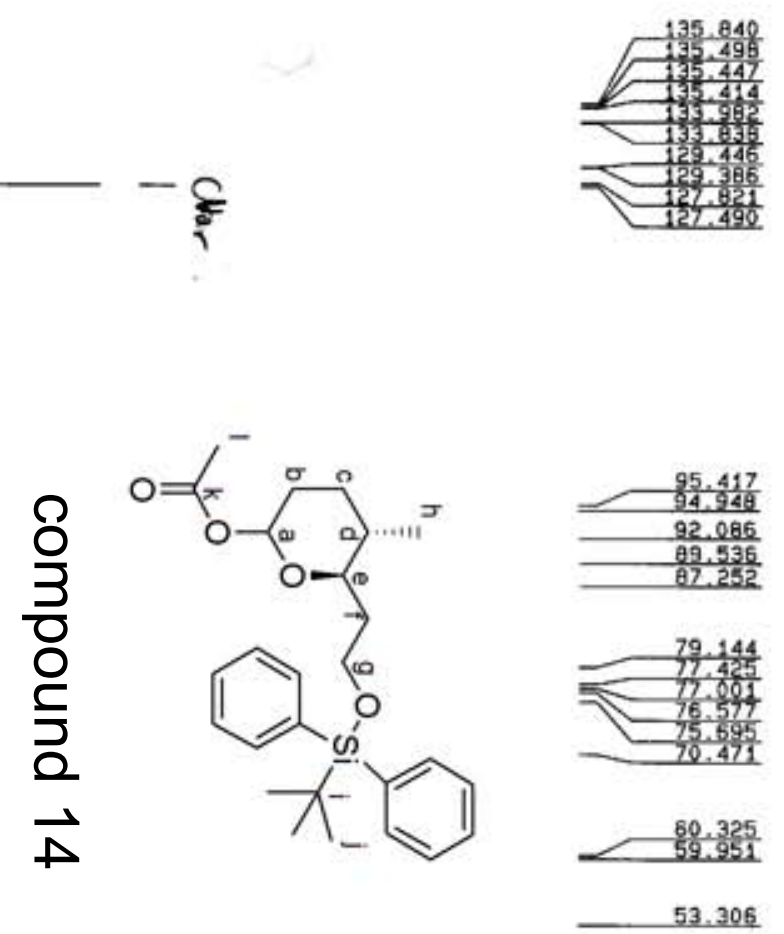

o

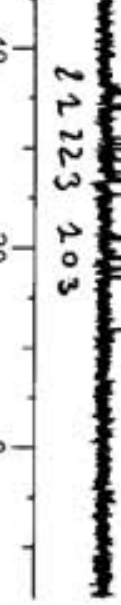

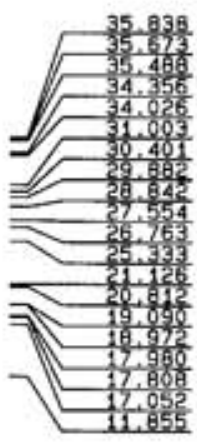

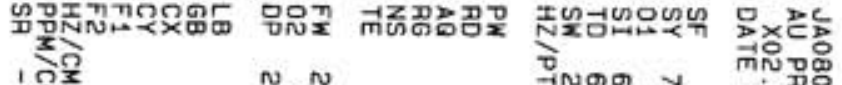

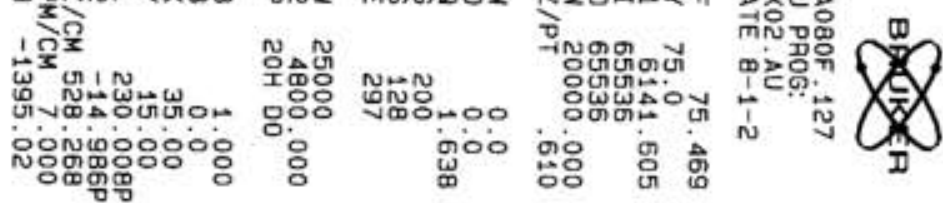




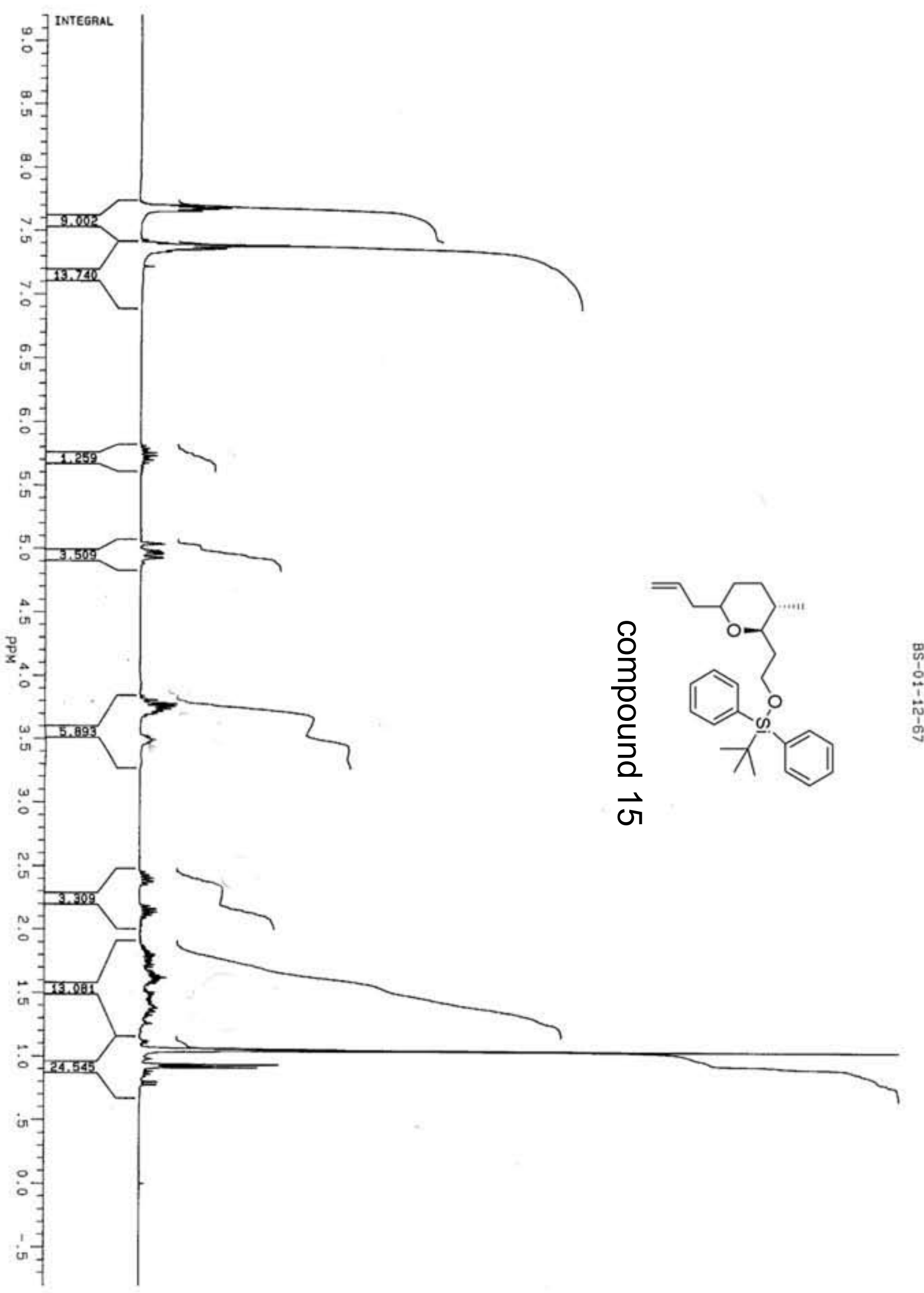

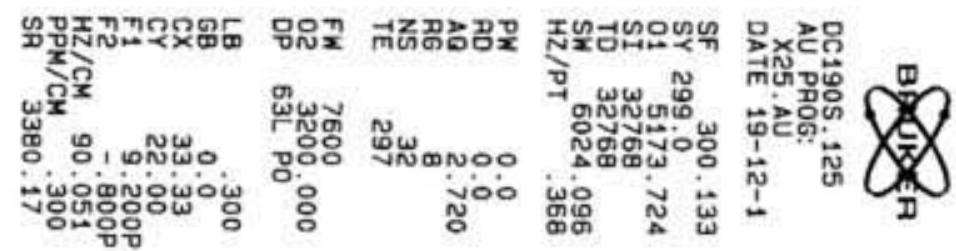



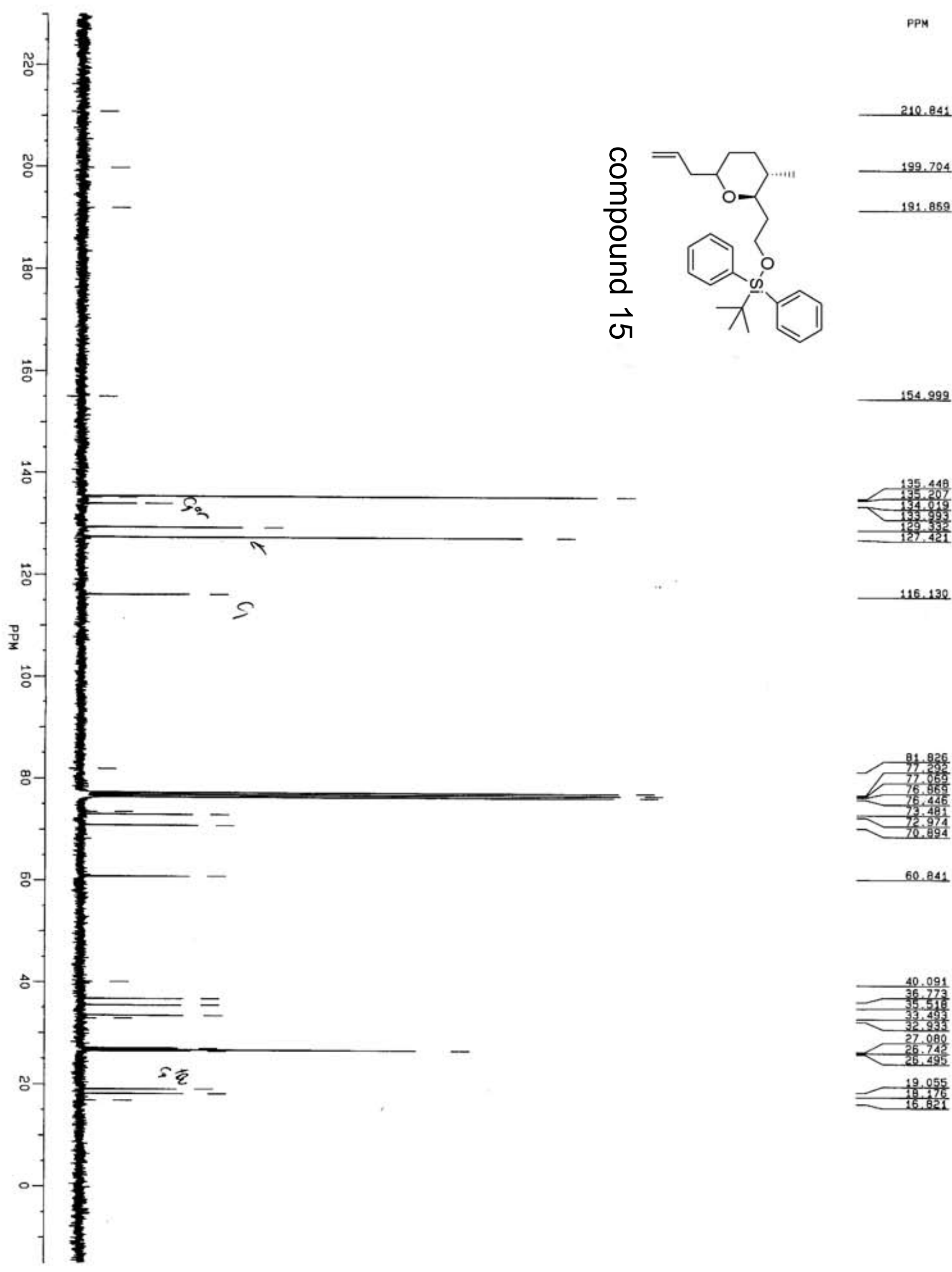

116. 130

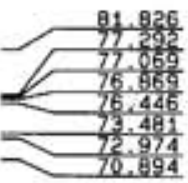

60. 841.

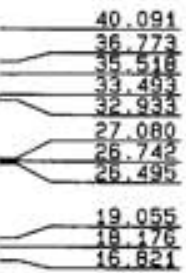

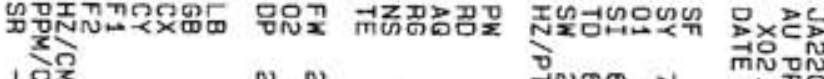

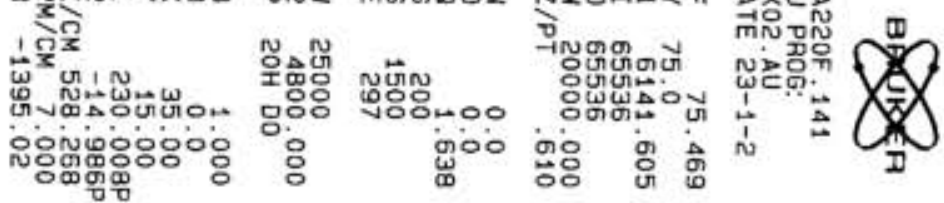




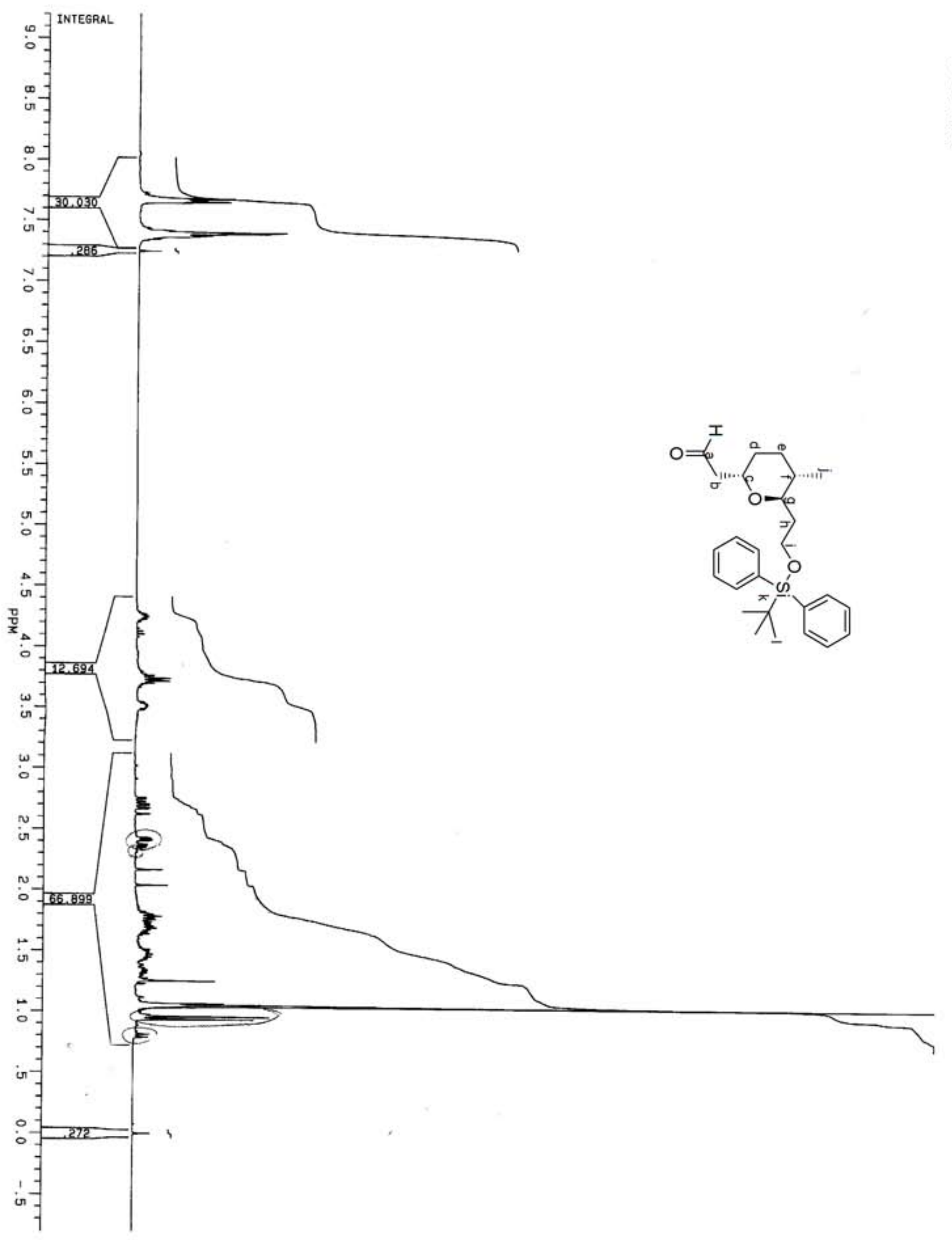

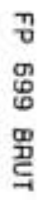

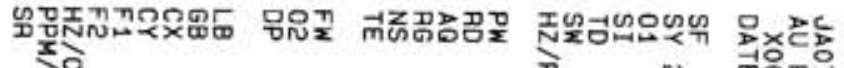

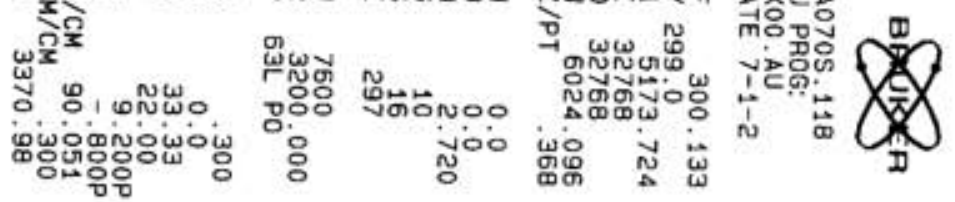




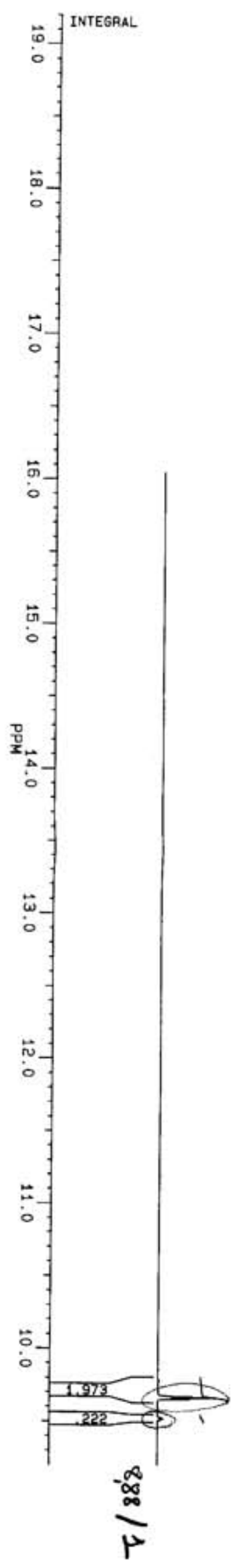

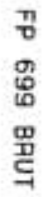
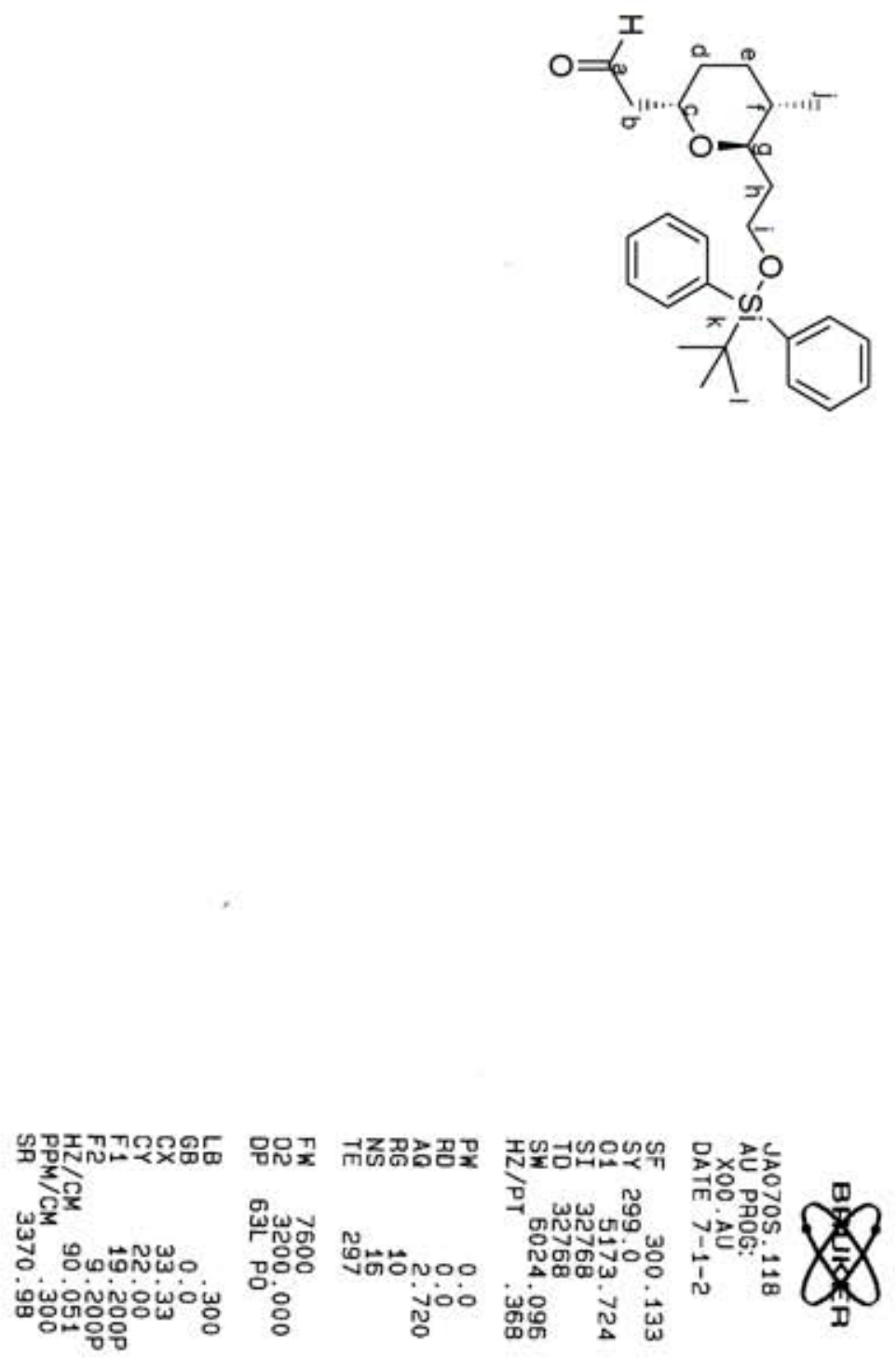

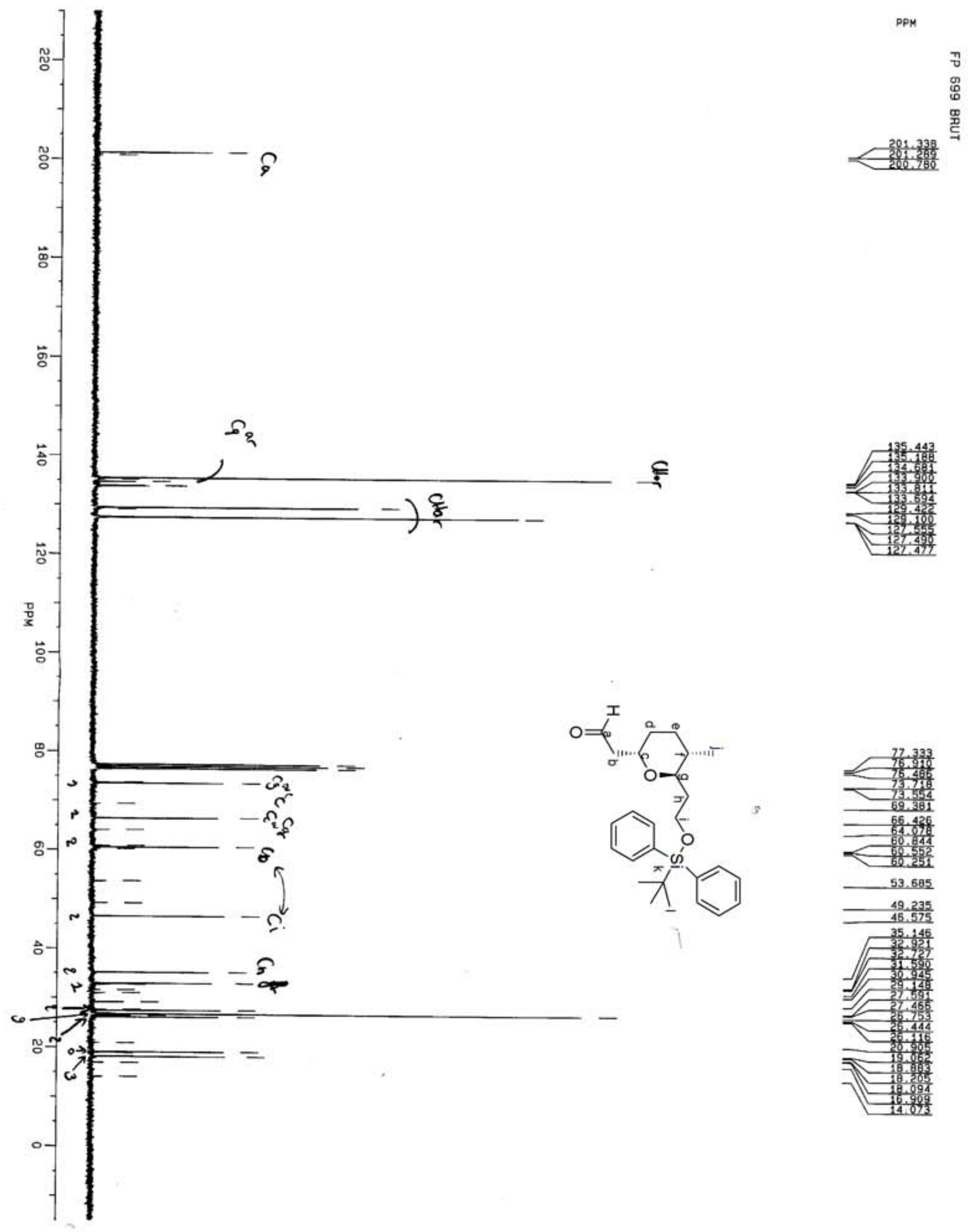

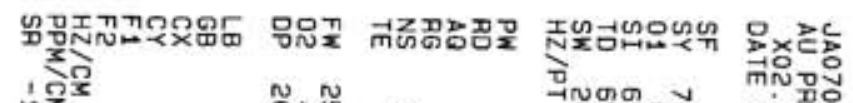

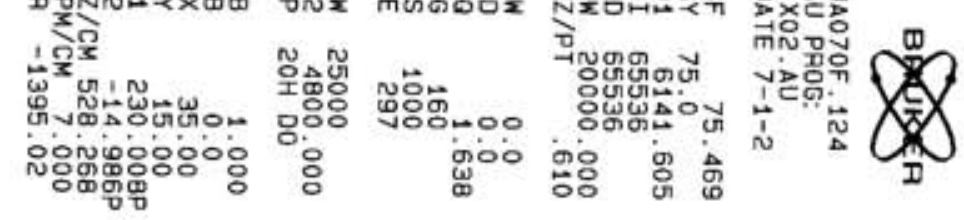



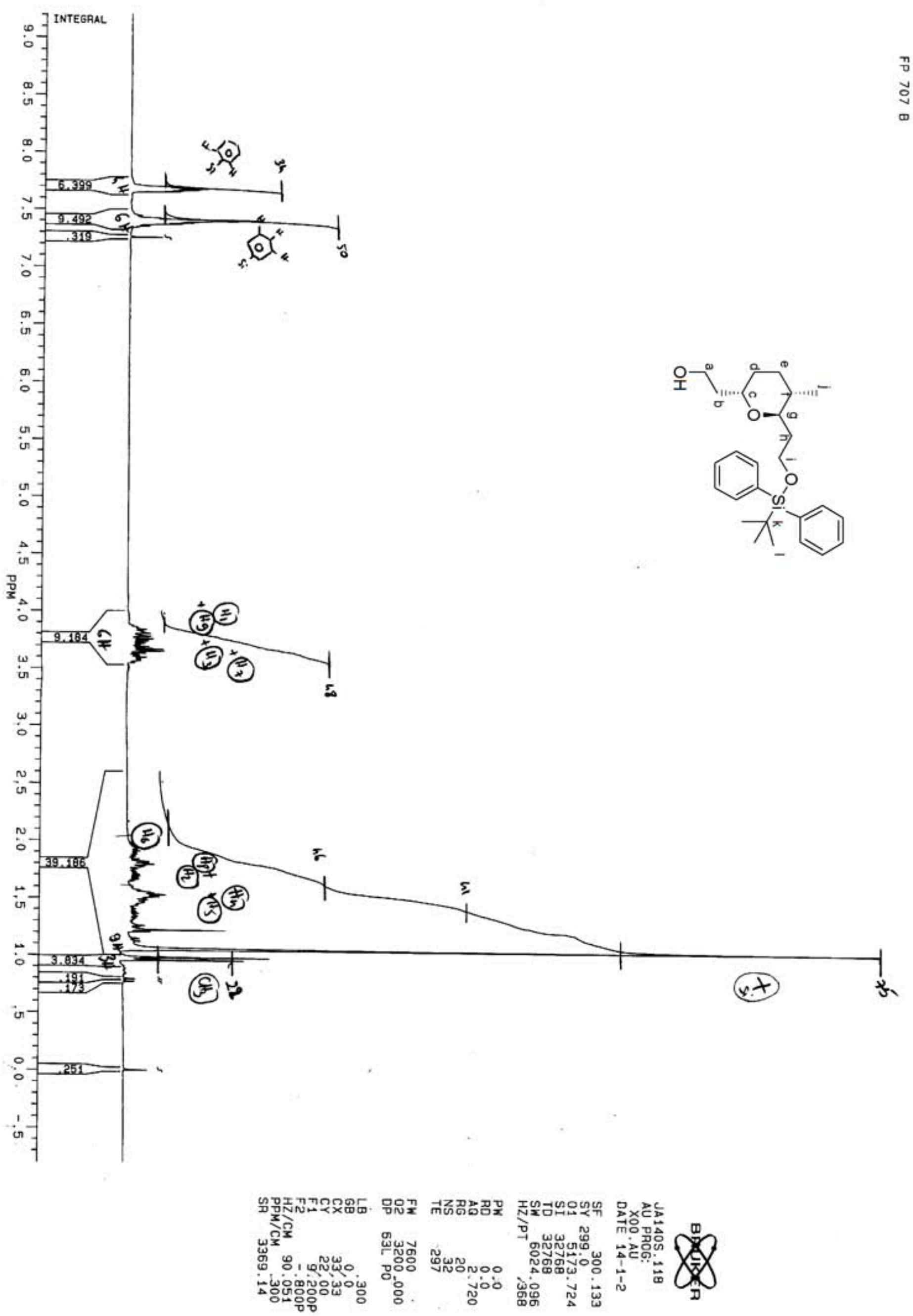


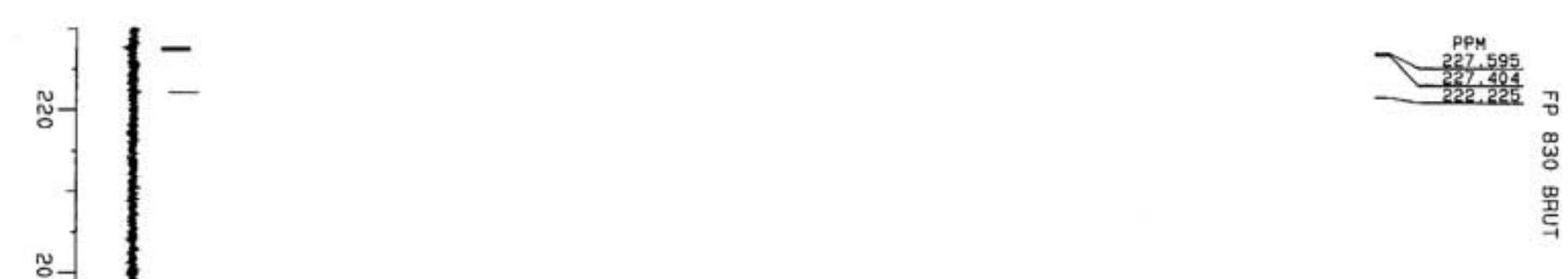

.70 .951

149.489
142.918
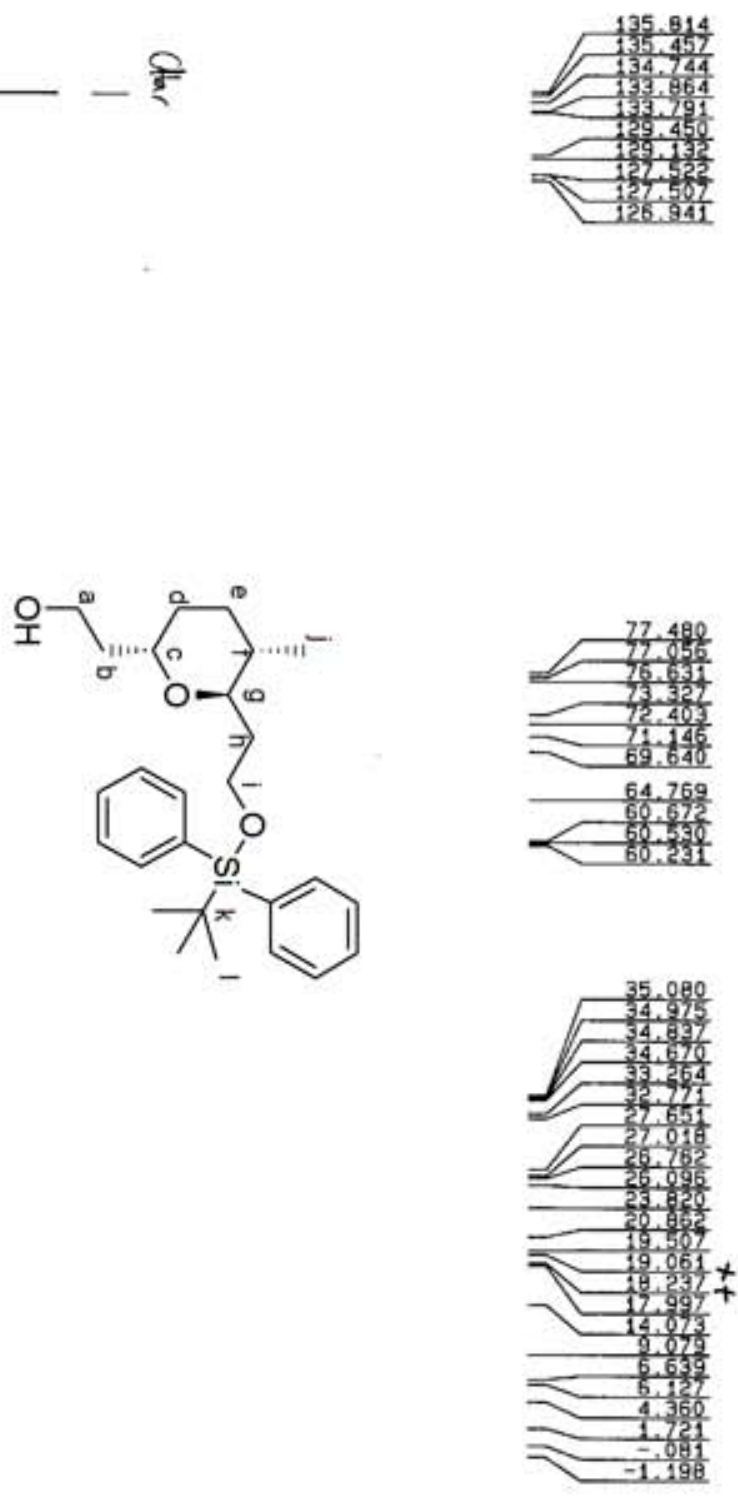

$-12.706$

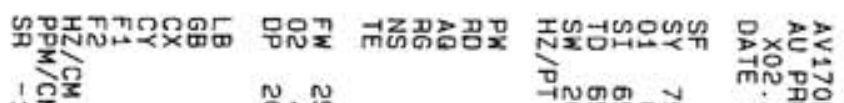

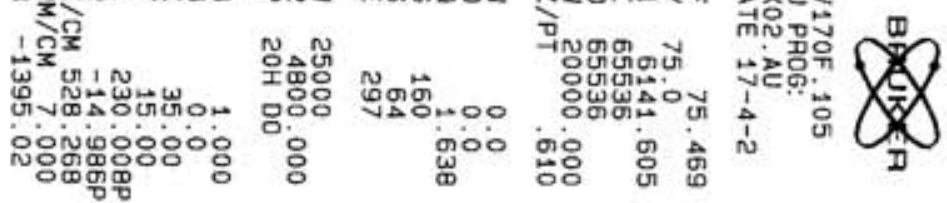




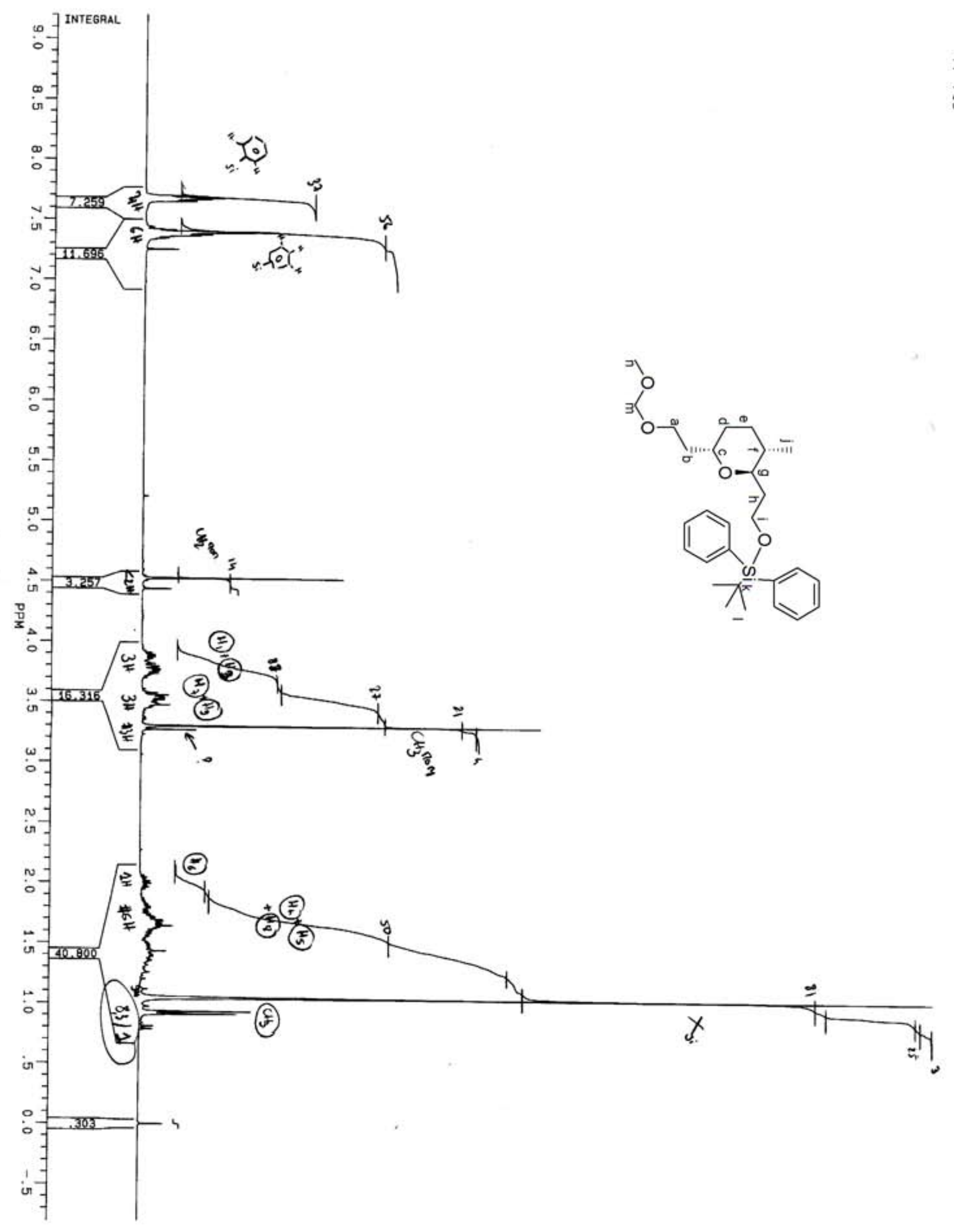

गे 

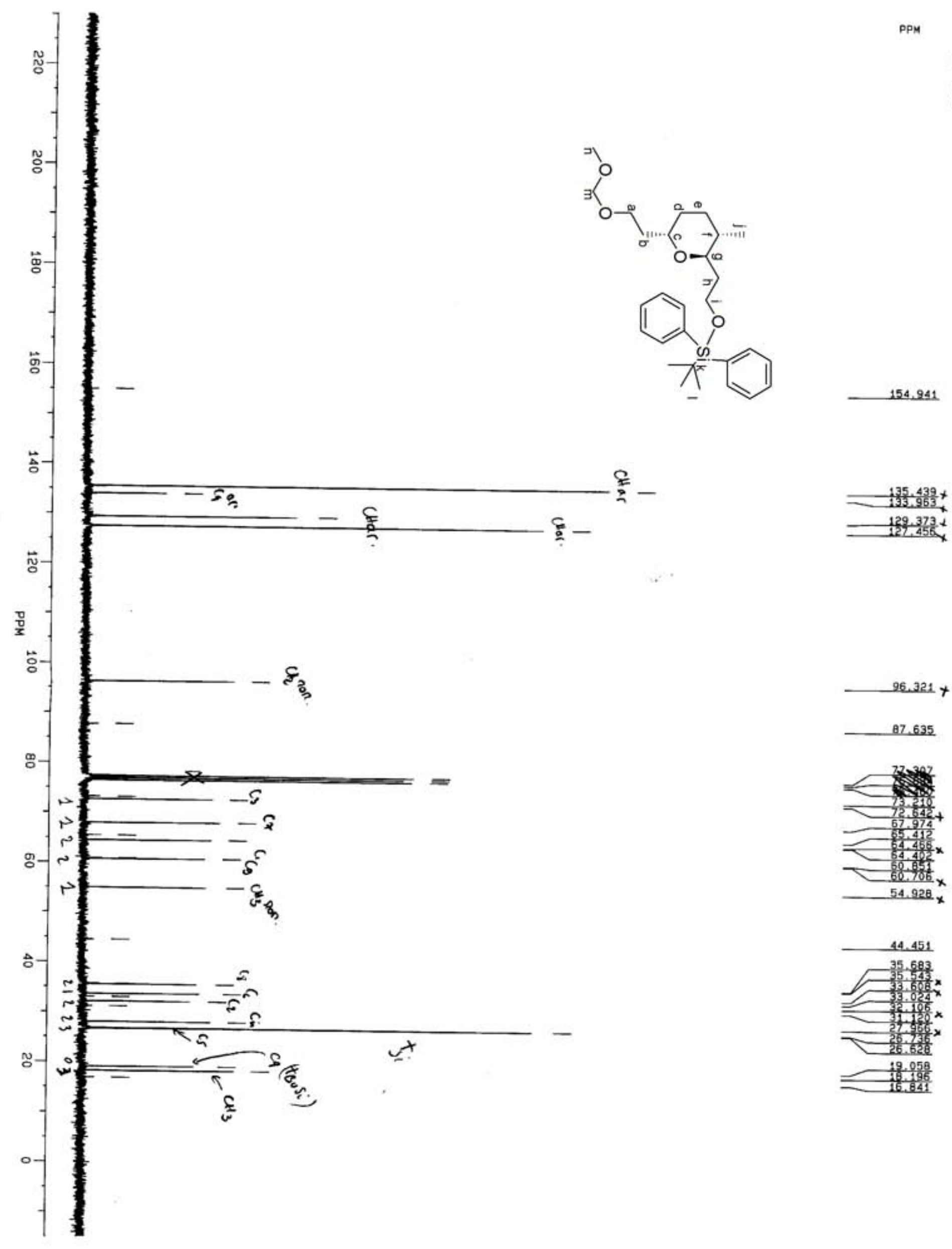

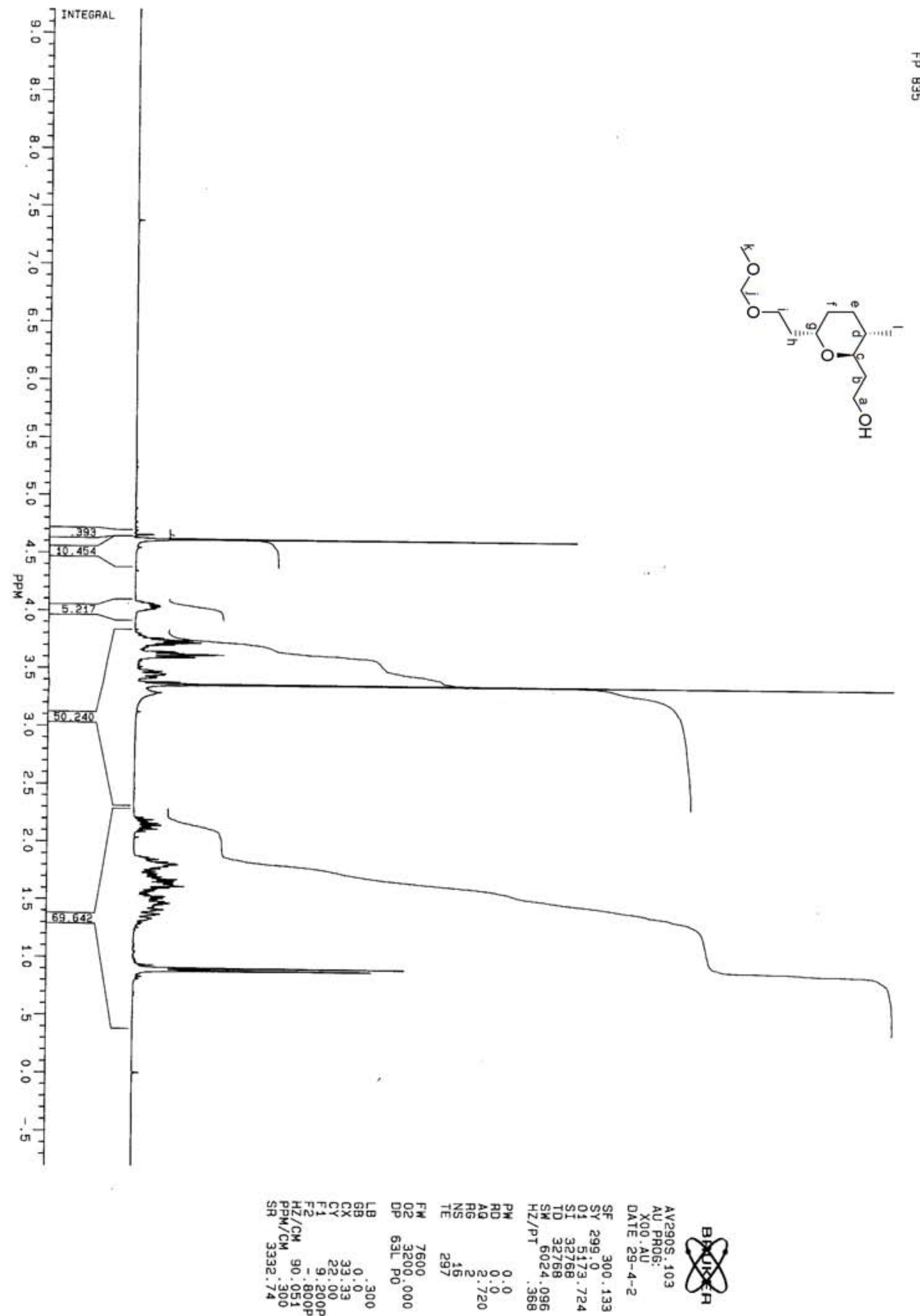

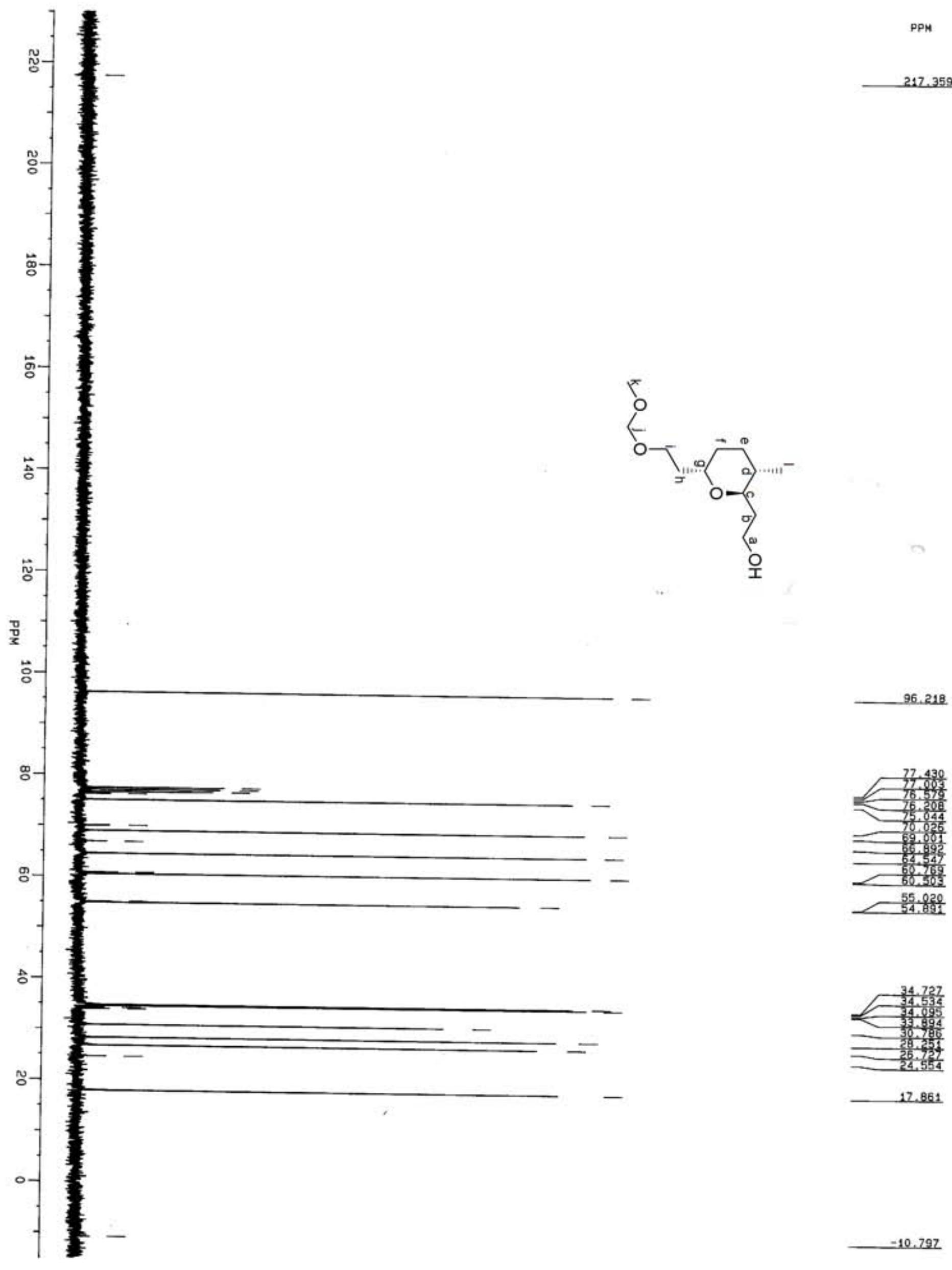

$-10.797$

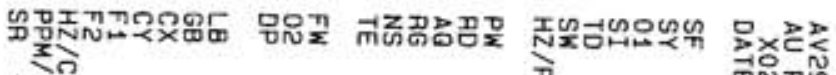

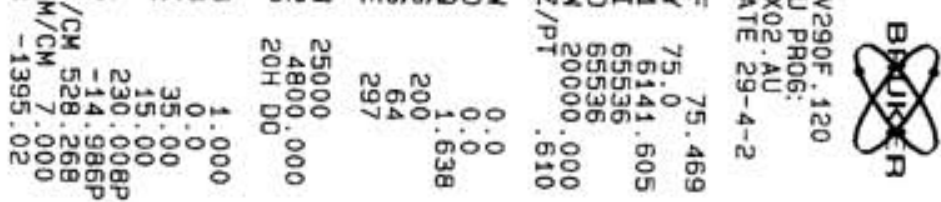



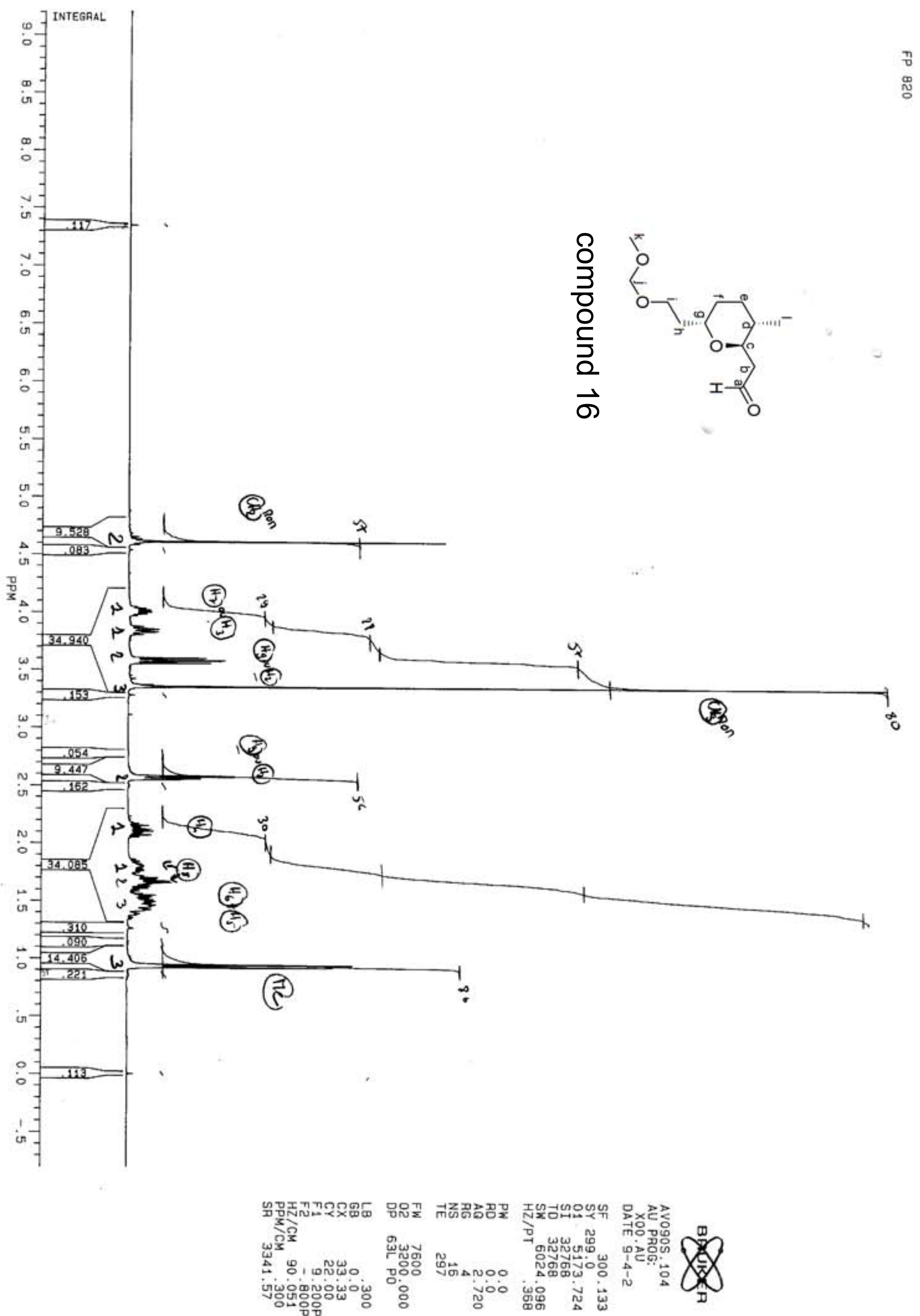


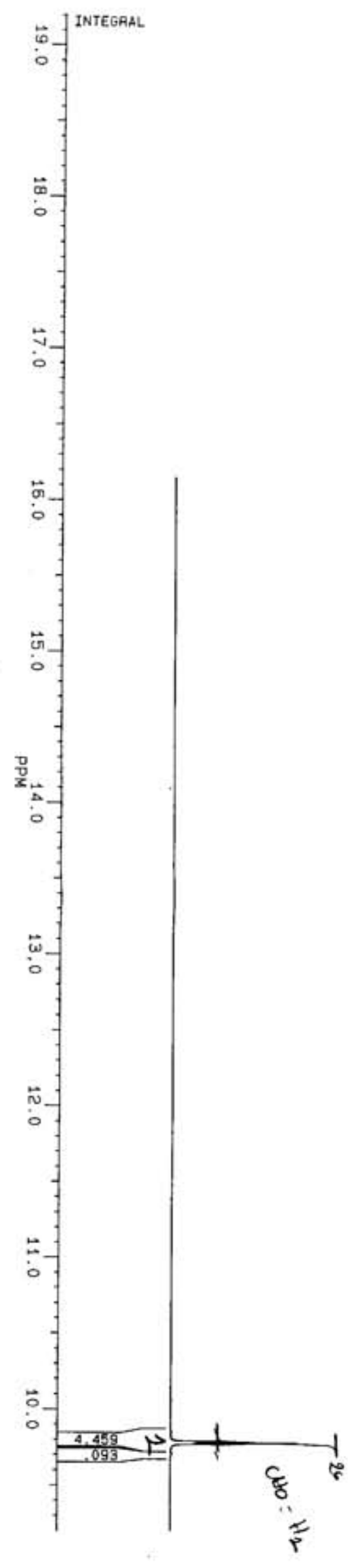

을
$\frac{3}{0}$
들
을

$\vec{\sigma}$

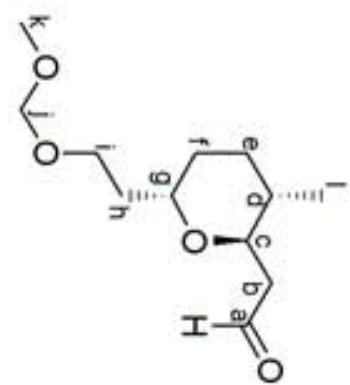

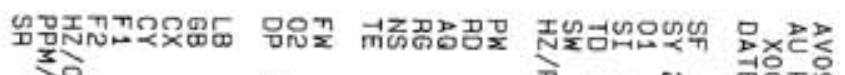

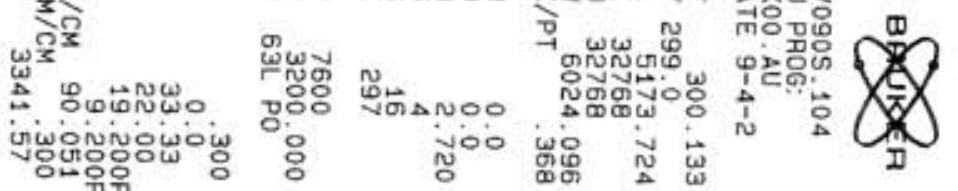



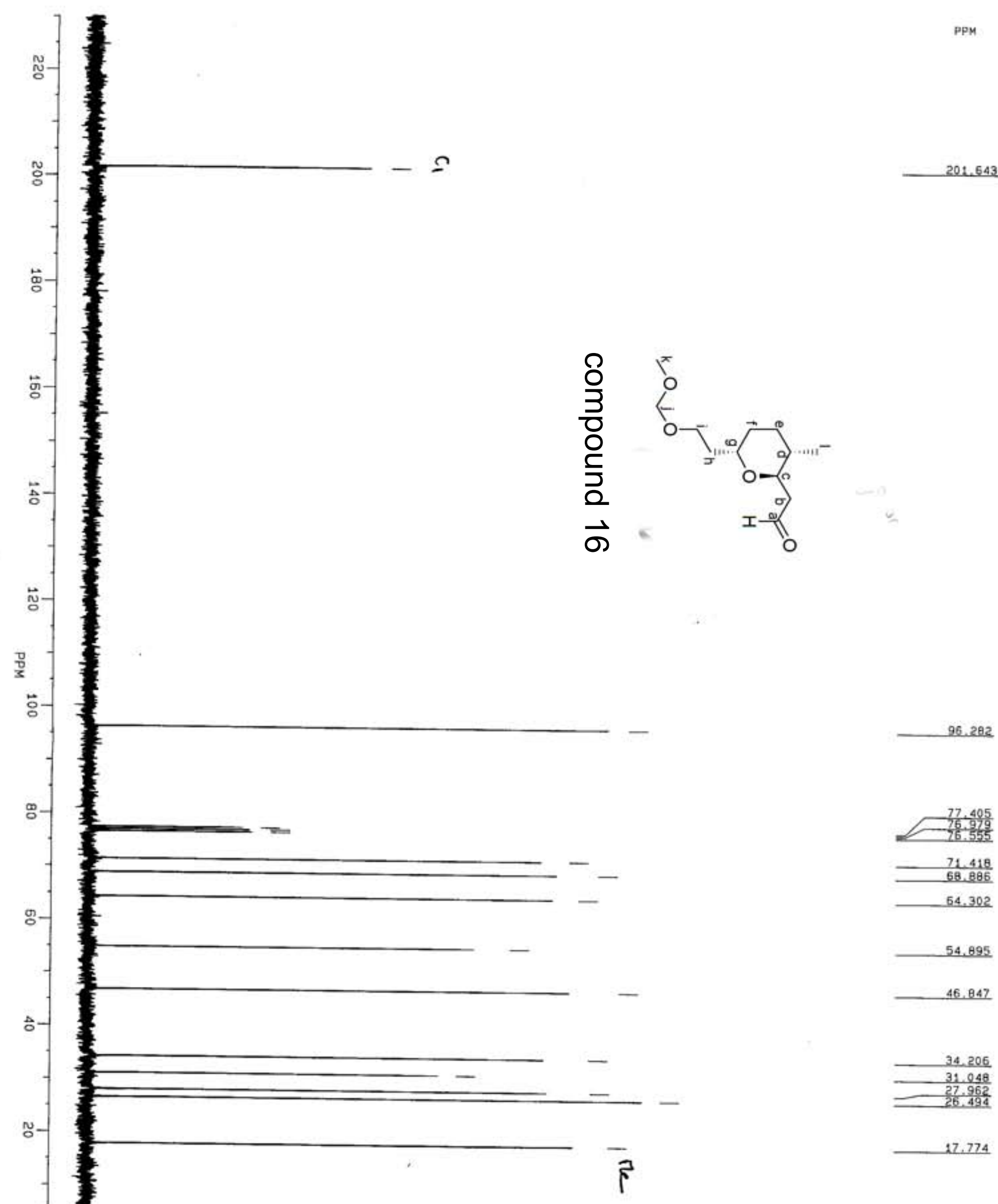

96.282

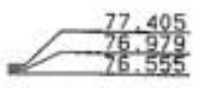

71.418 68.886

54.302

54.895

46.847

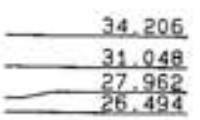

27.774

(1)

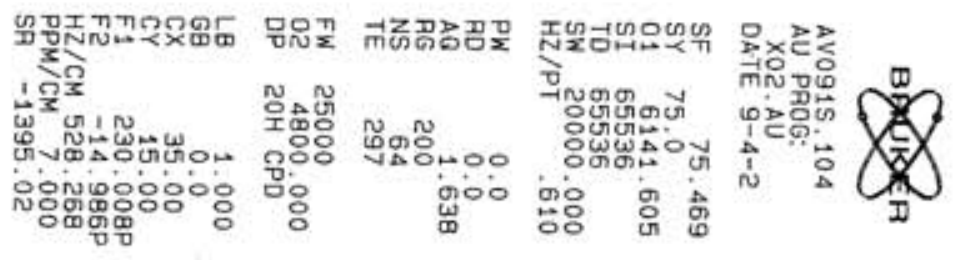




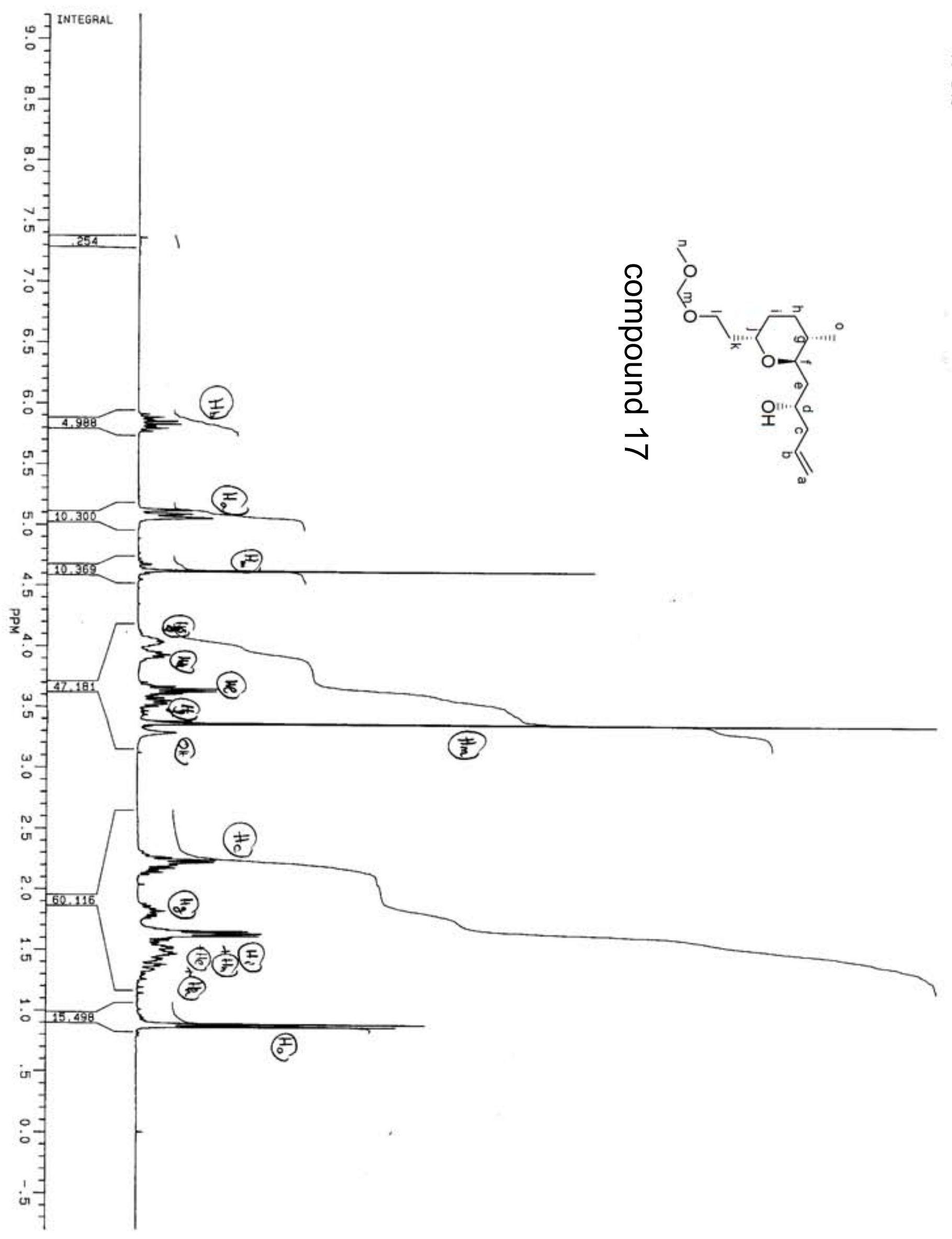

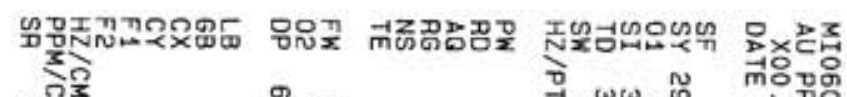

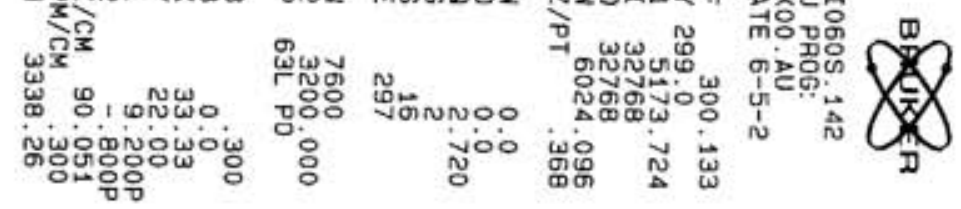



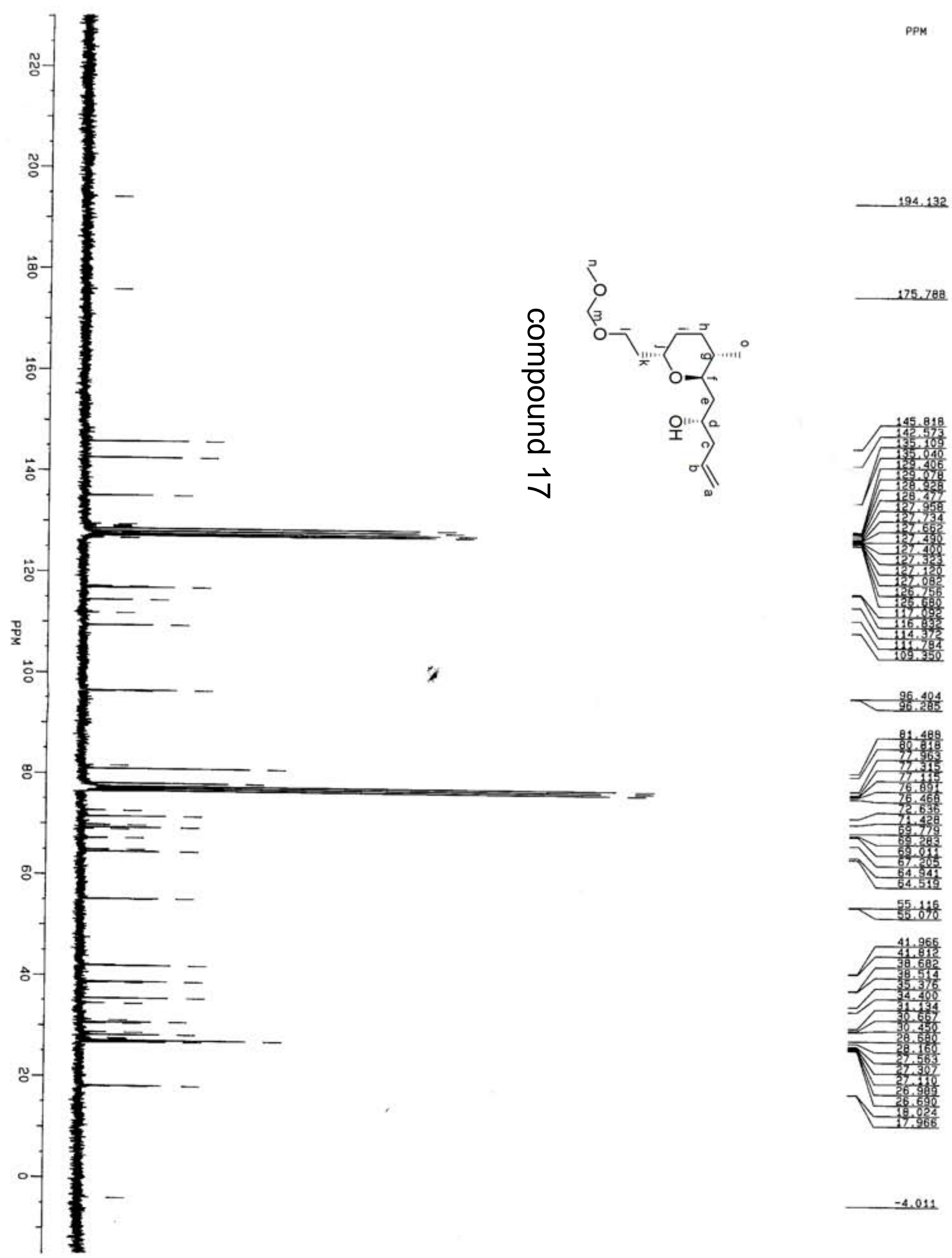

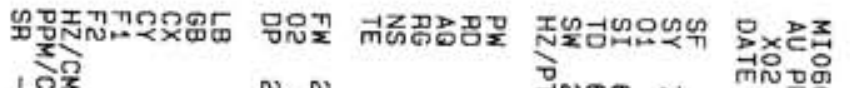

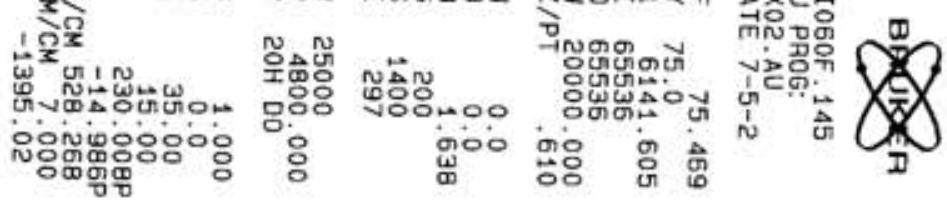



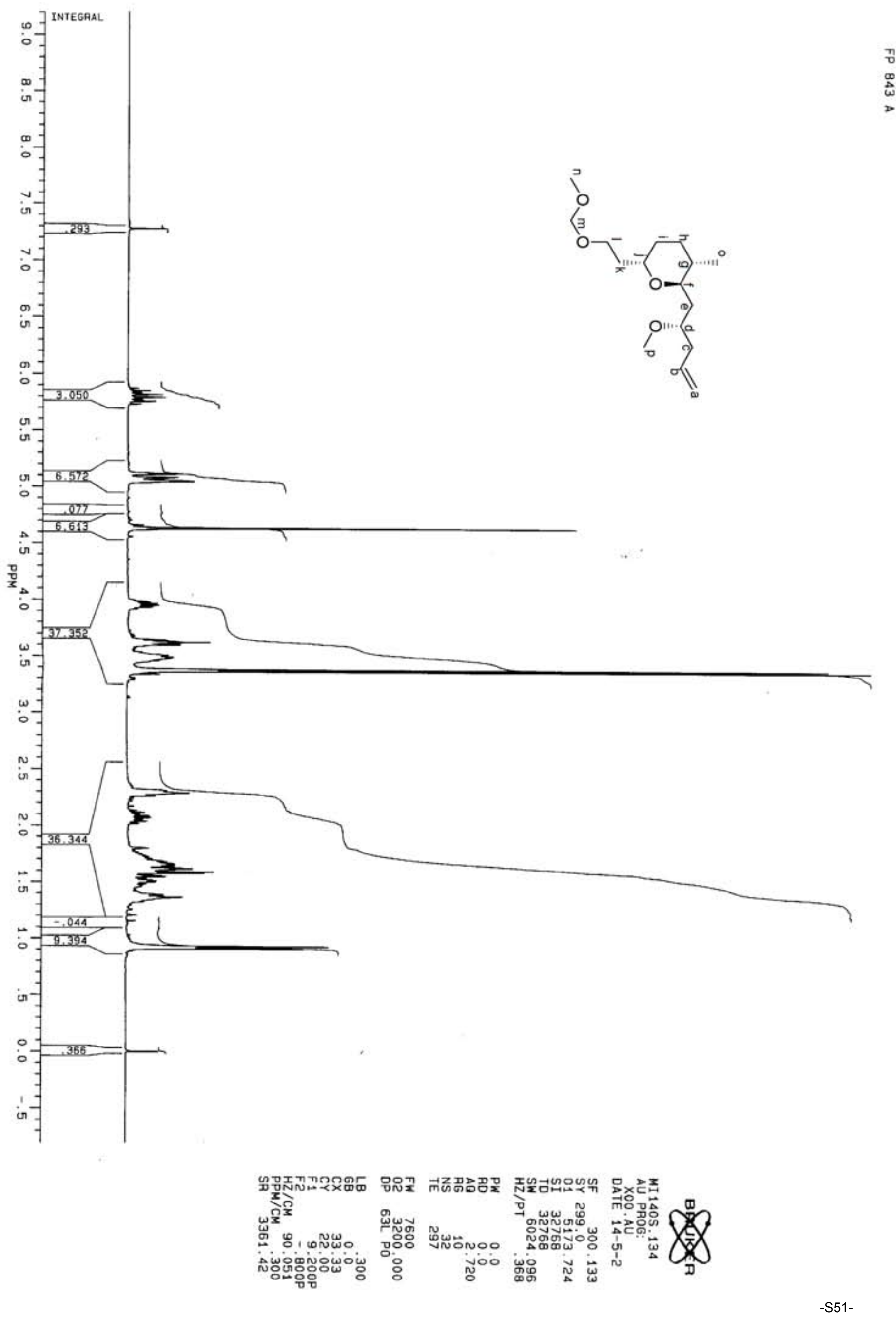

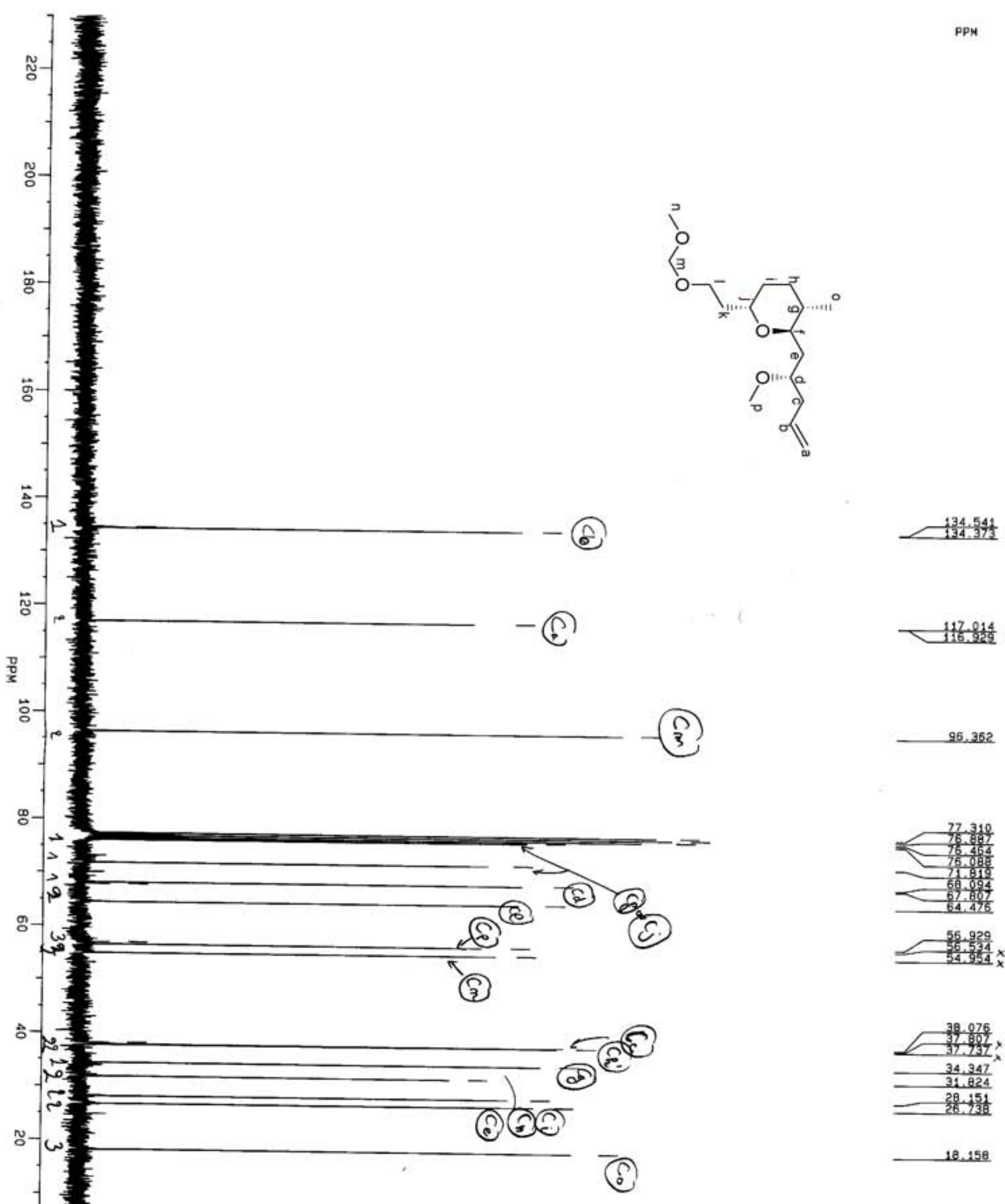

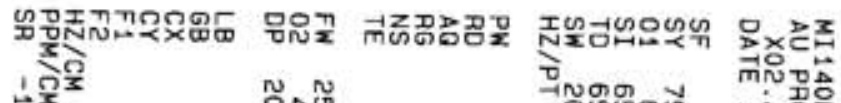

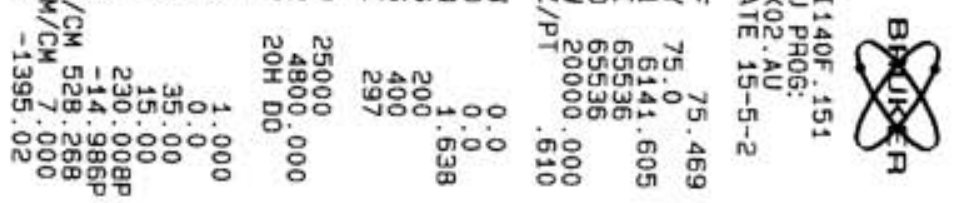




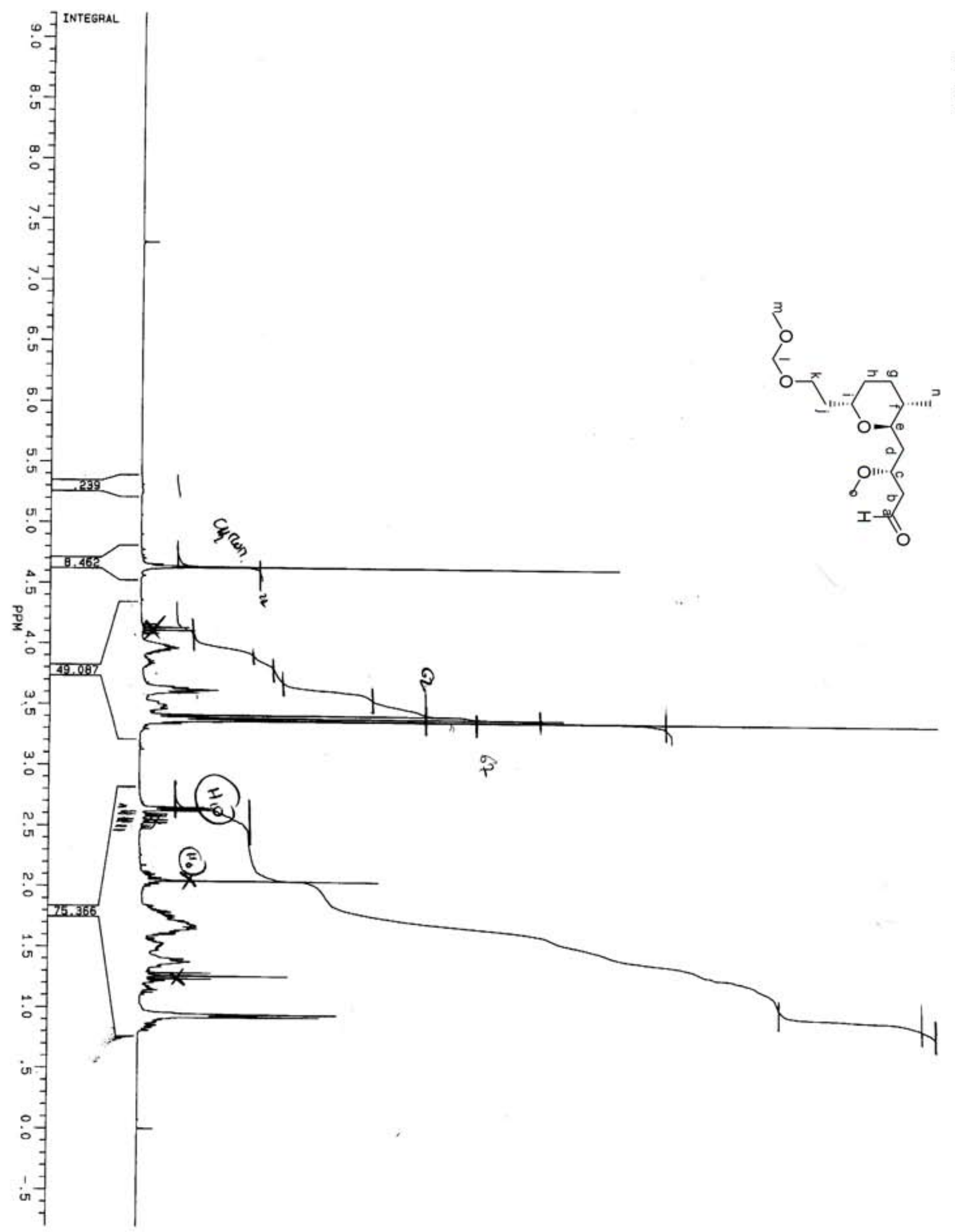

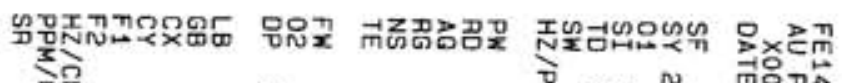

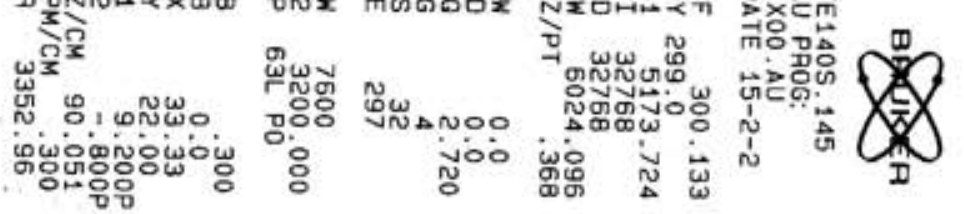



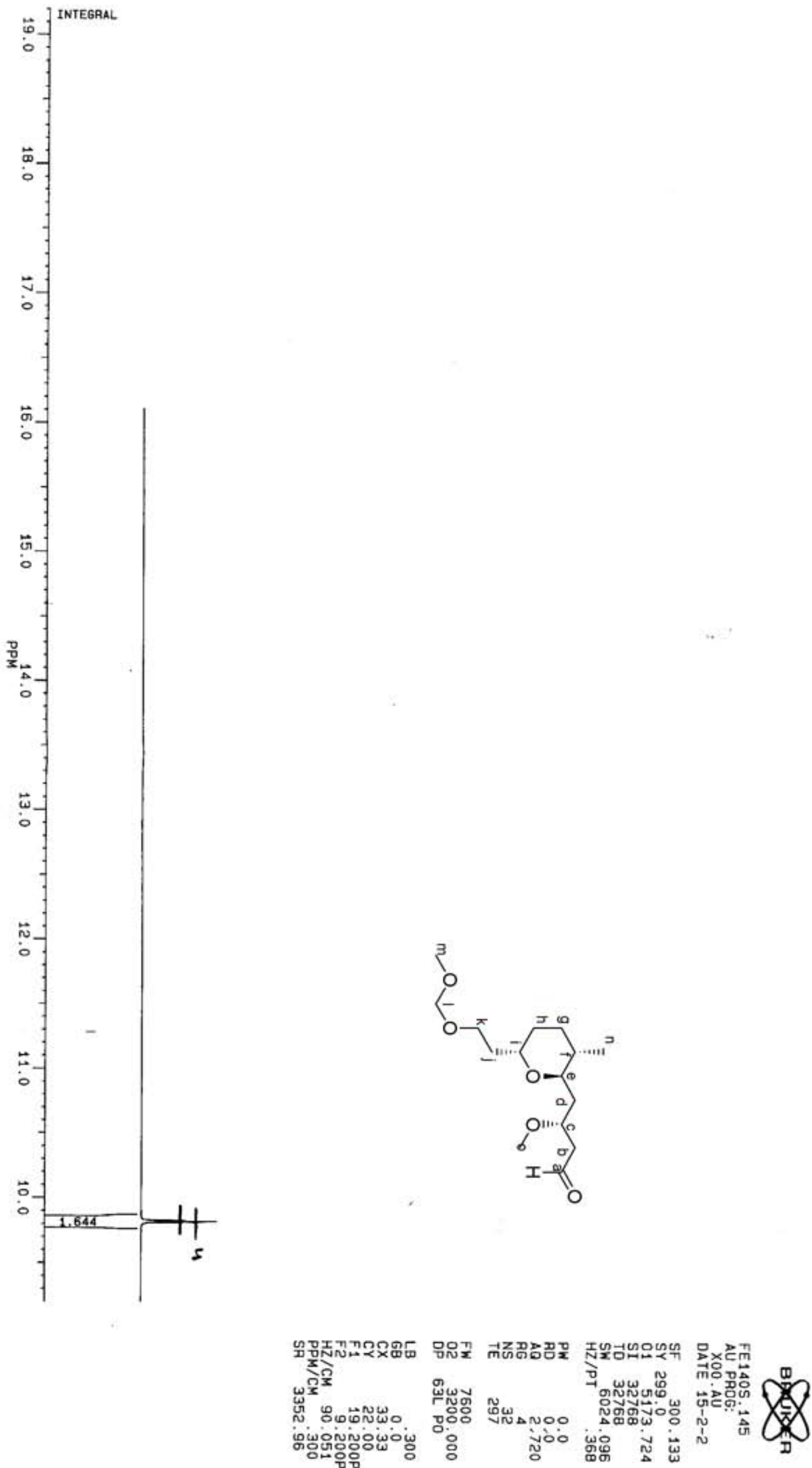


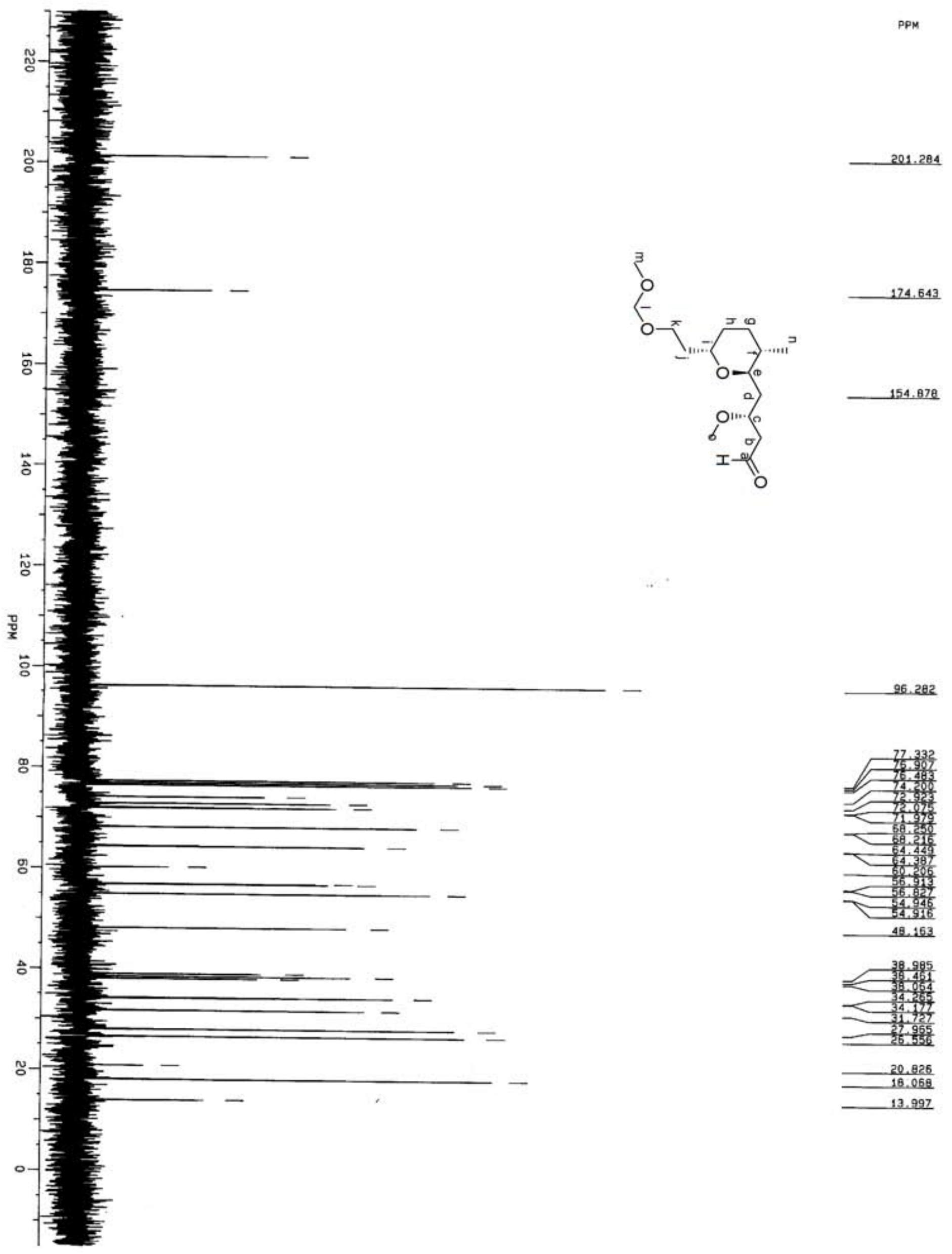

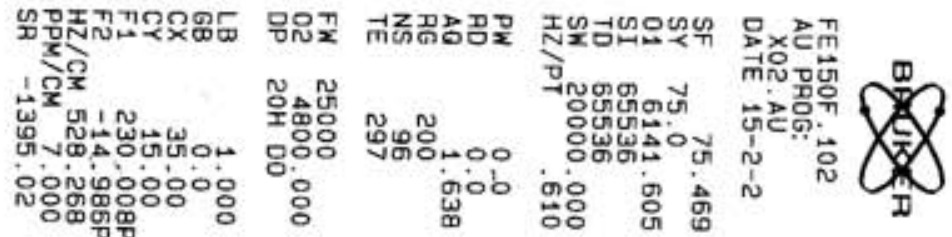




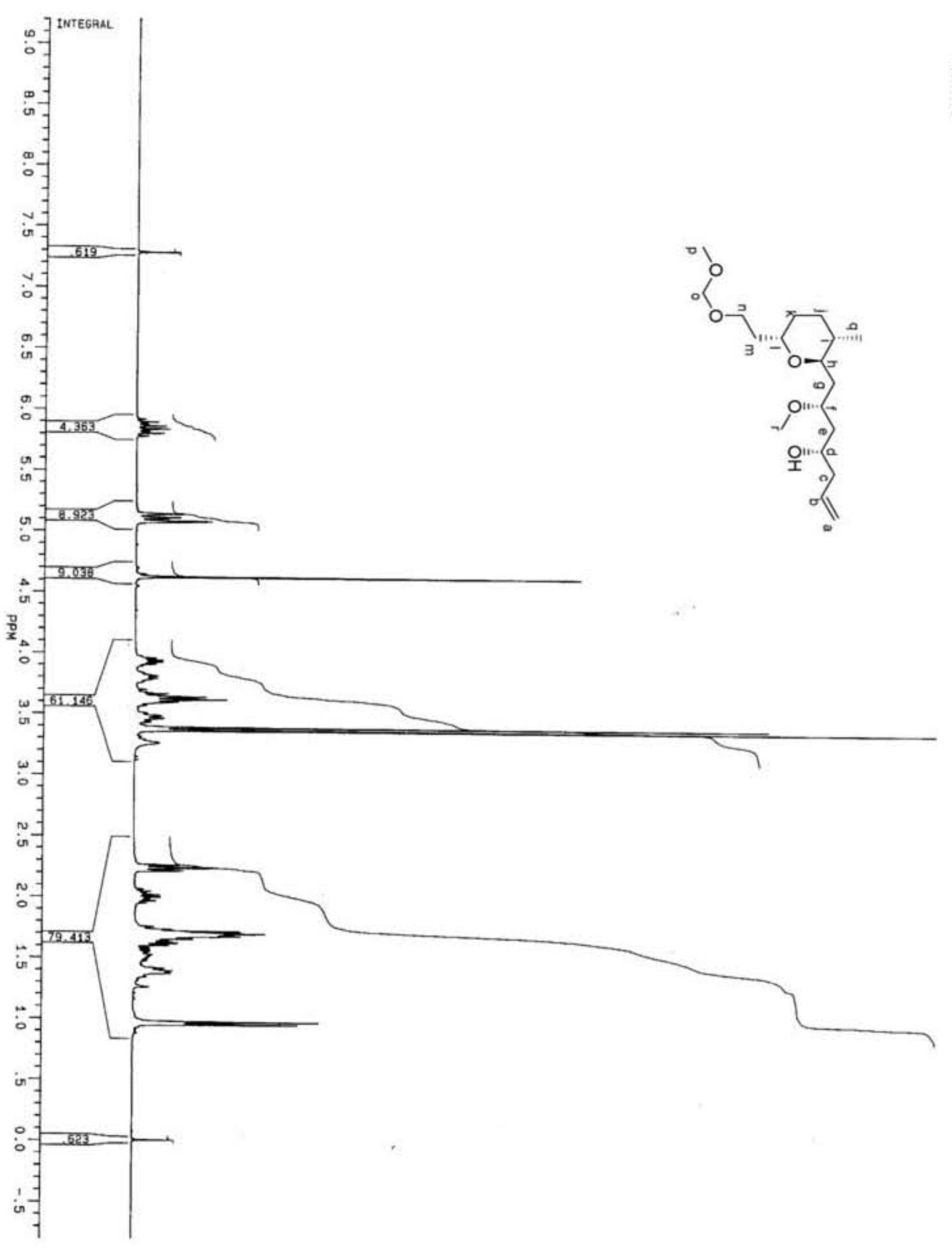

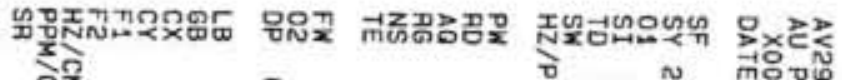

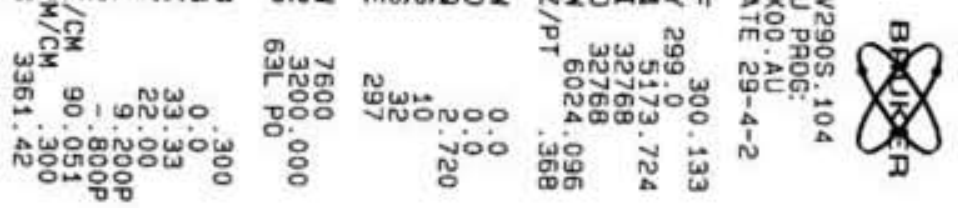




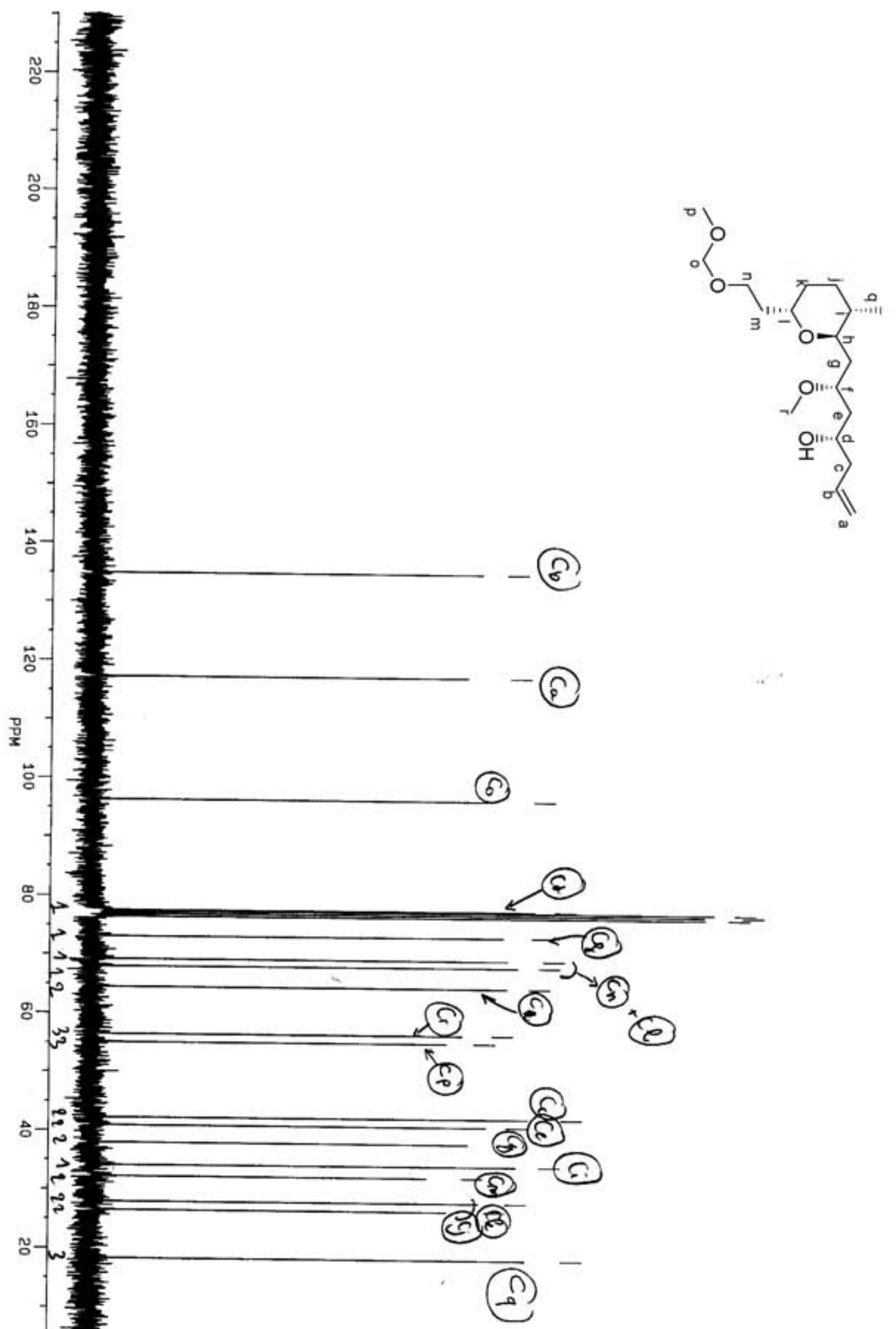

134.860

96.294

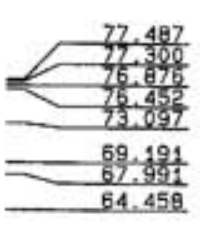

$\begin{array}{r}56.412 \\ \hline 5.034 \\ \hline\end{array}$

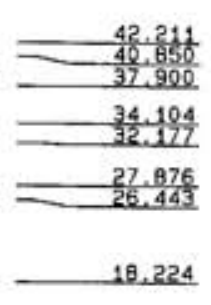

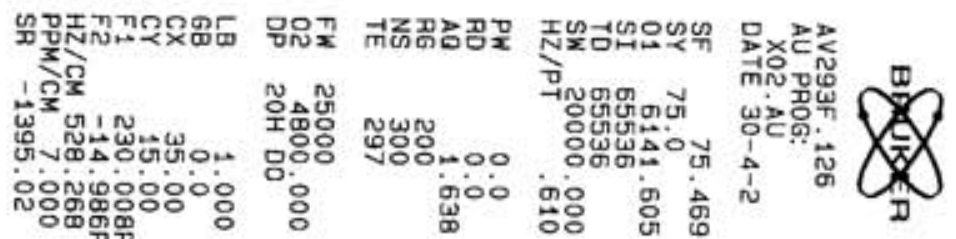




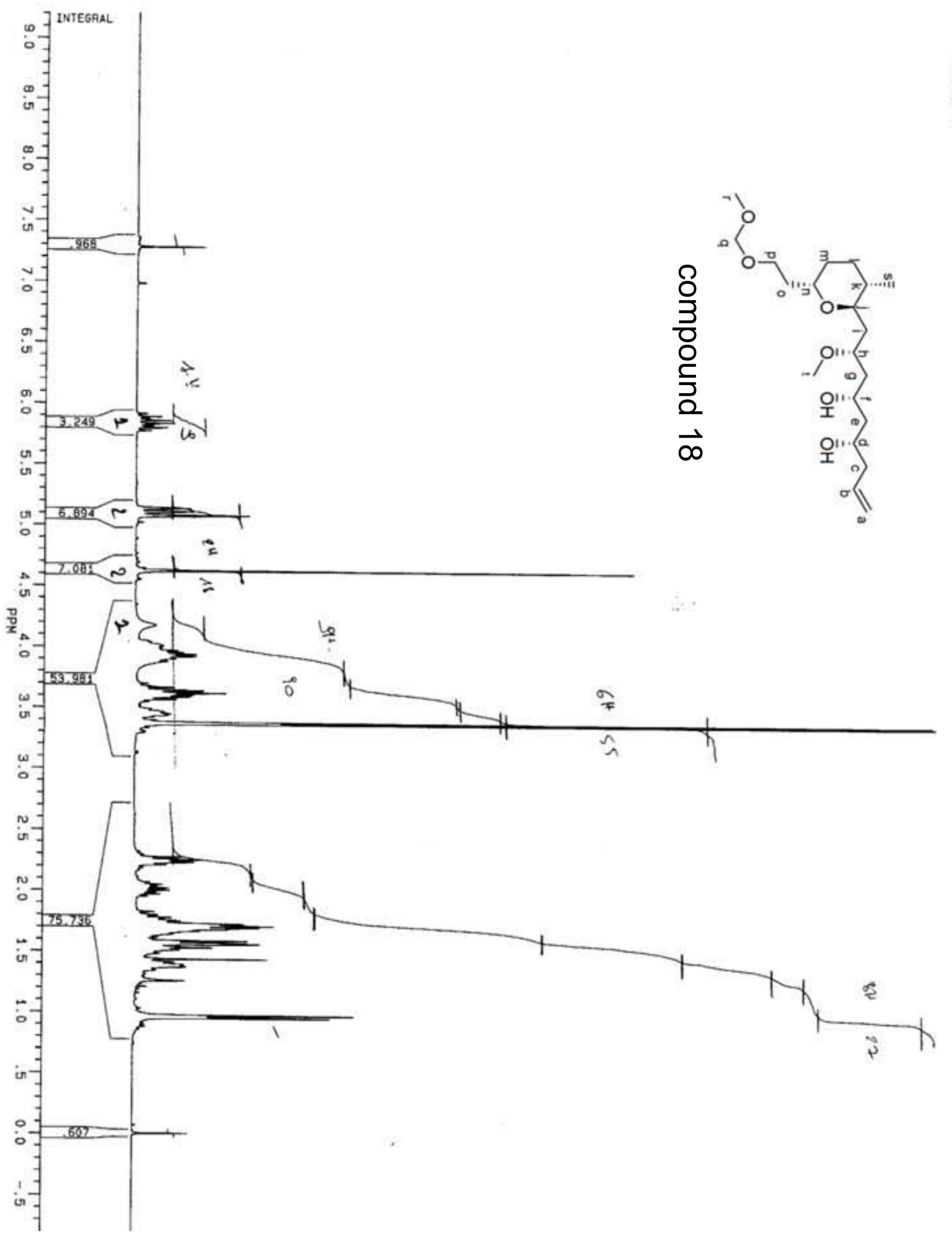

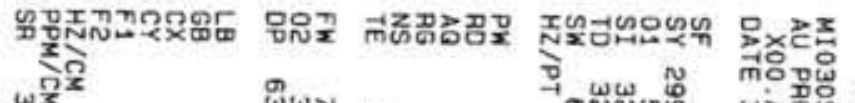

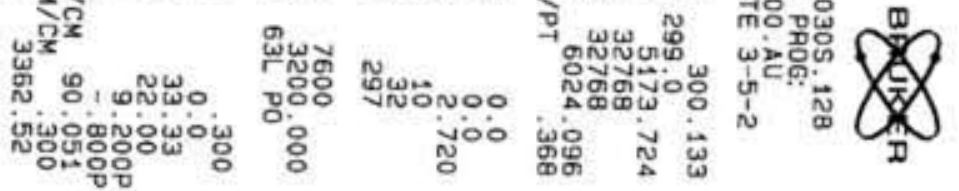



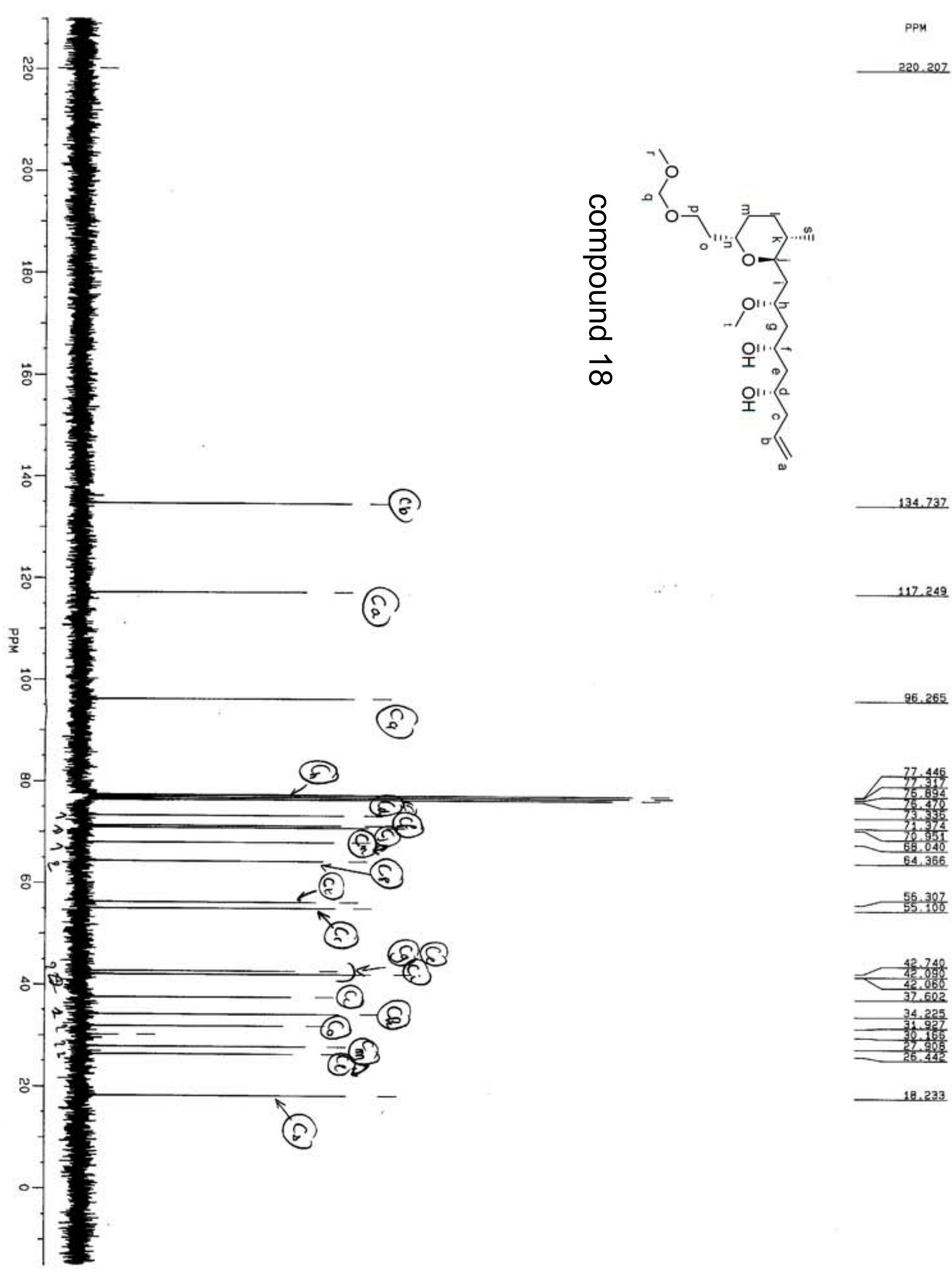

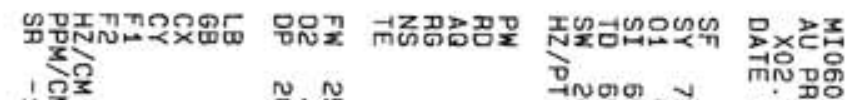
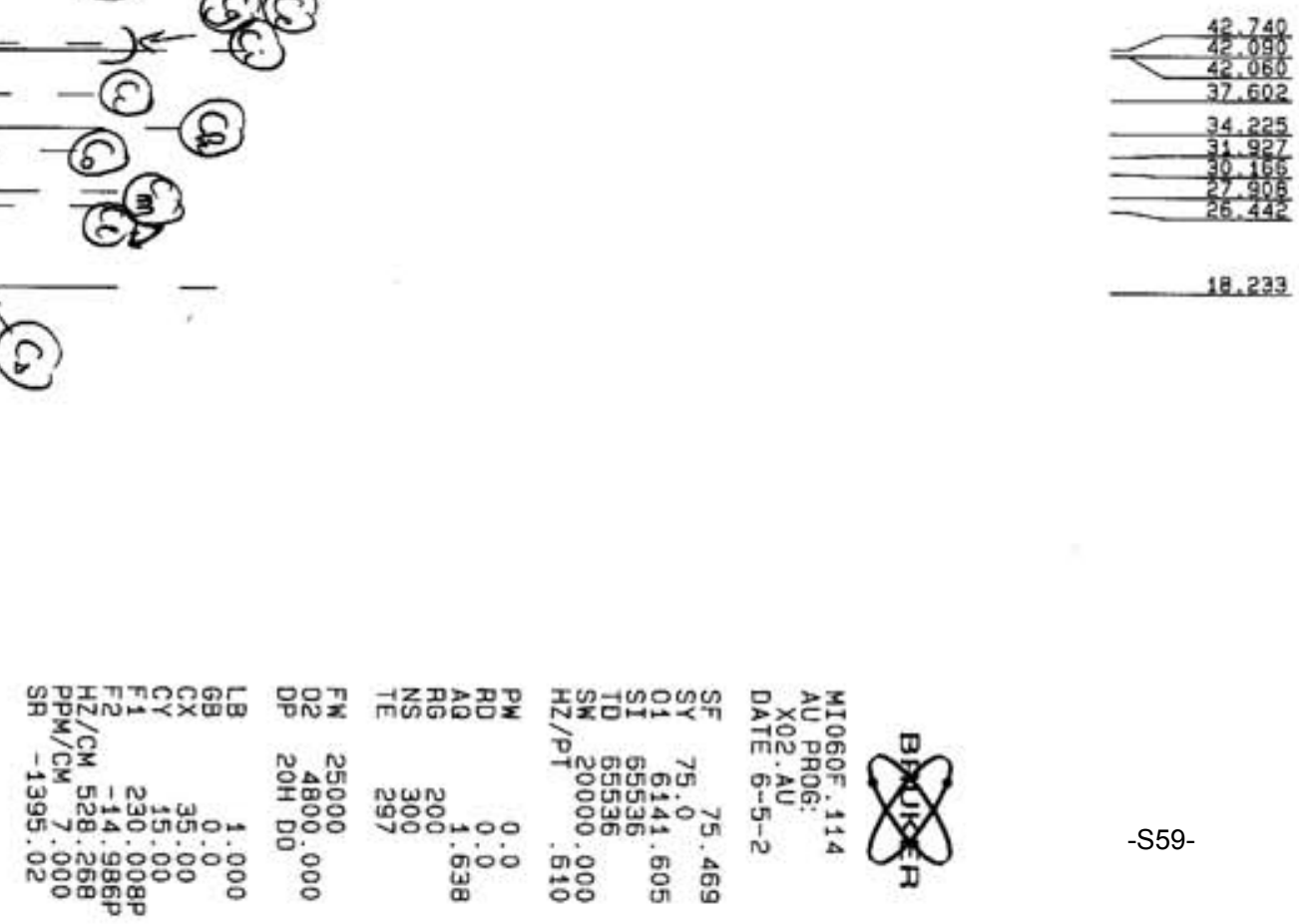


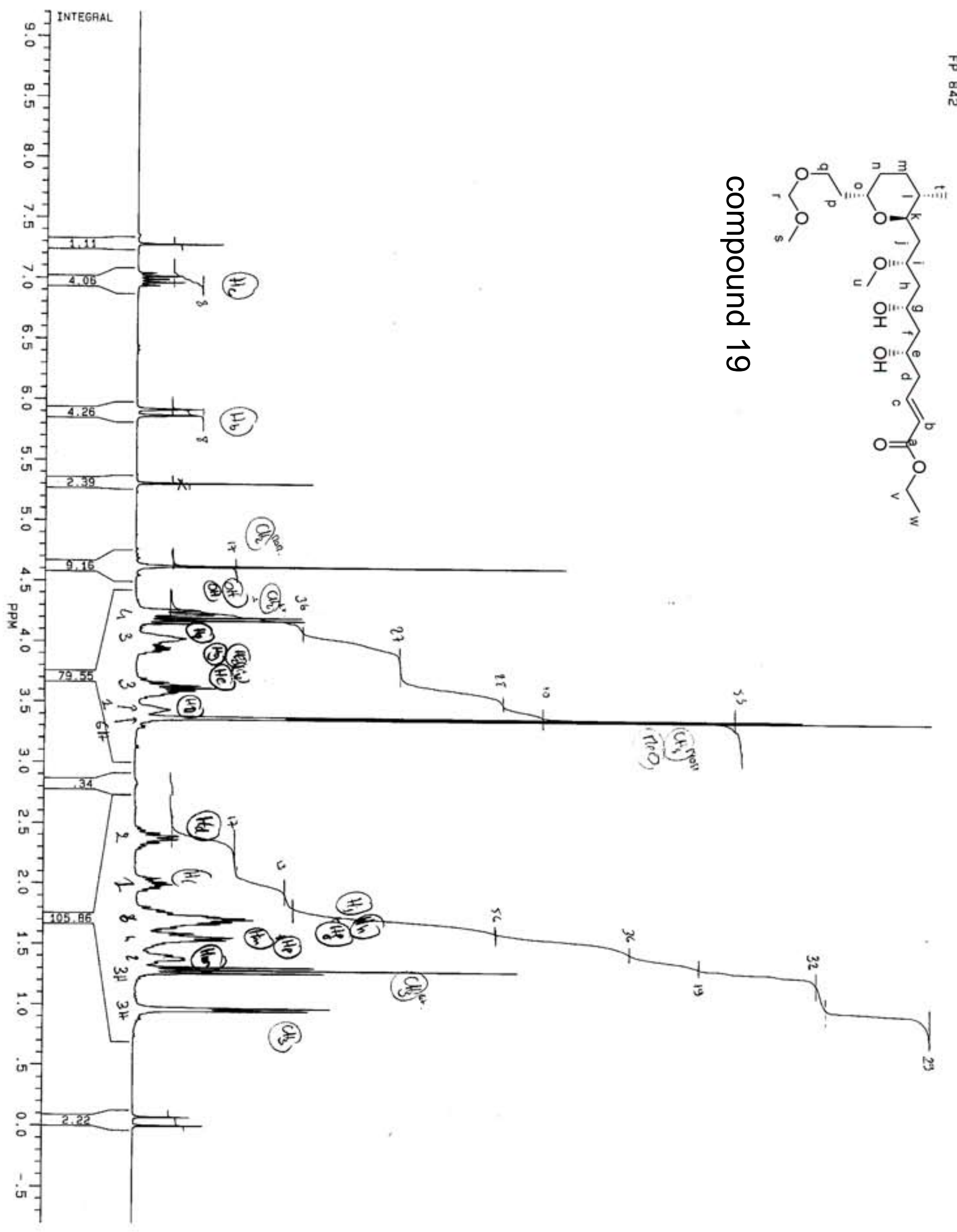



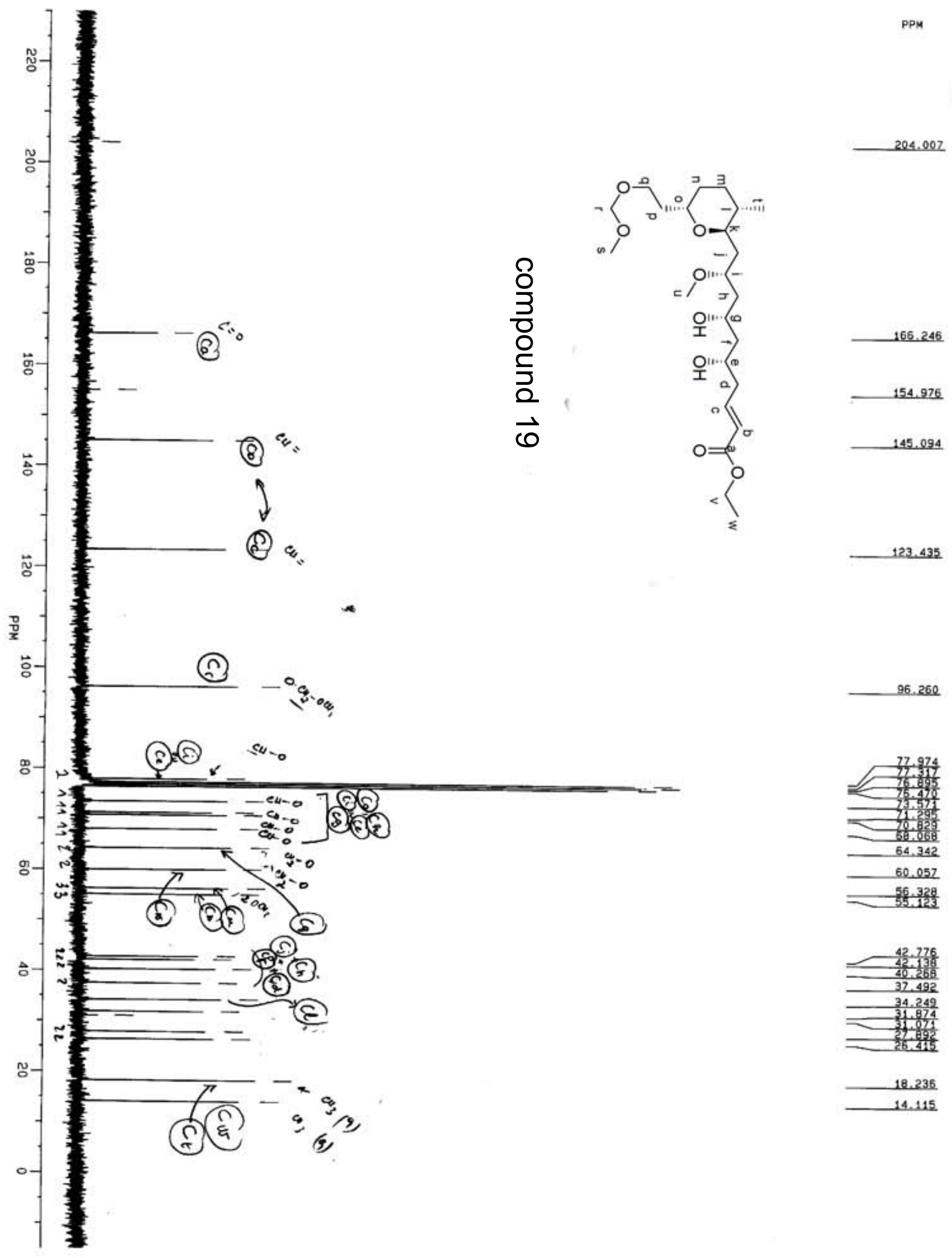

123.435

96.260
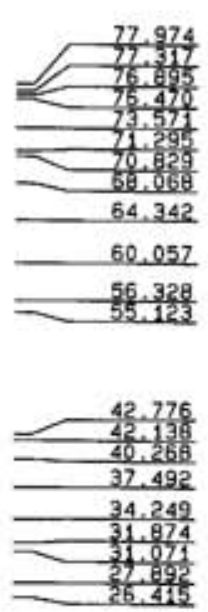

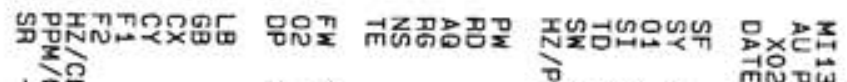

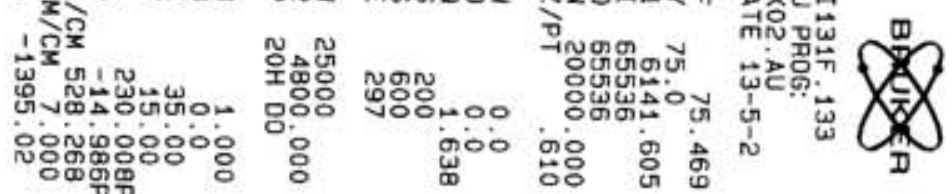




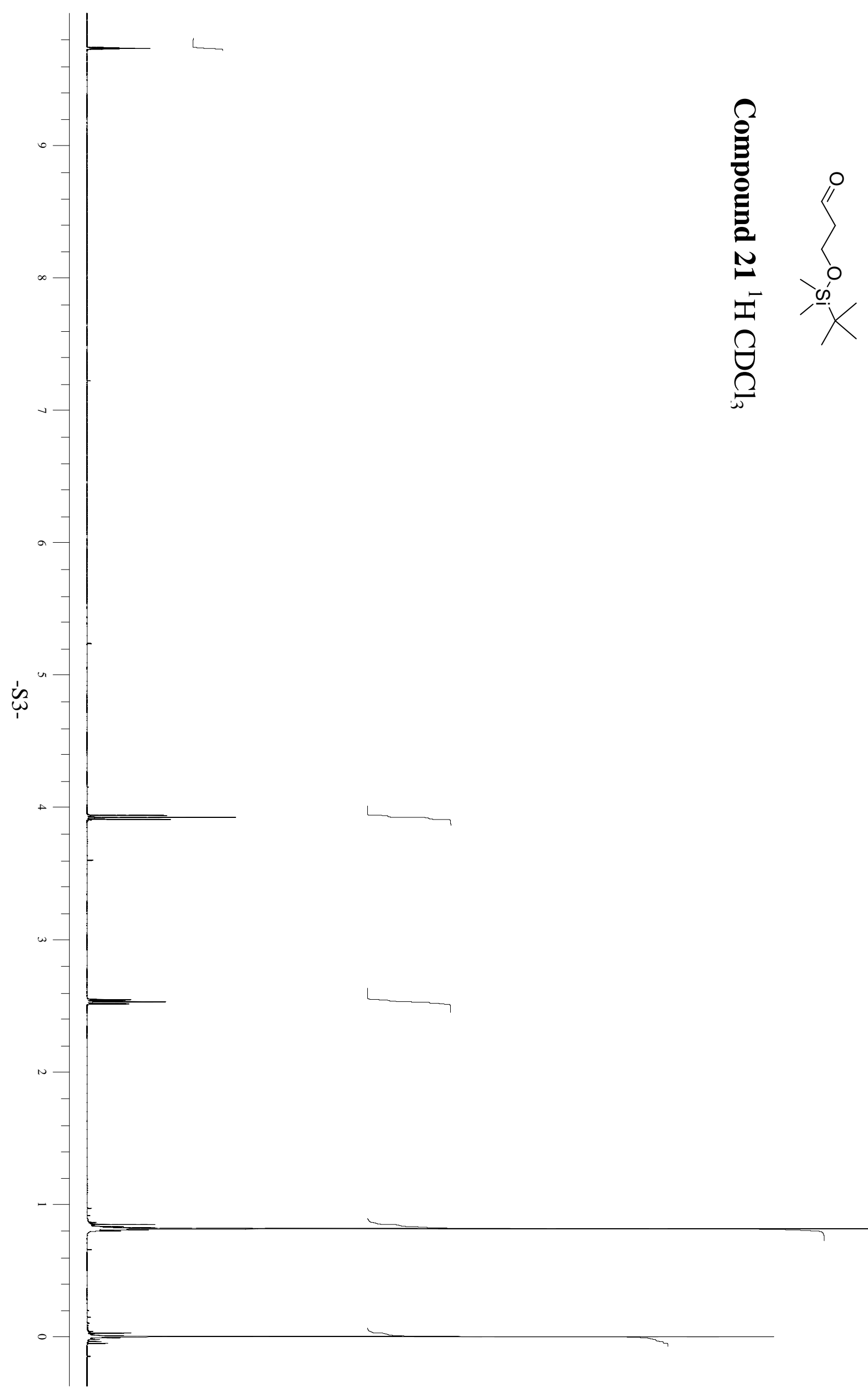




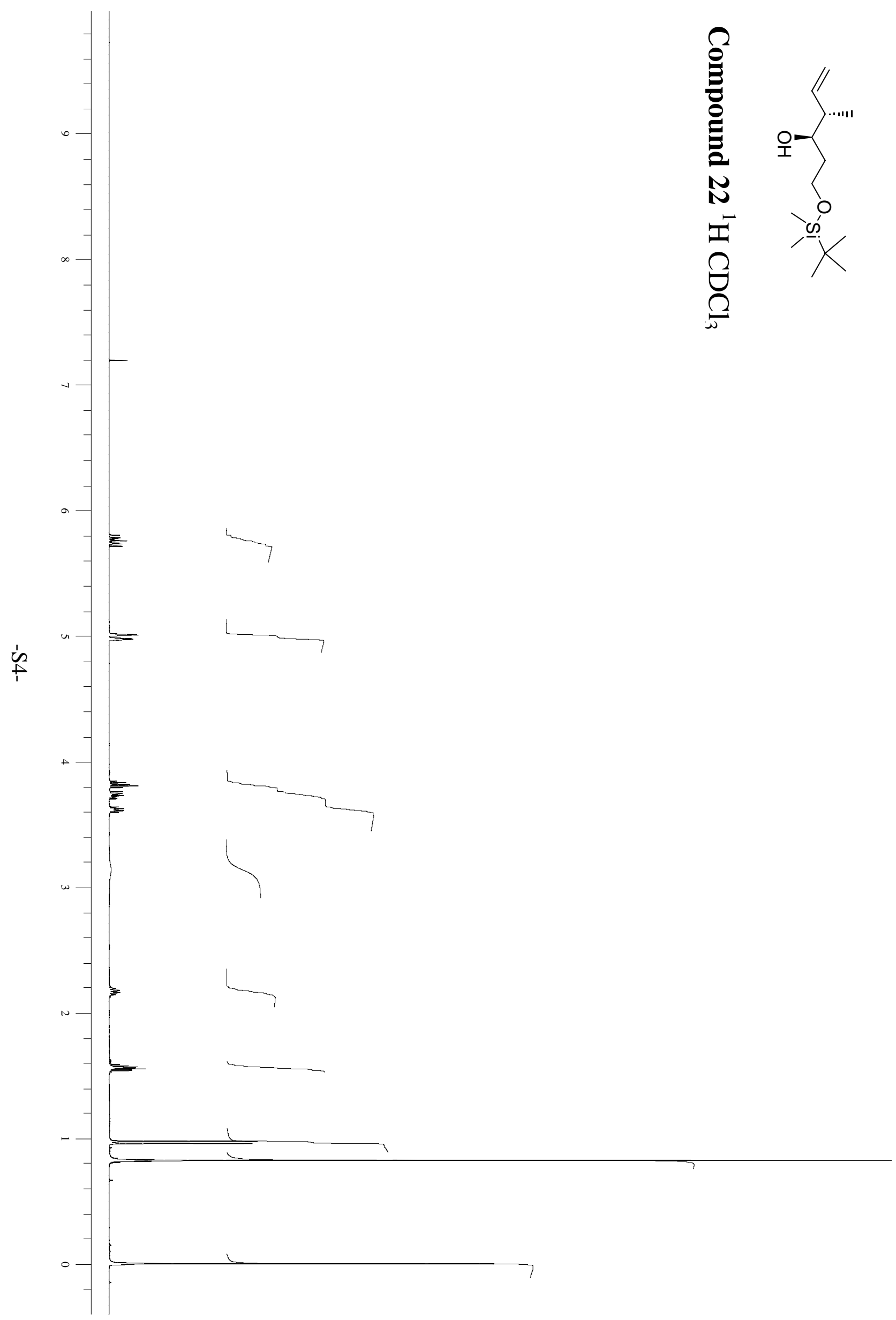




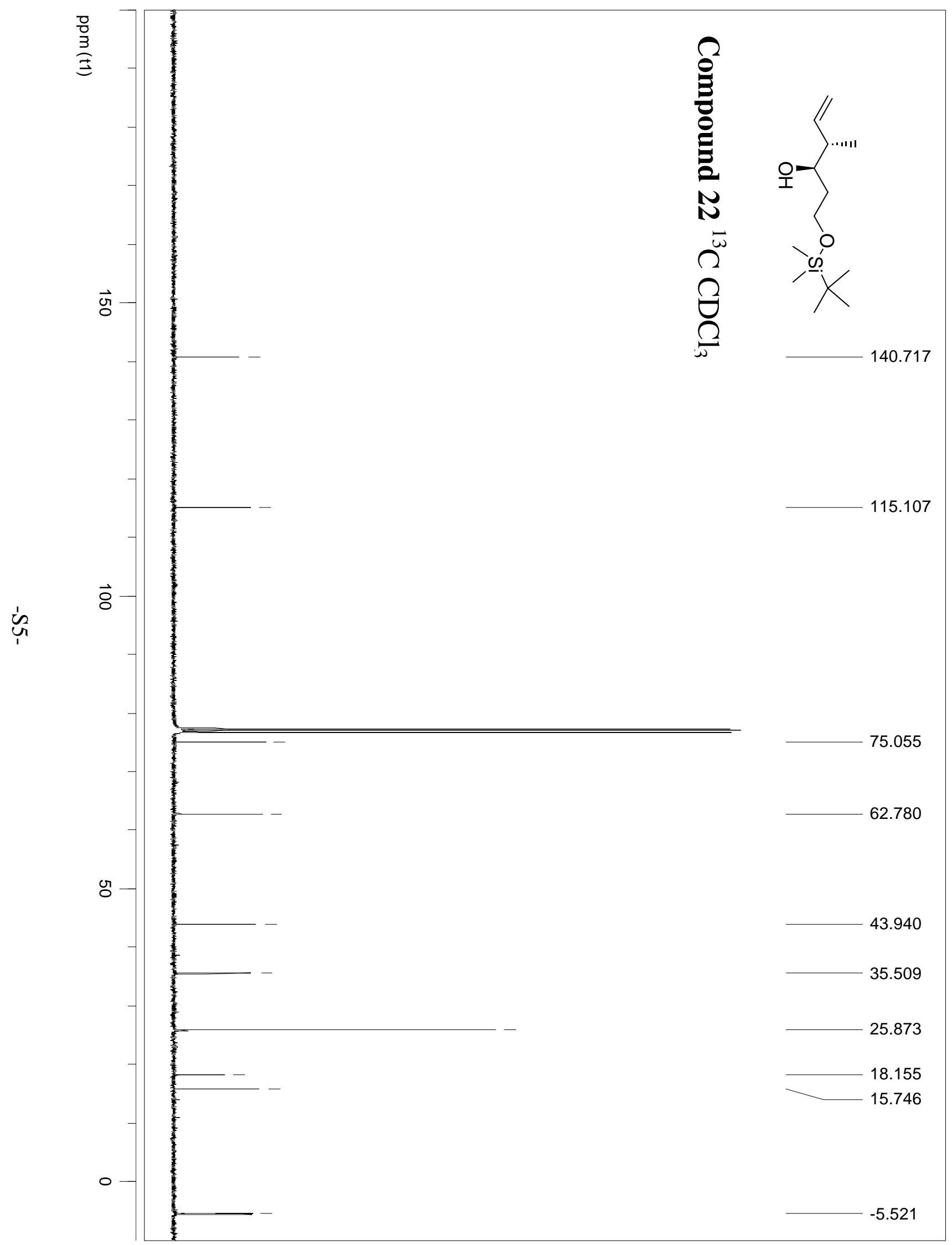




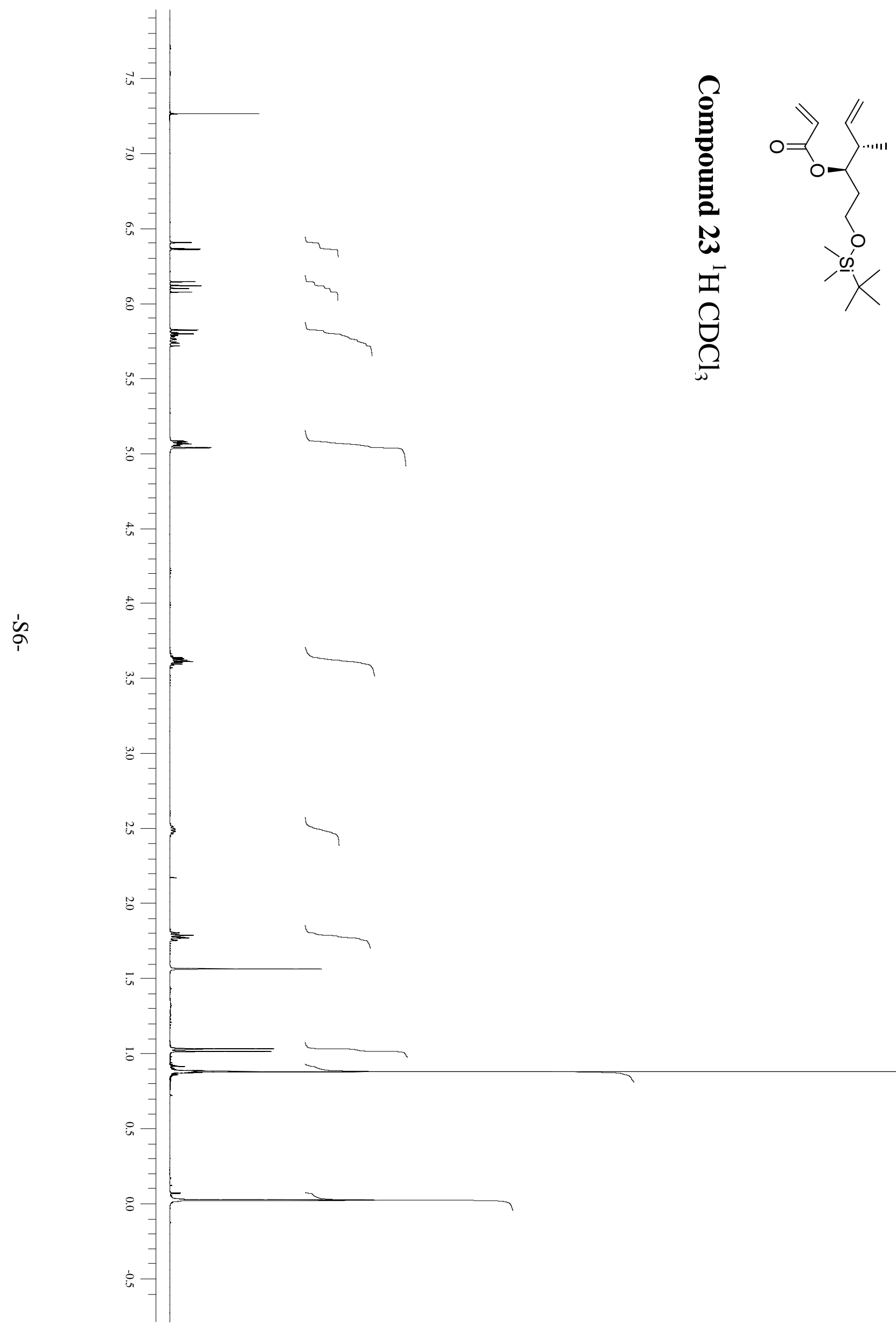




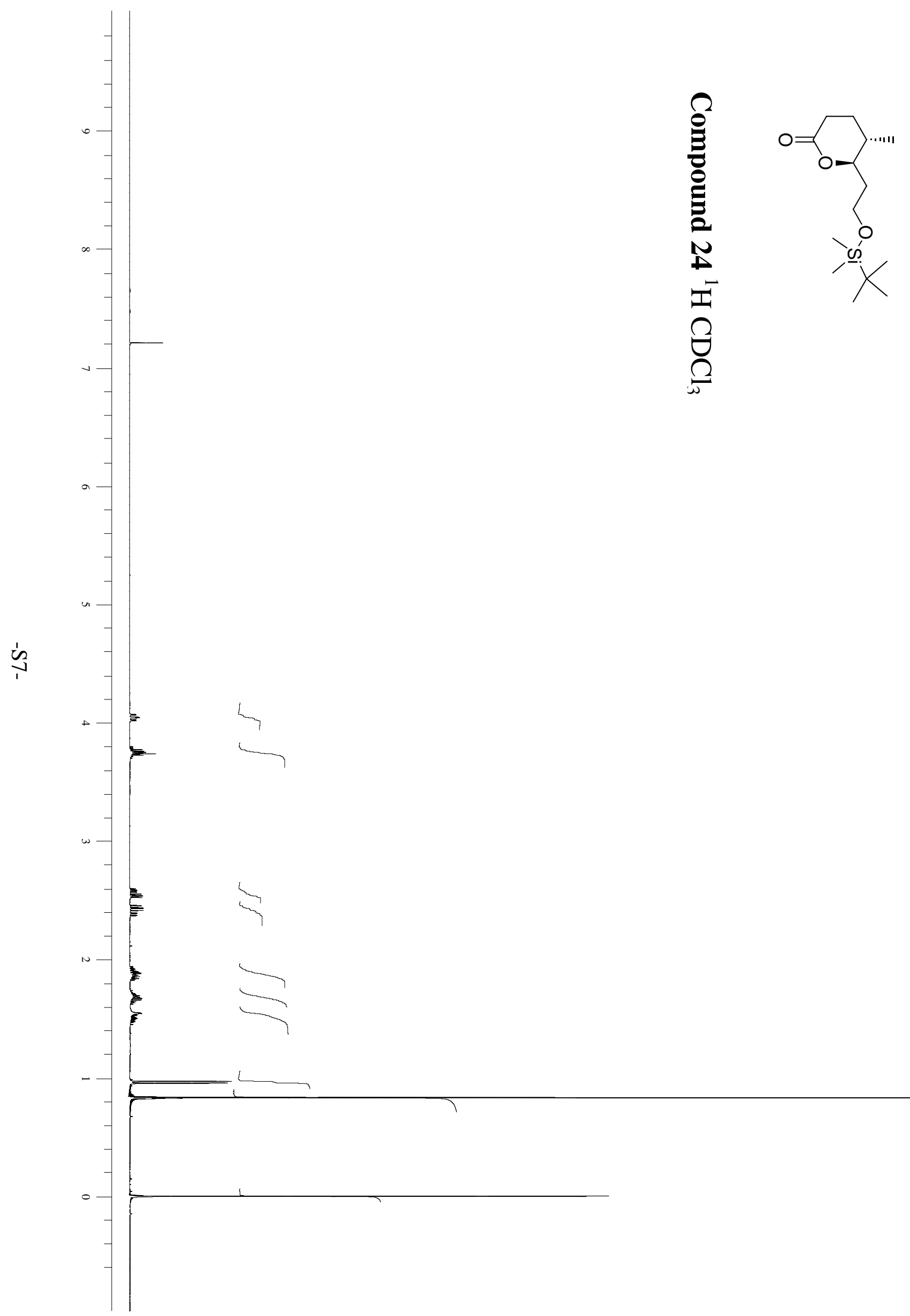




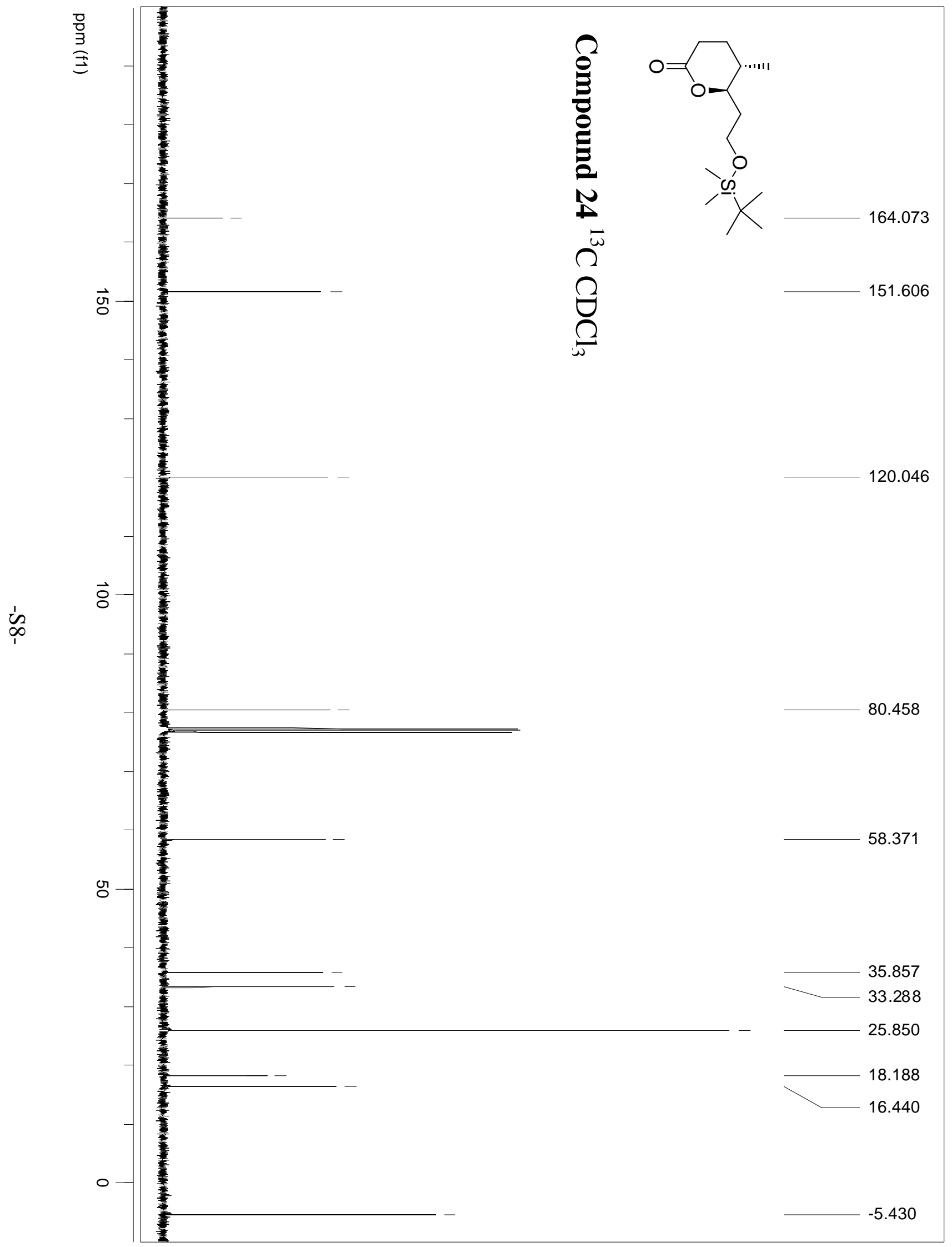




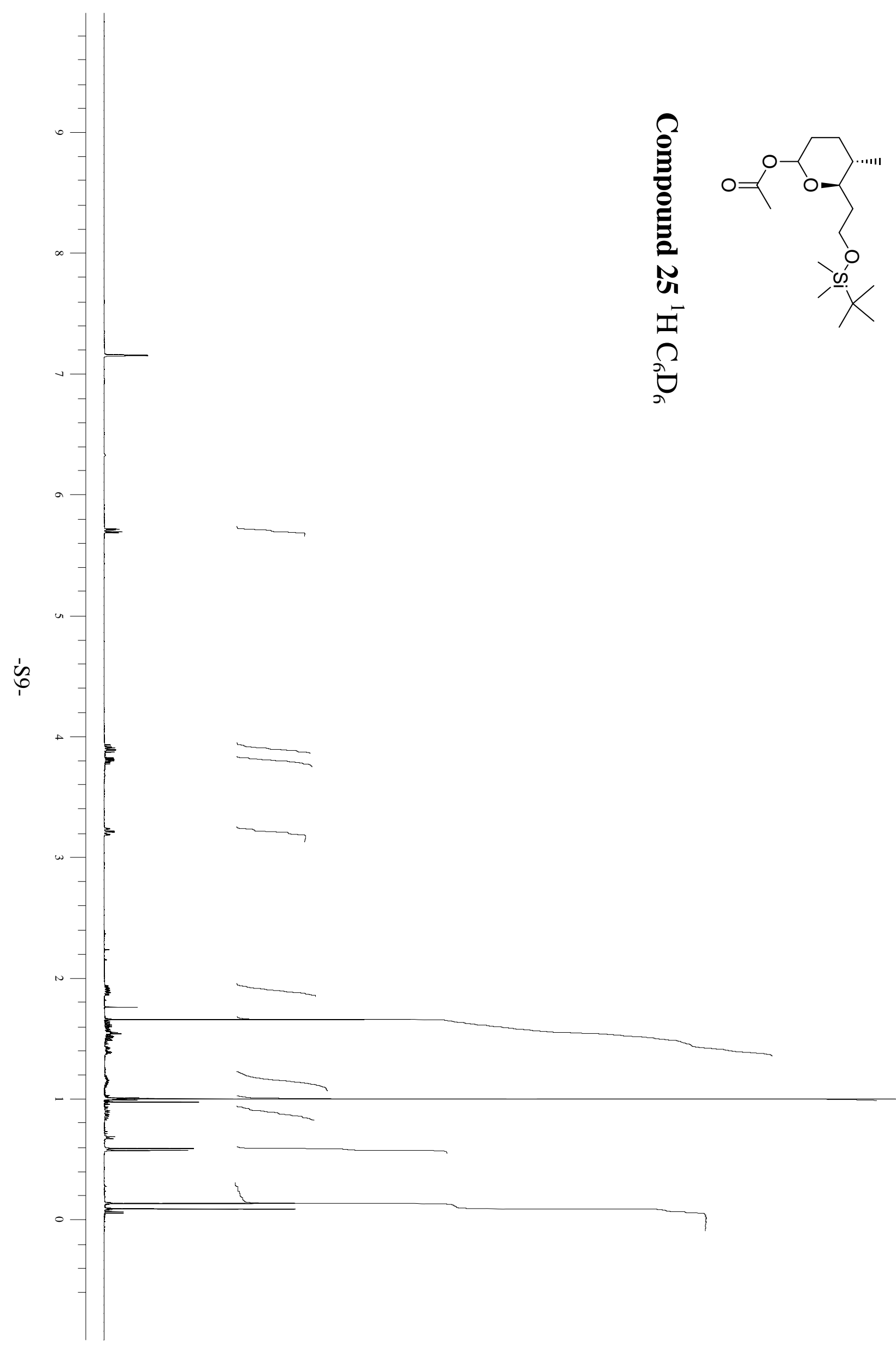




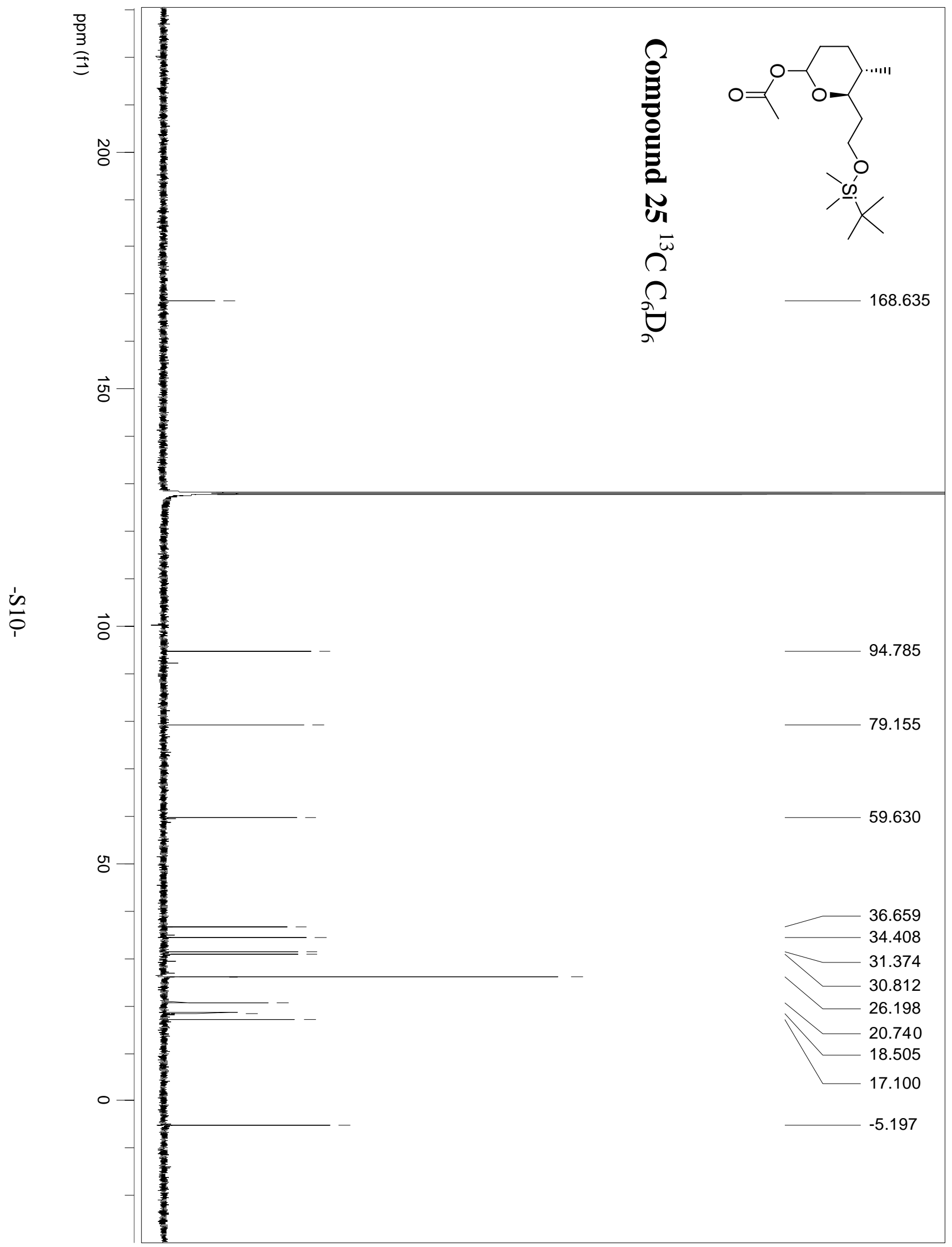




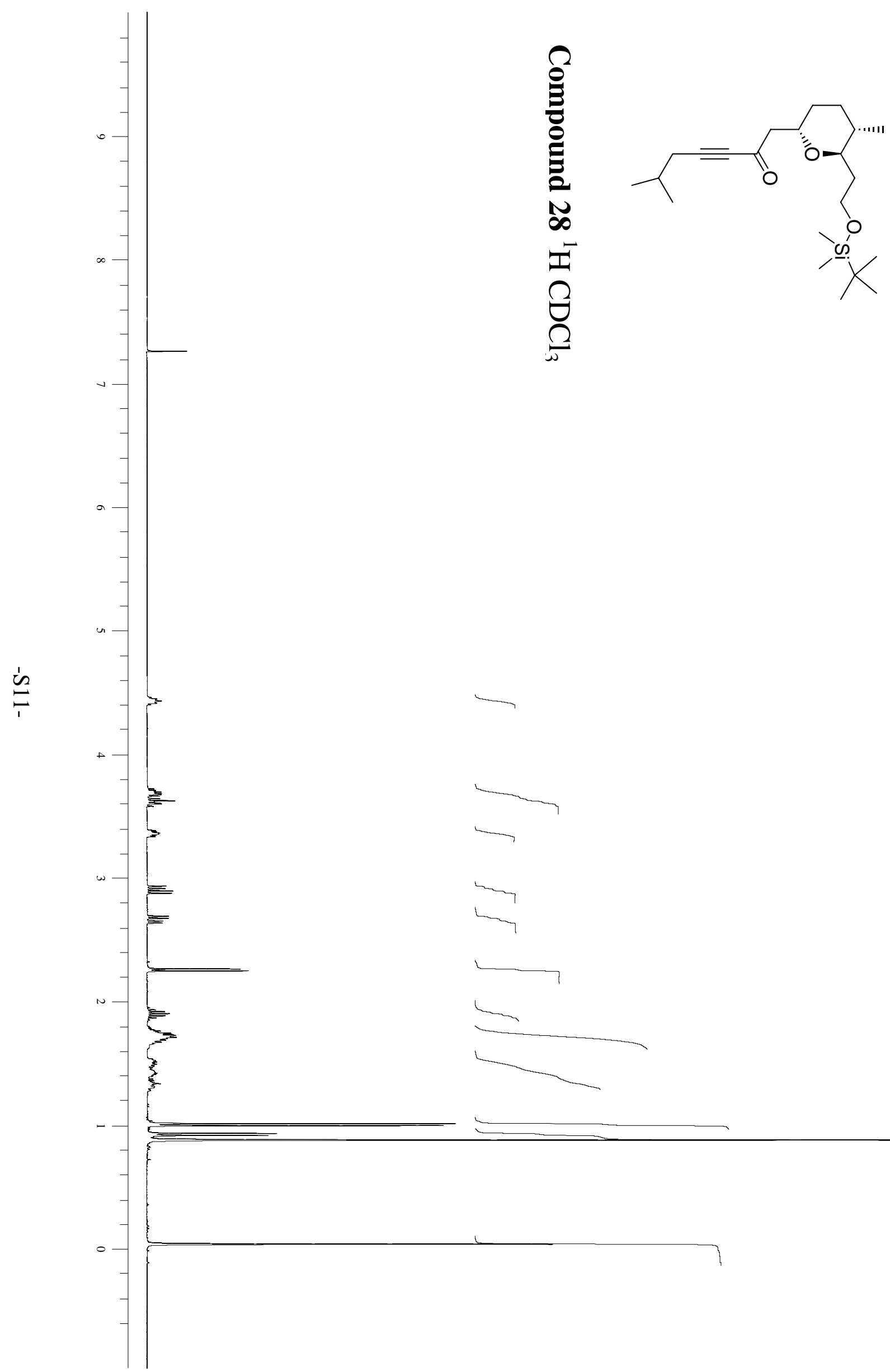




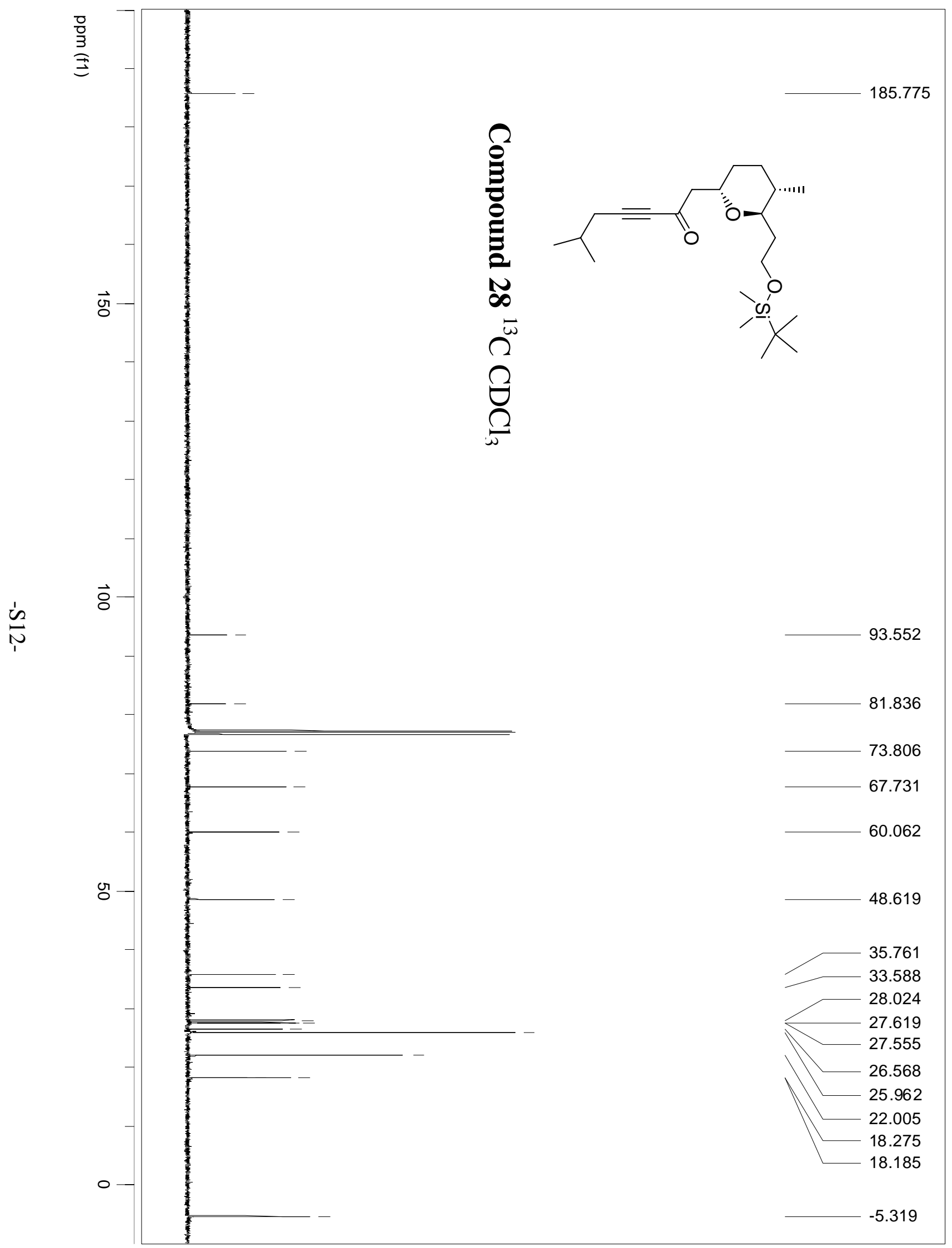




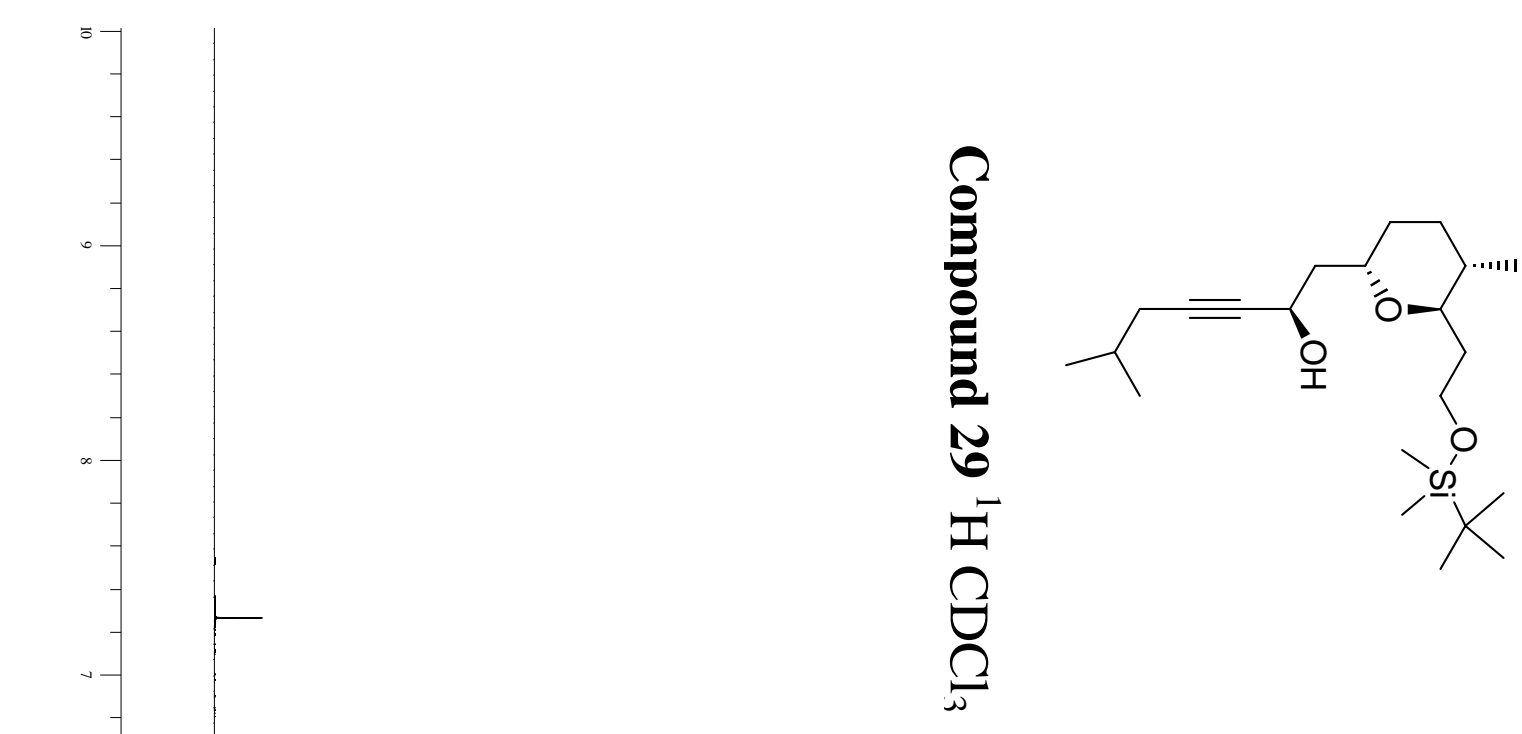

$\stackrel{\omega}{\omega}_{1}^{\prime}$ 


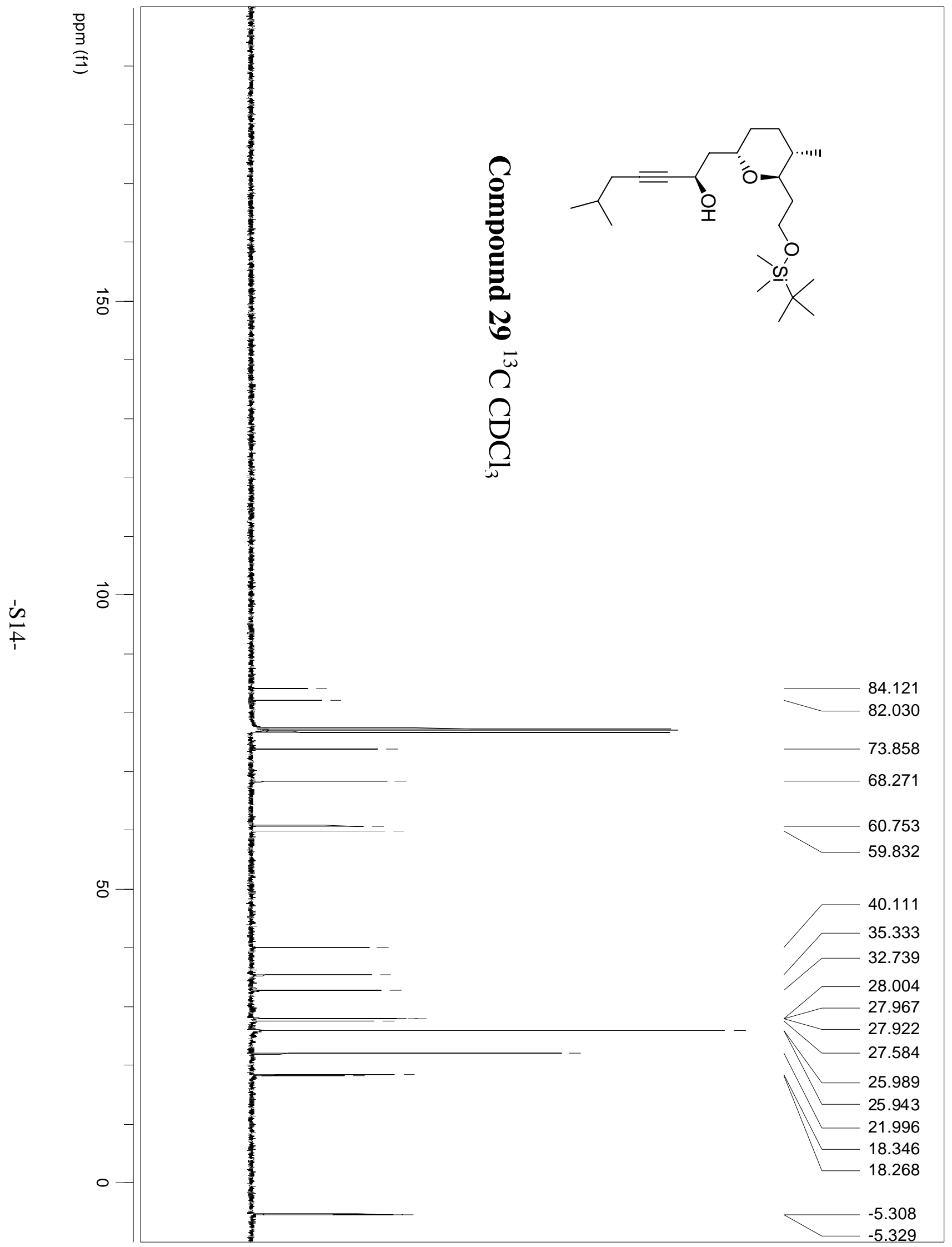




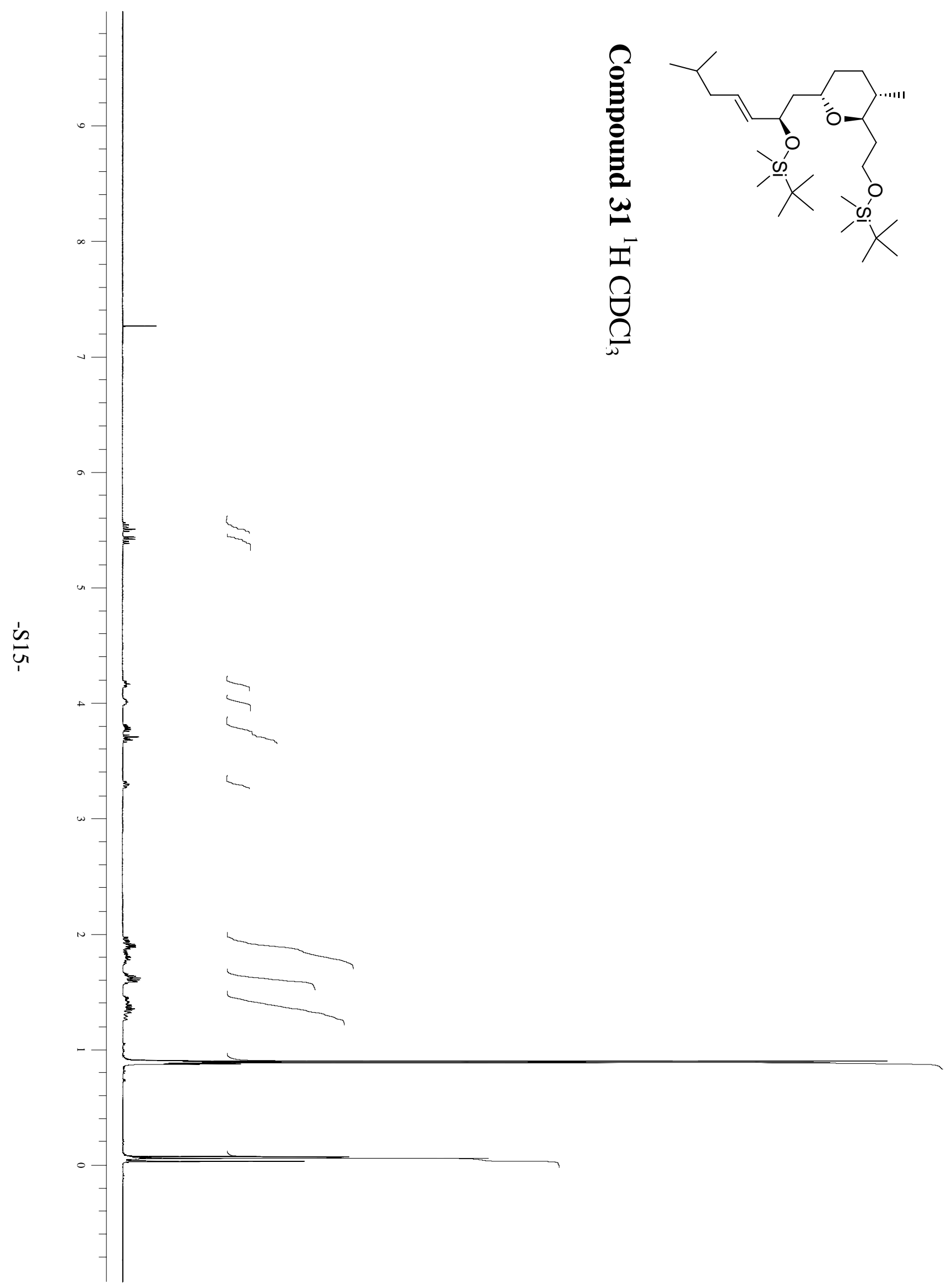




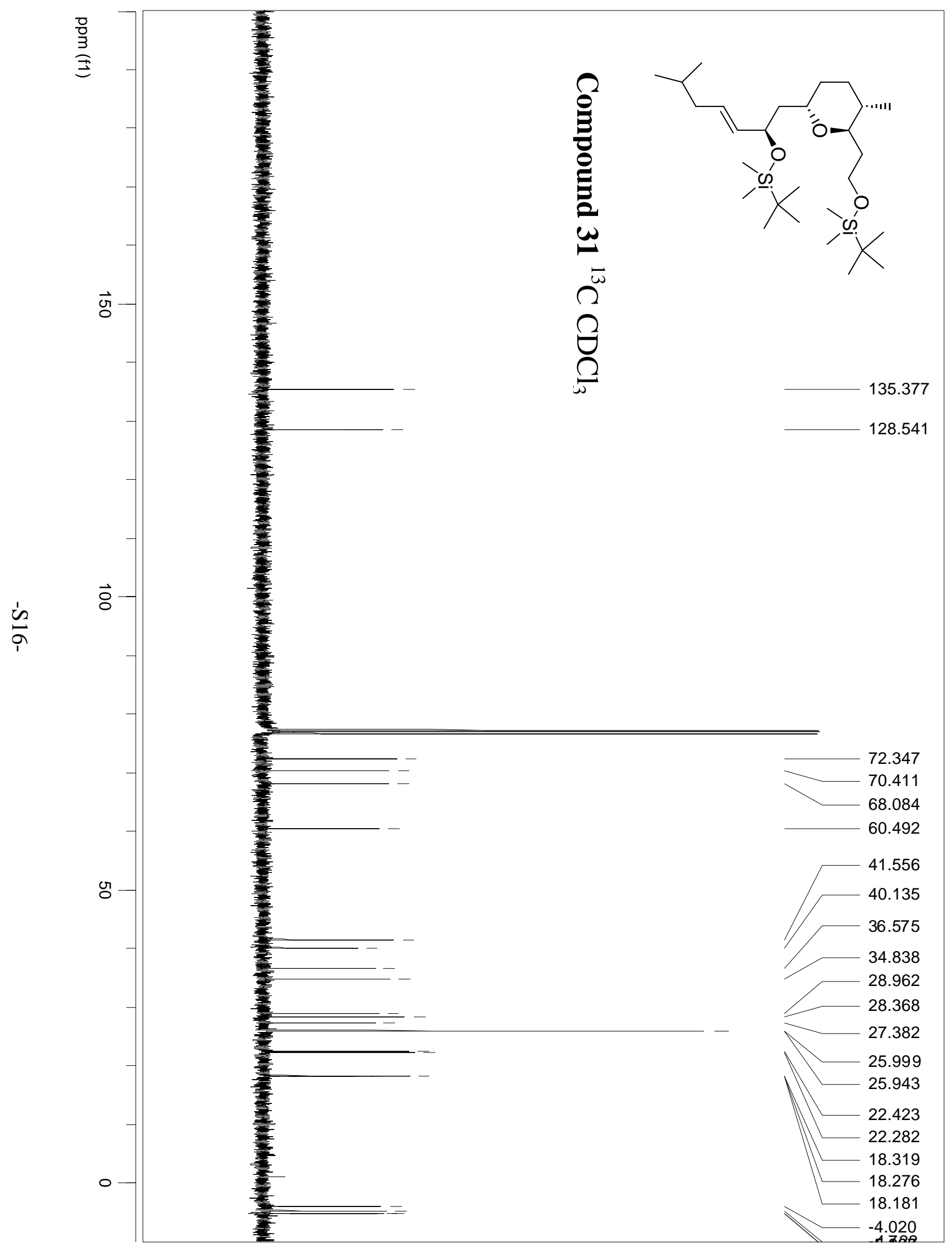




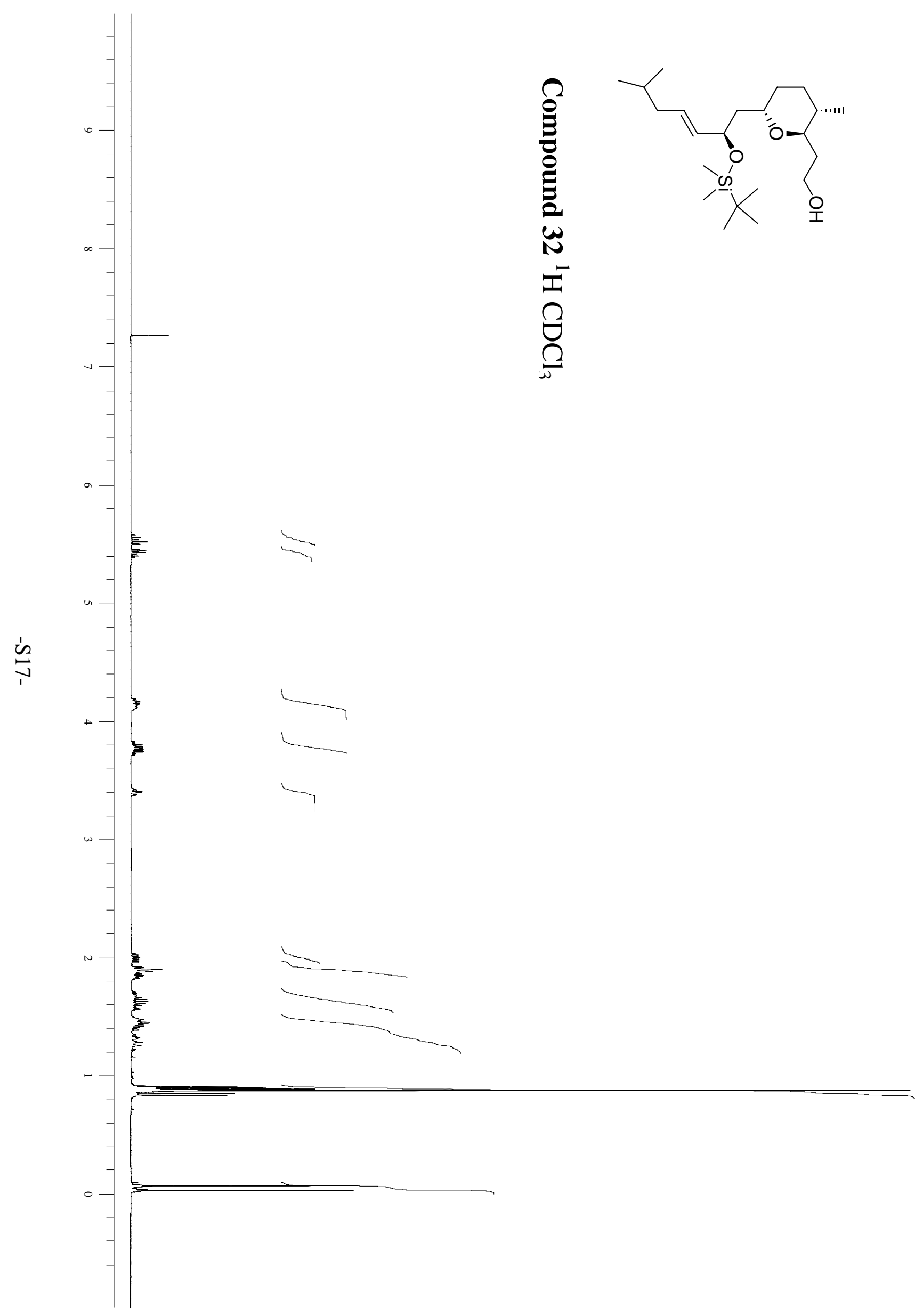




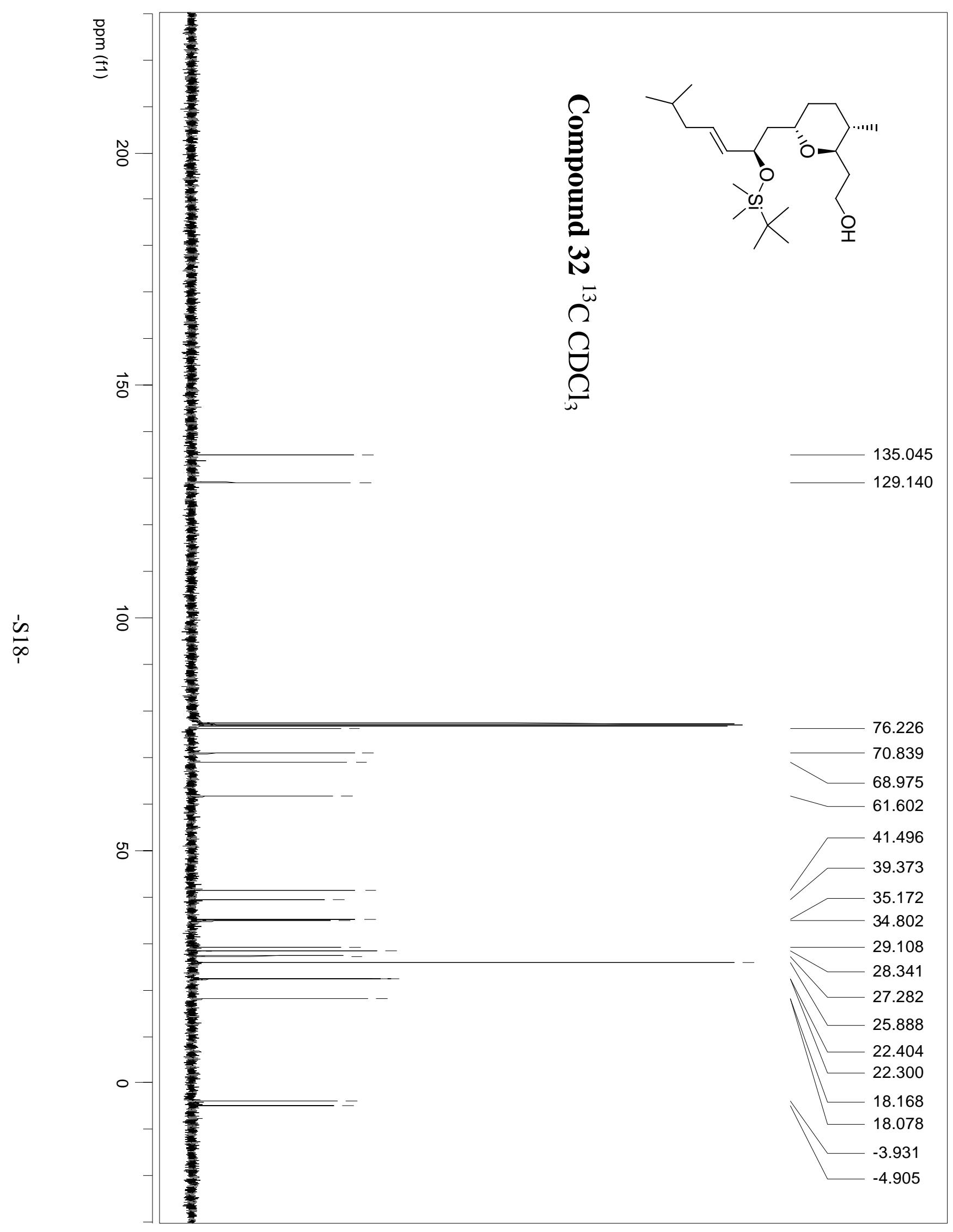




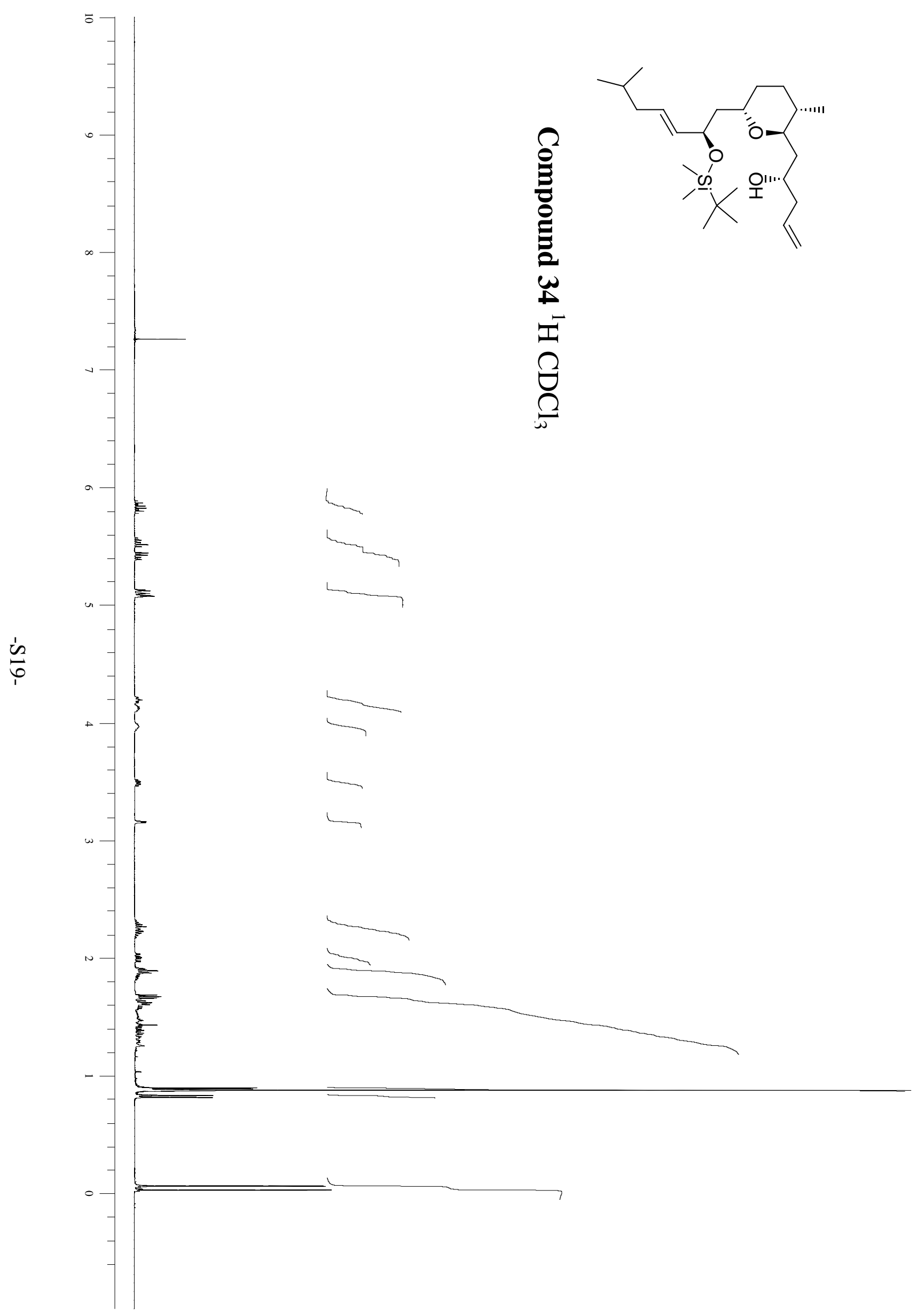

-S78- 


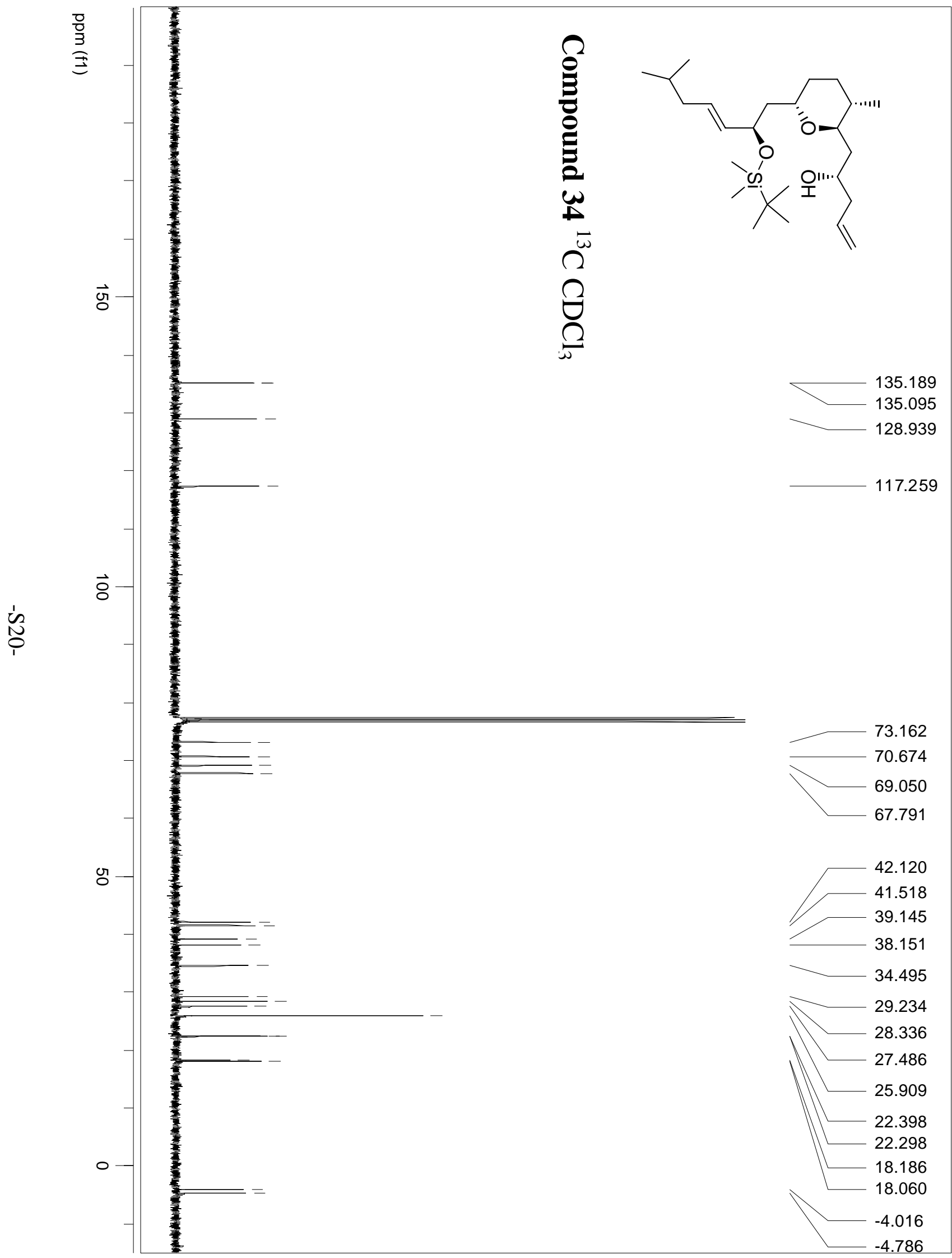




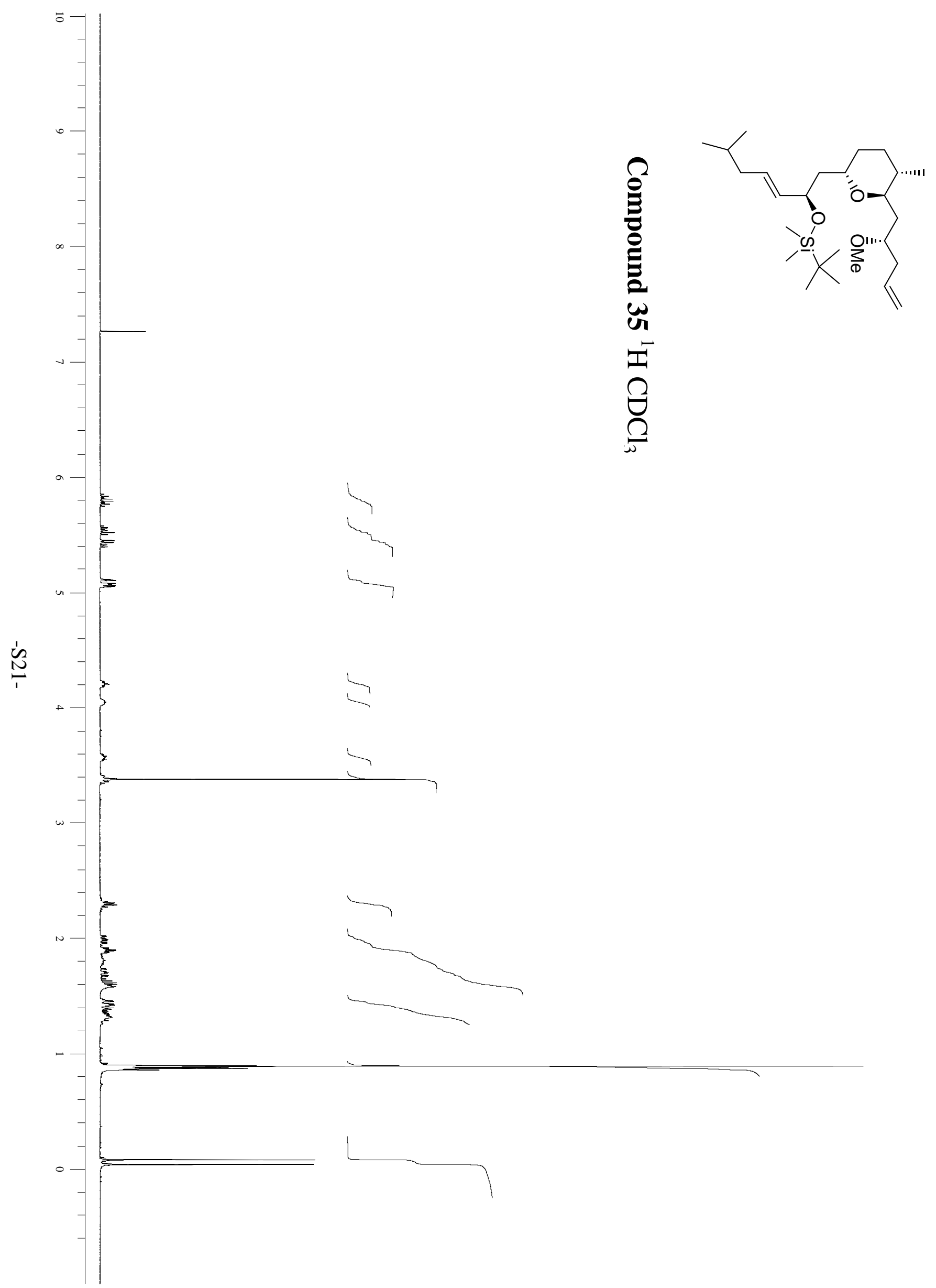




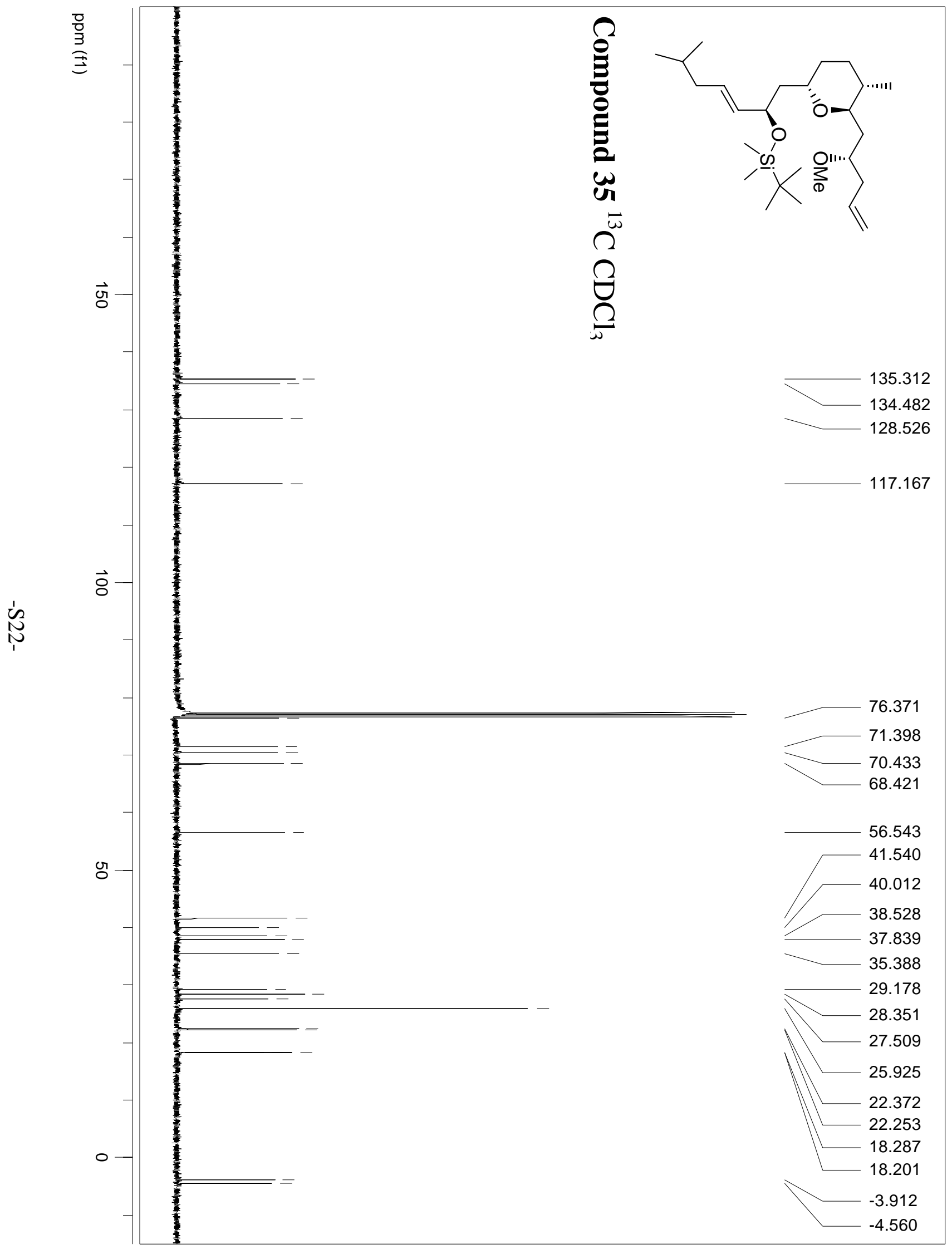




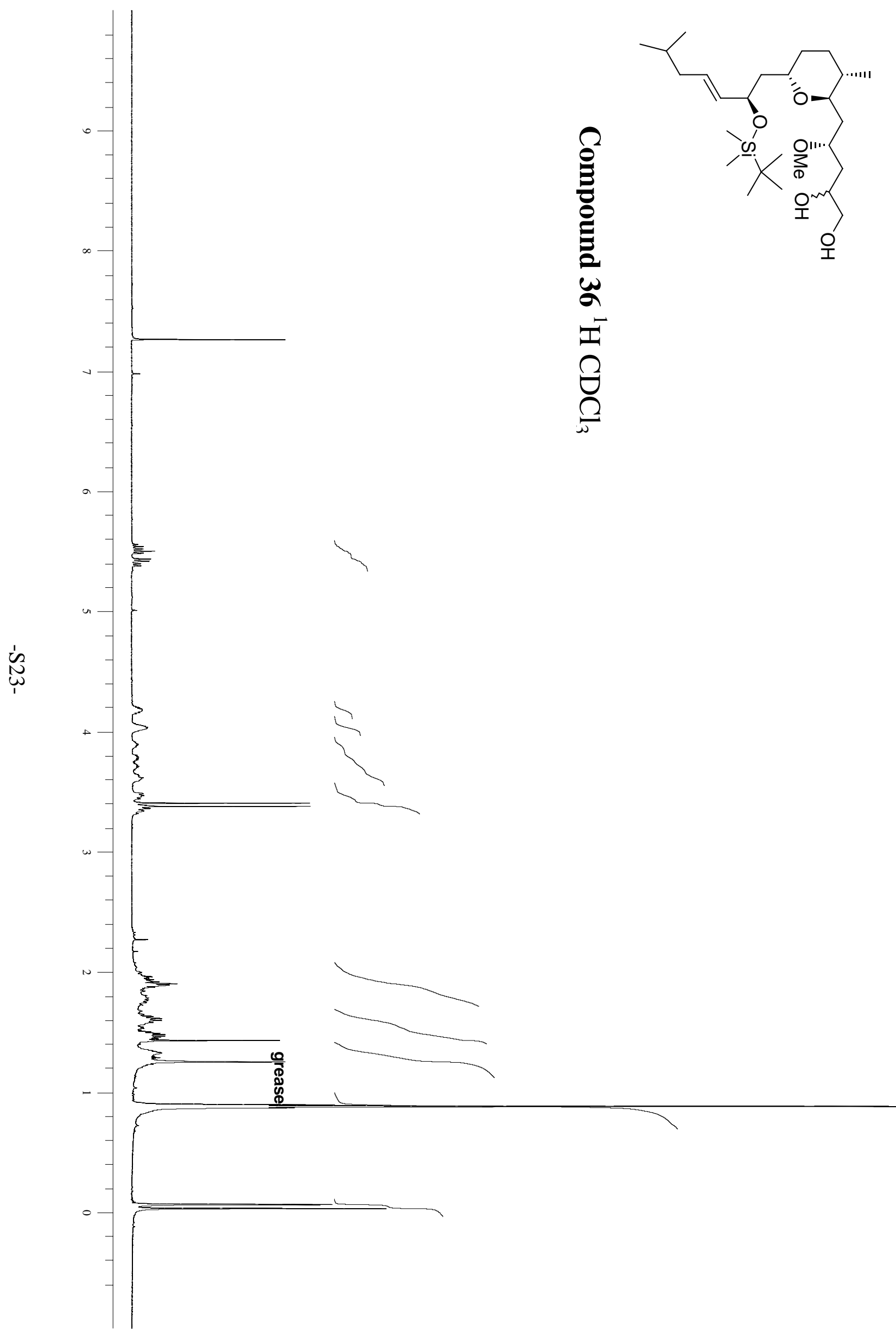




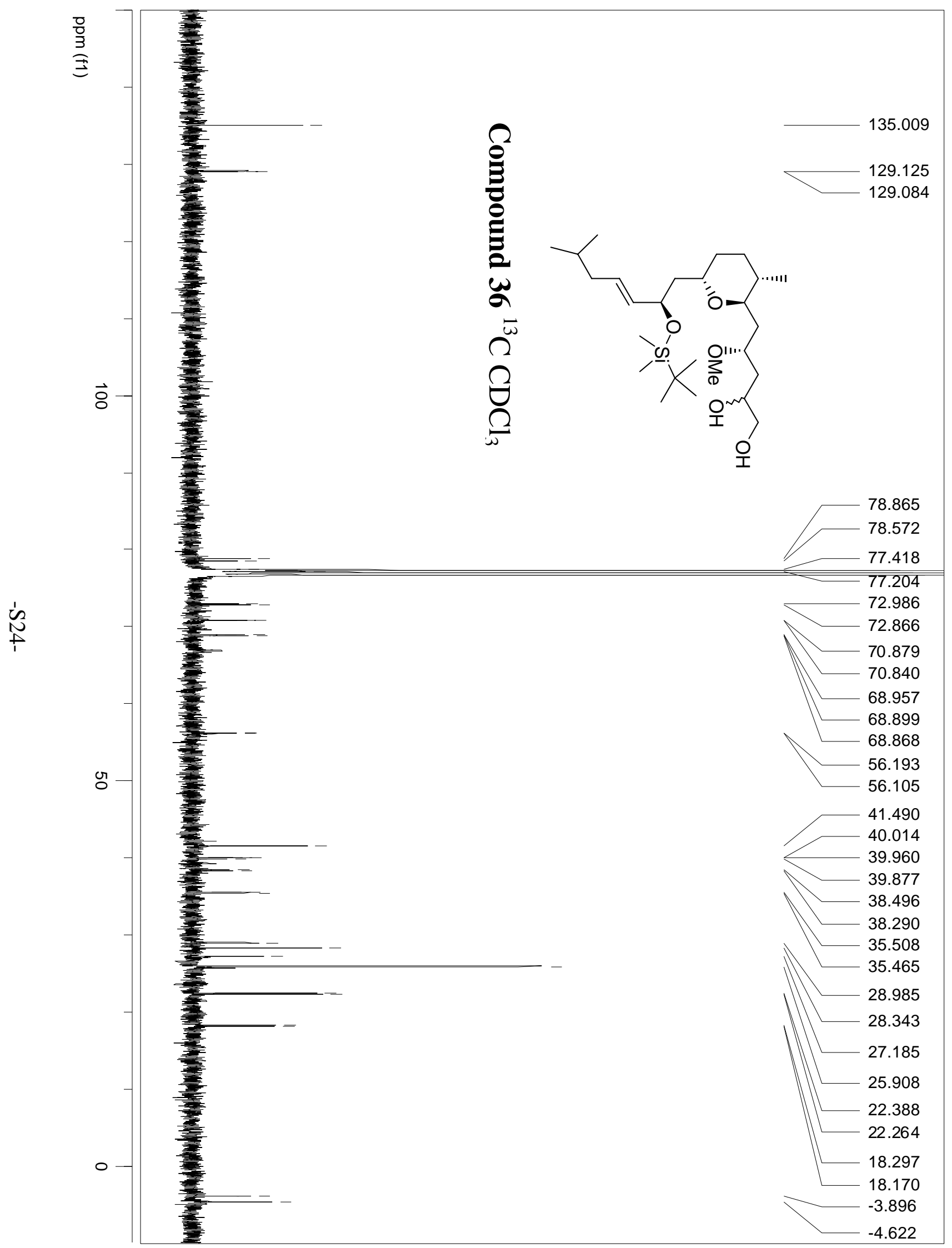




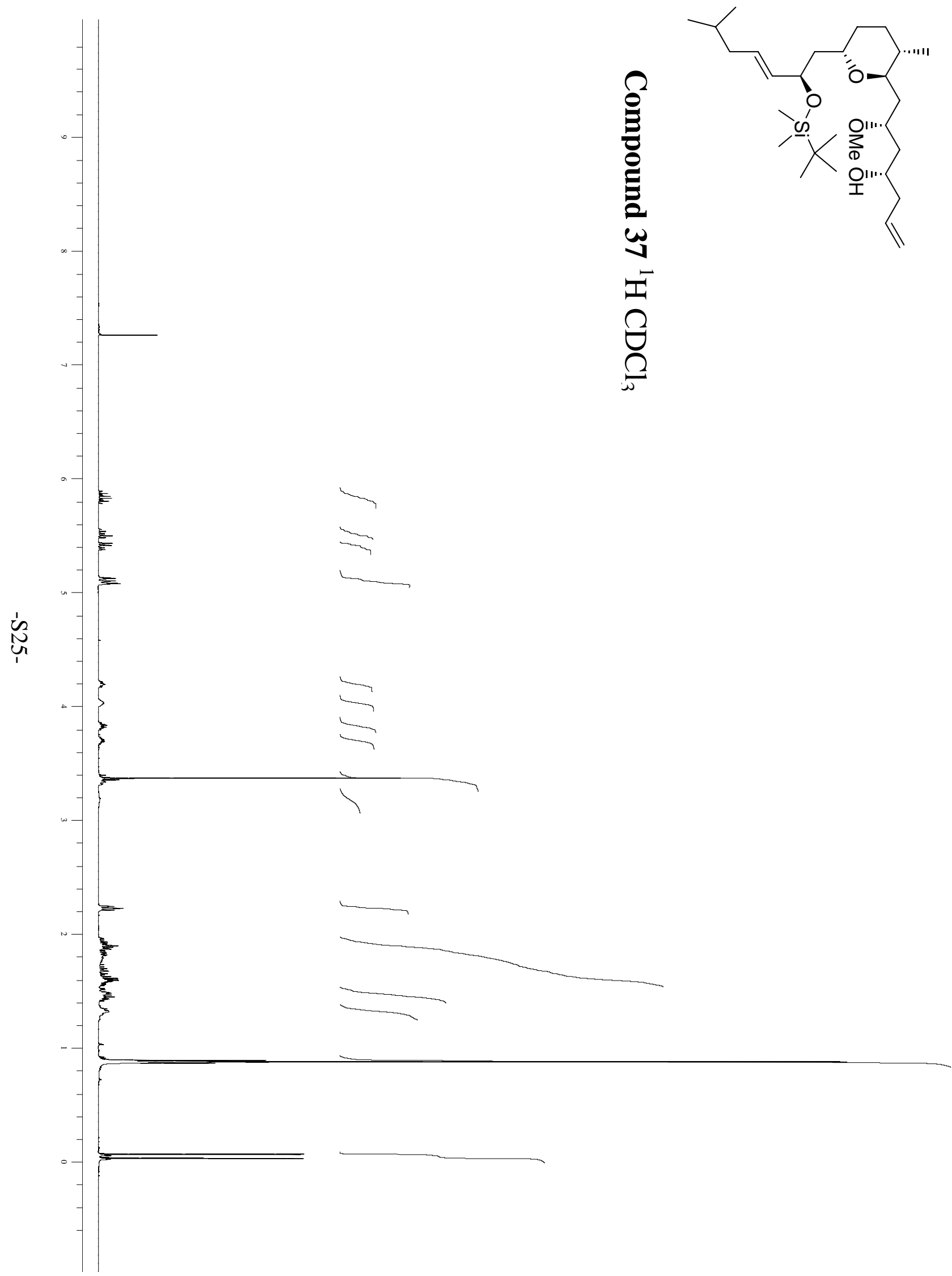




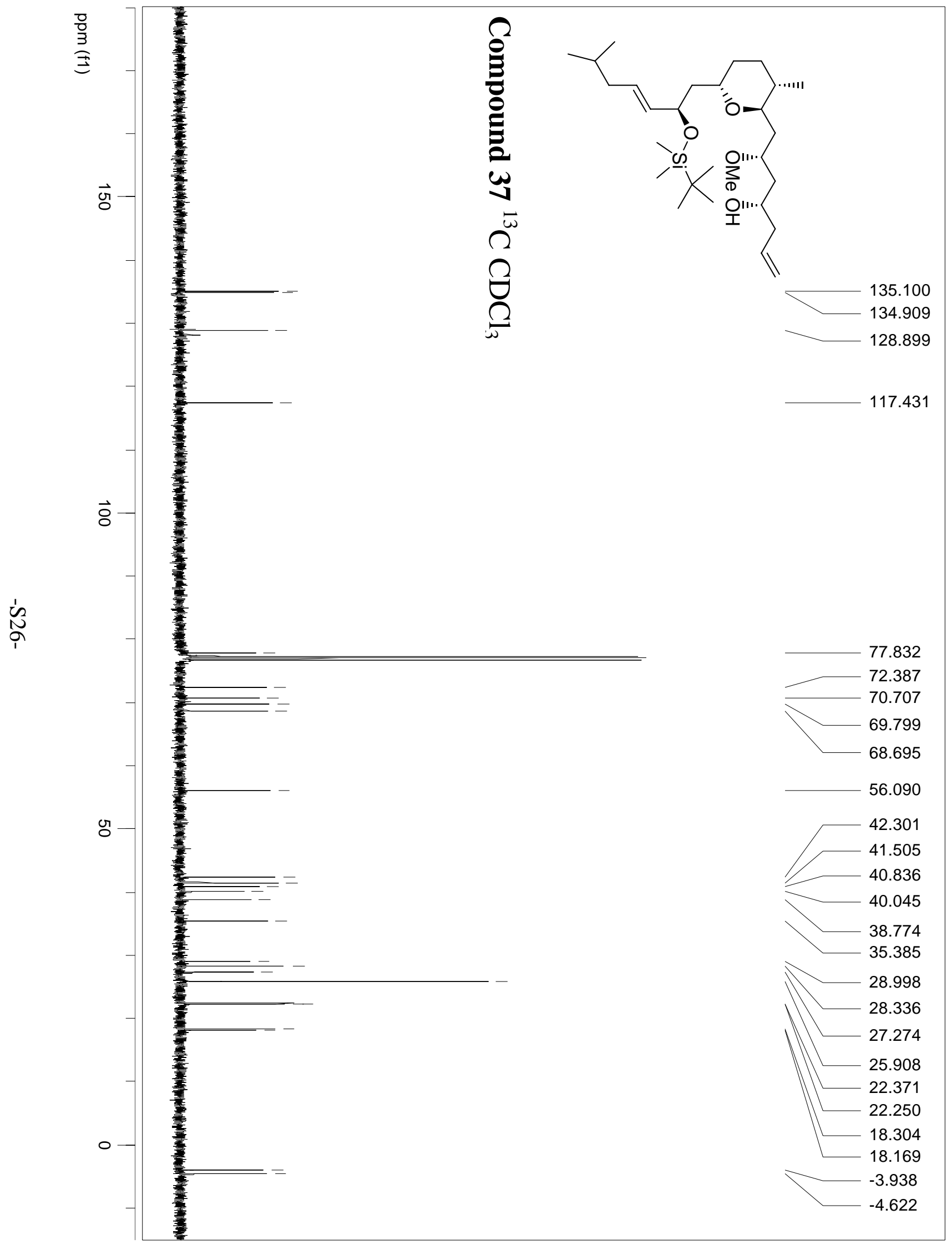




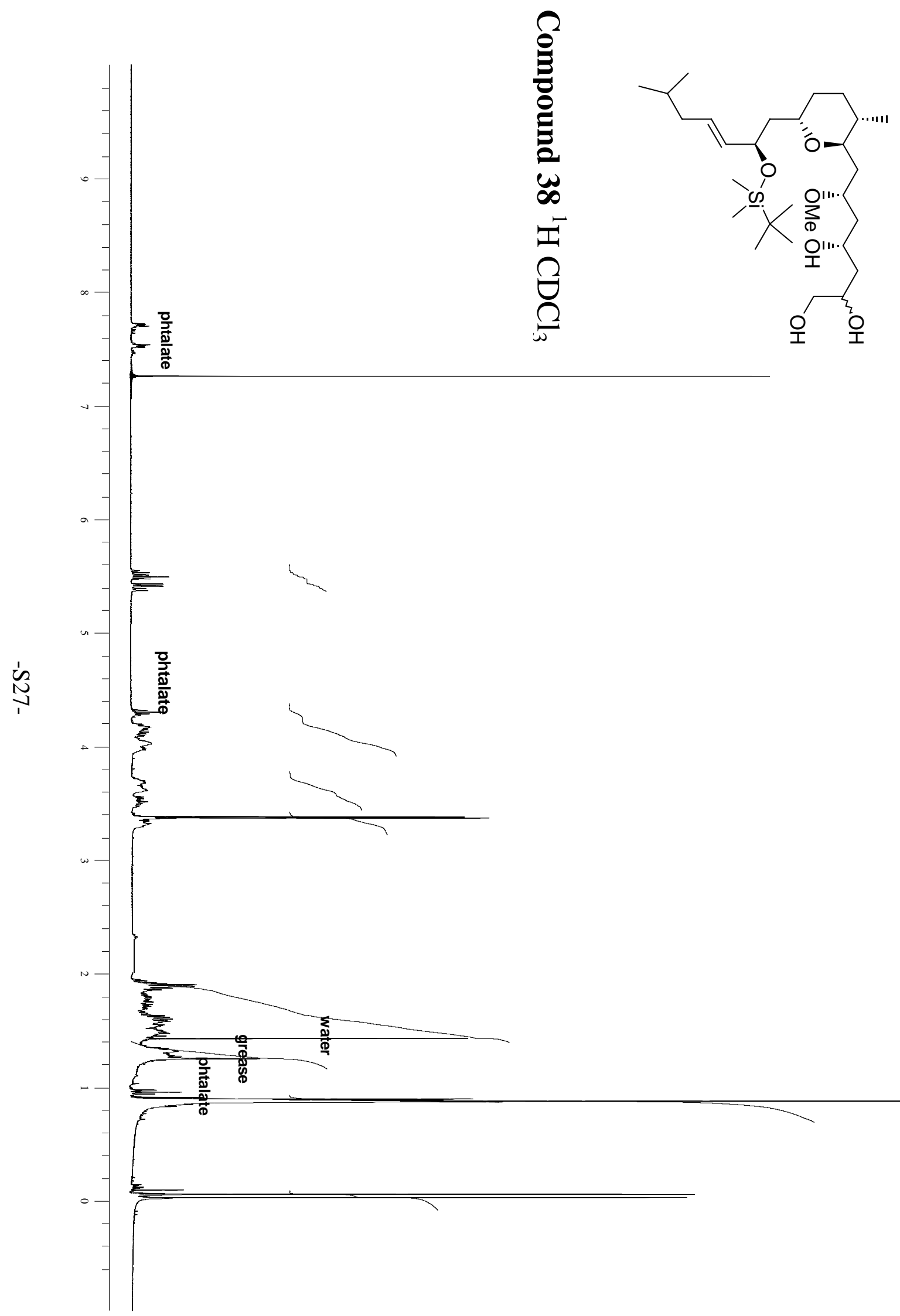




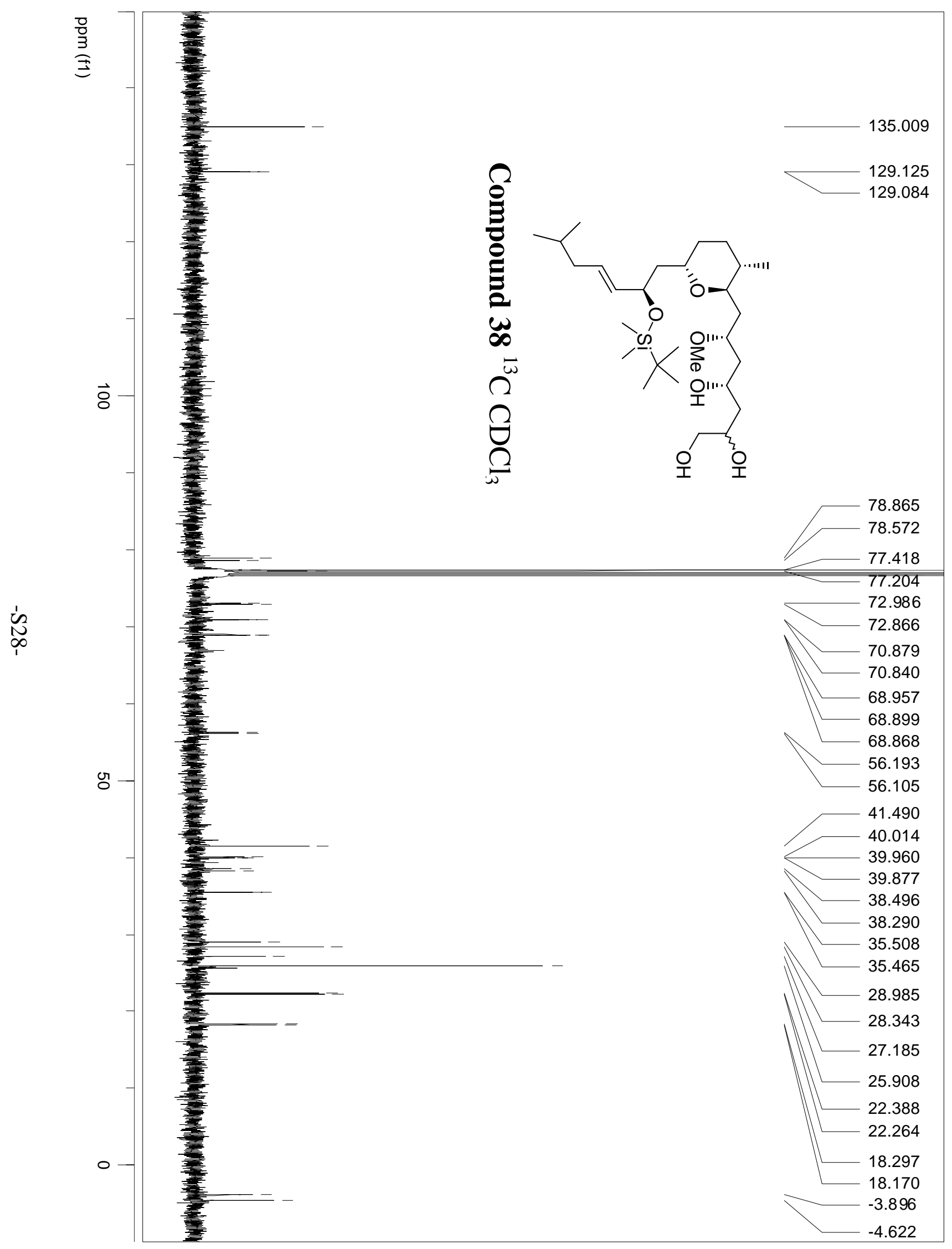




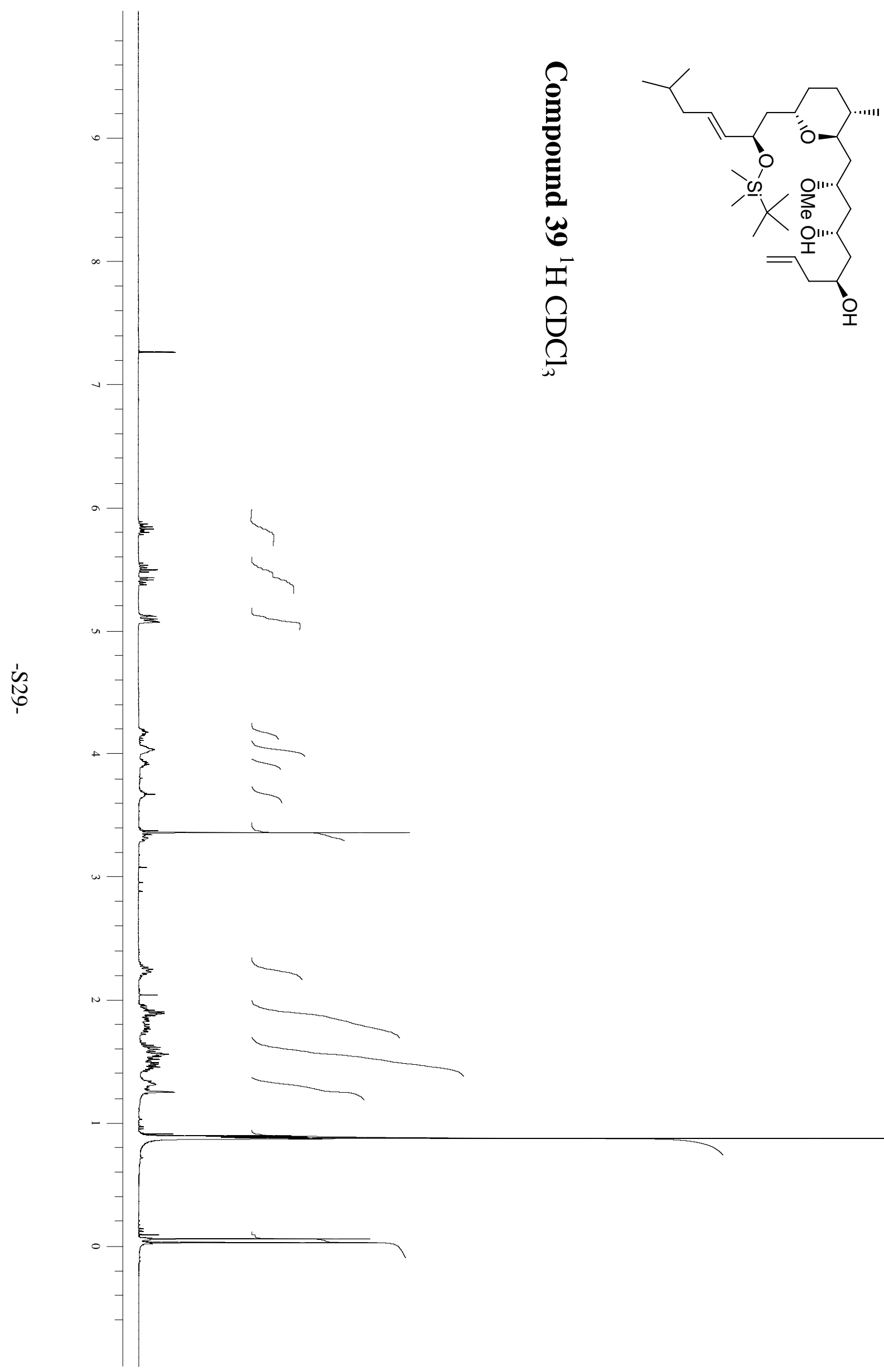




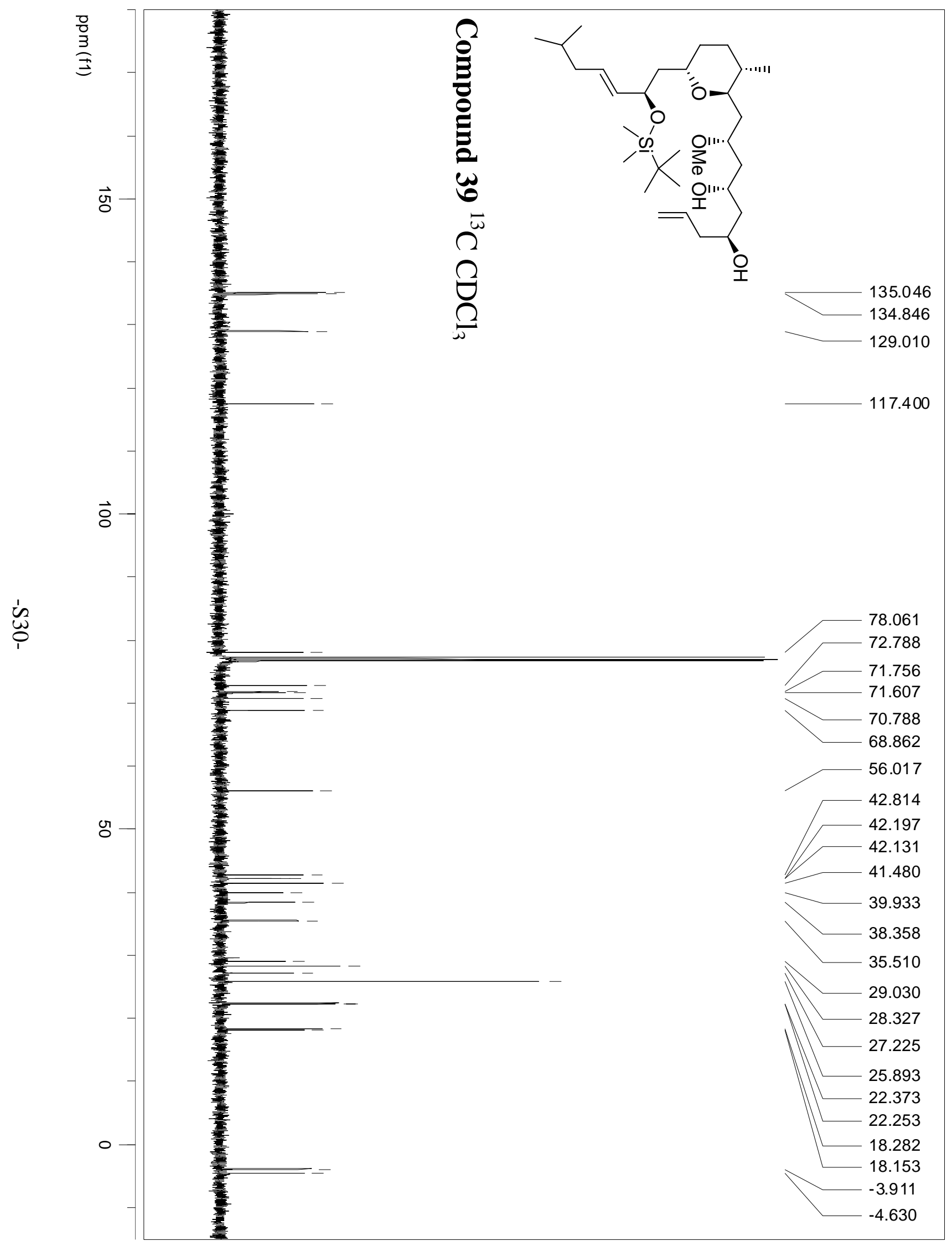




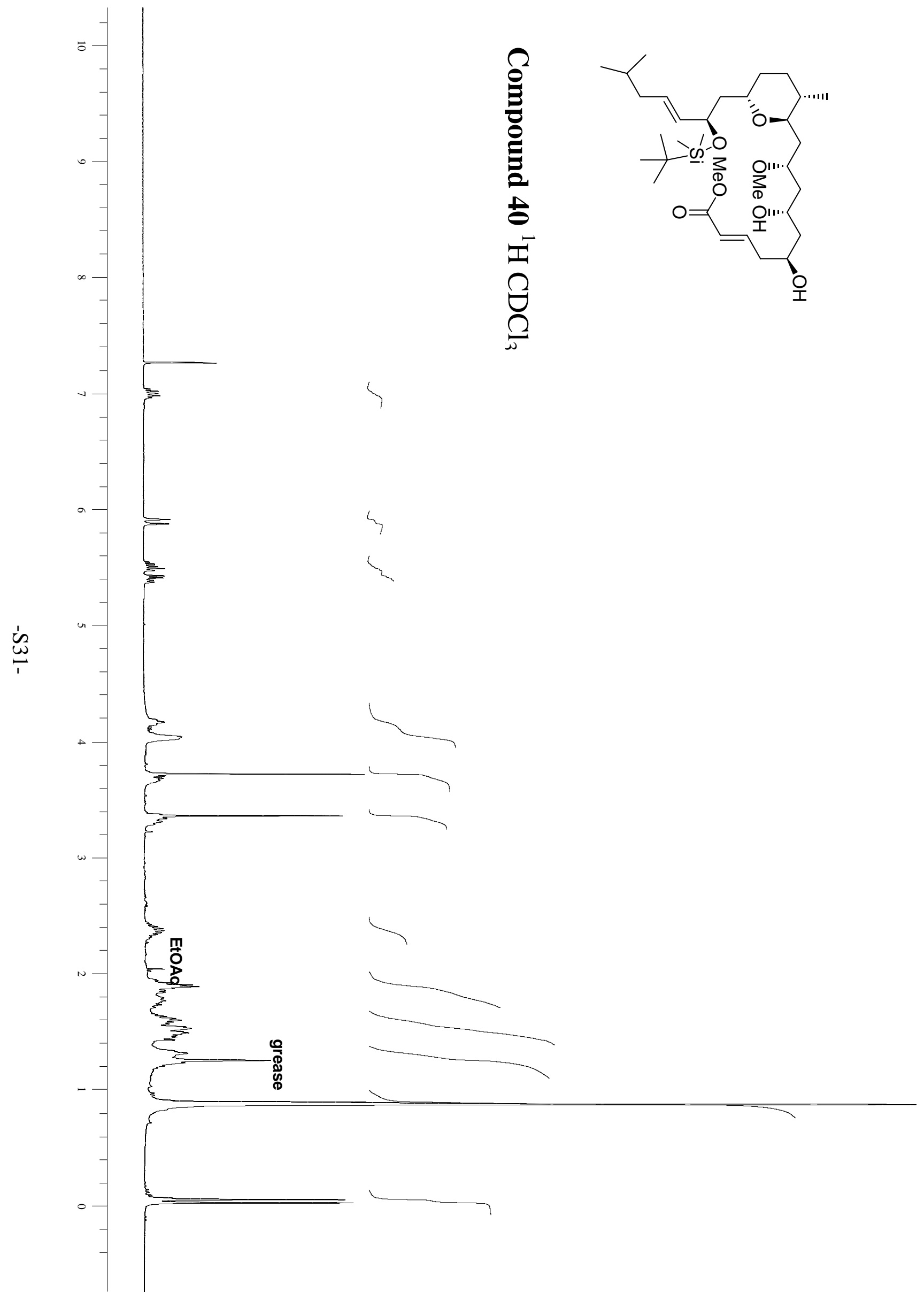




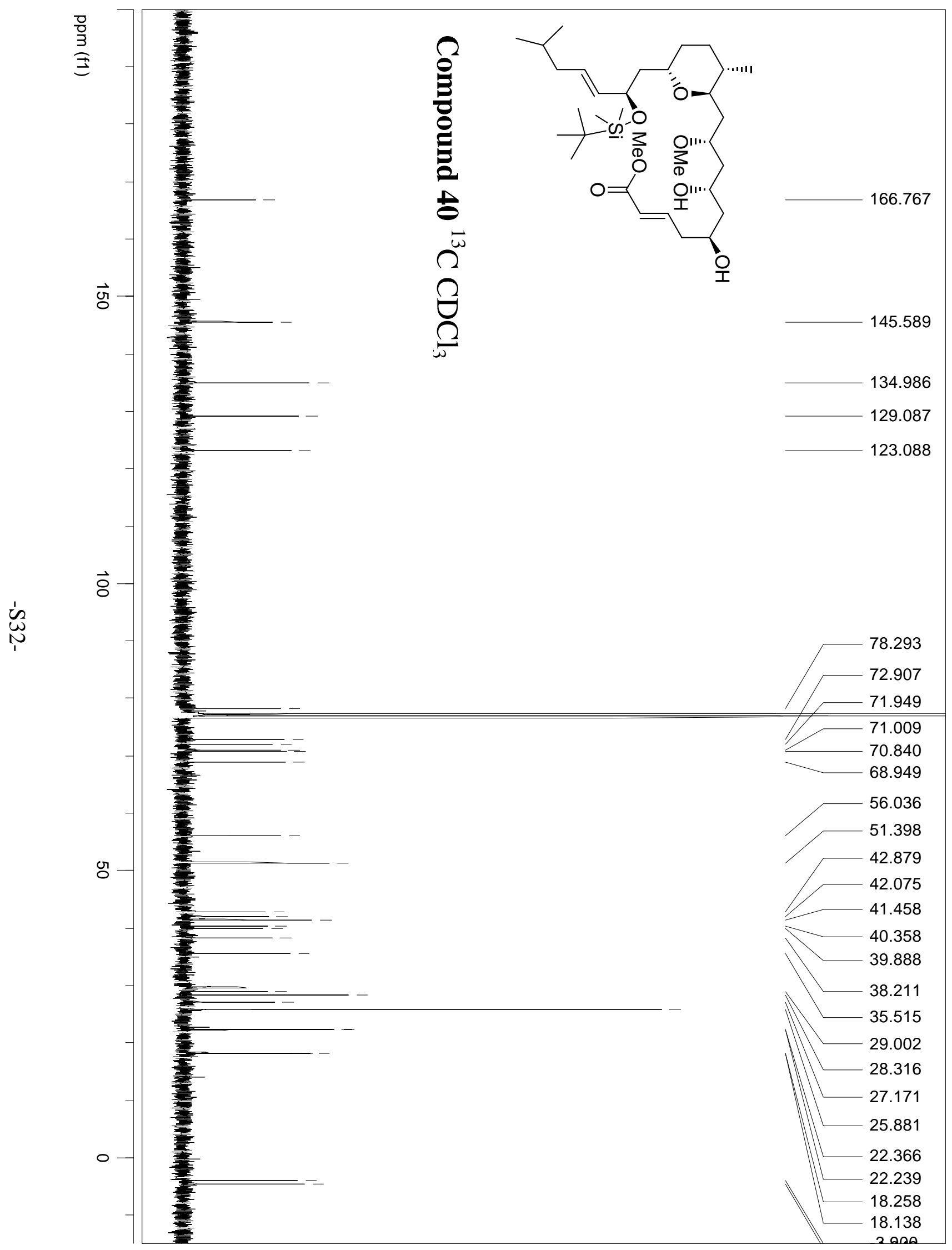




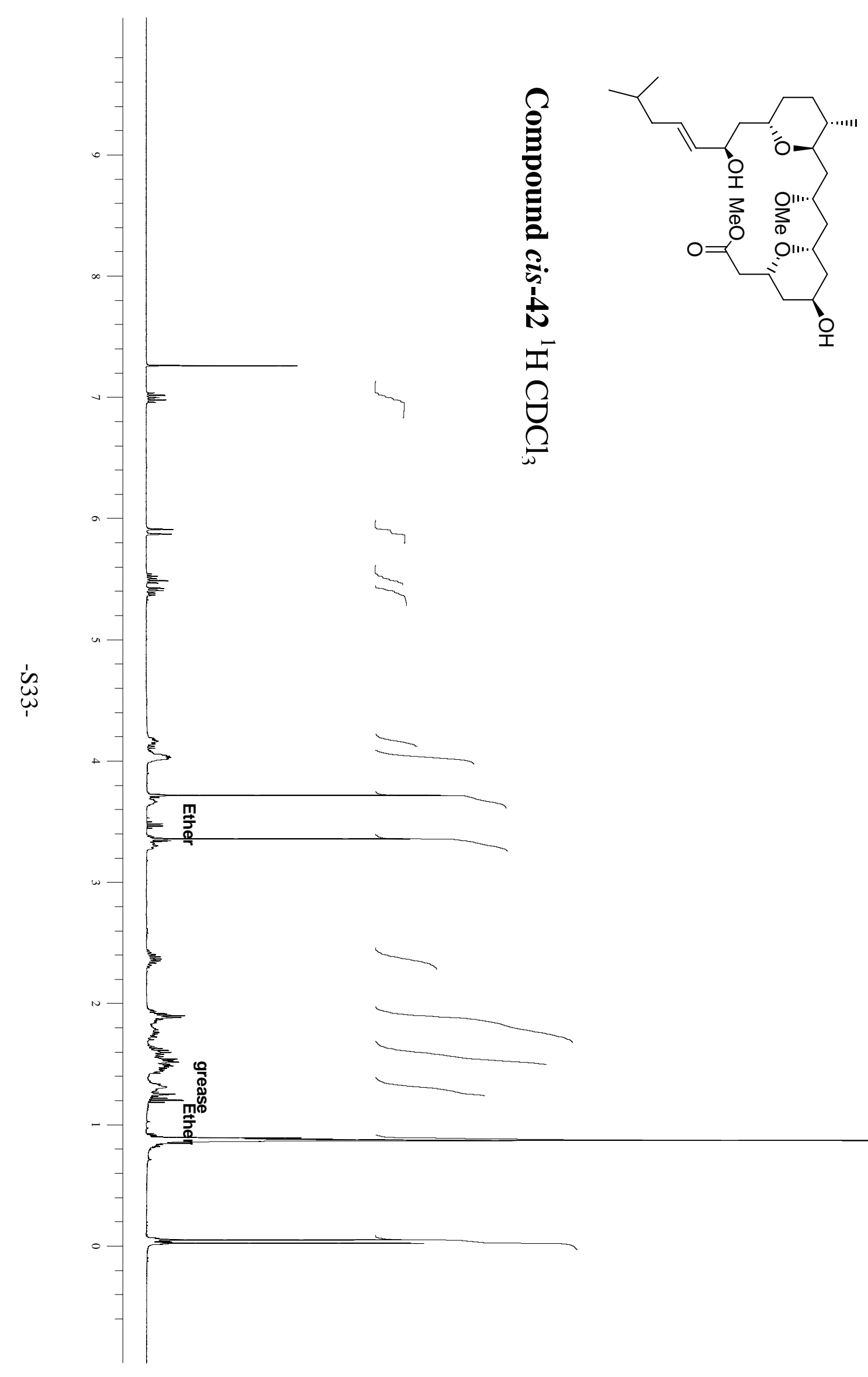




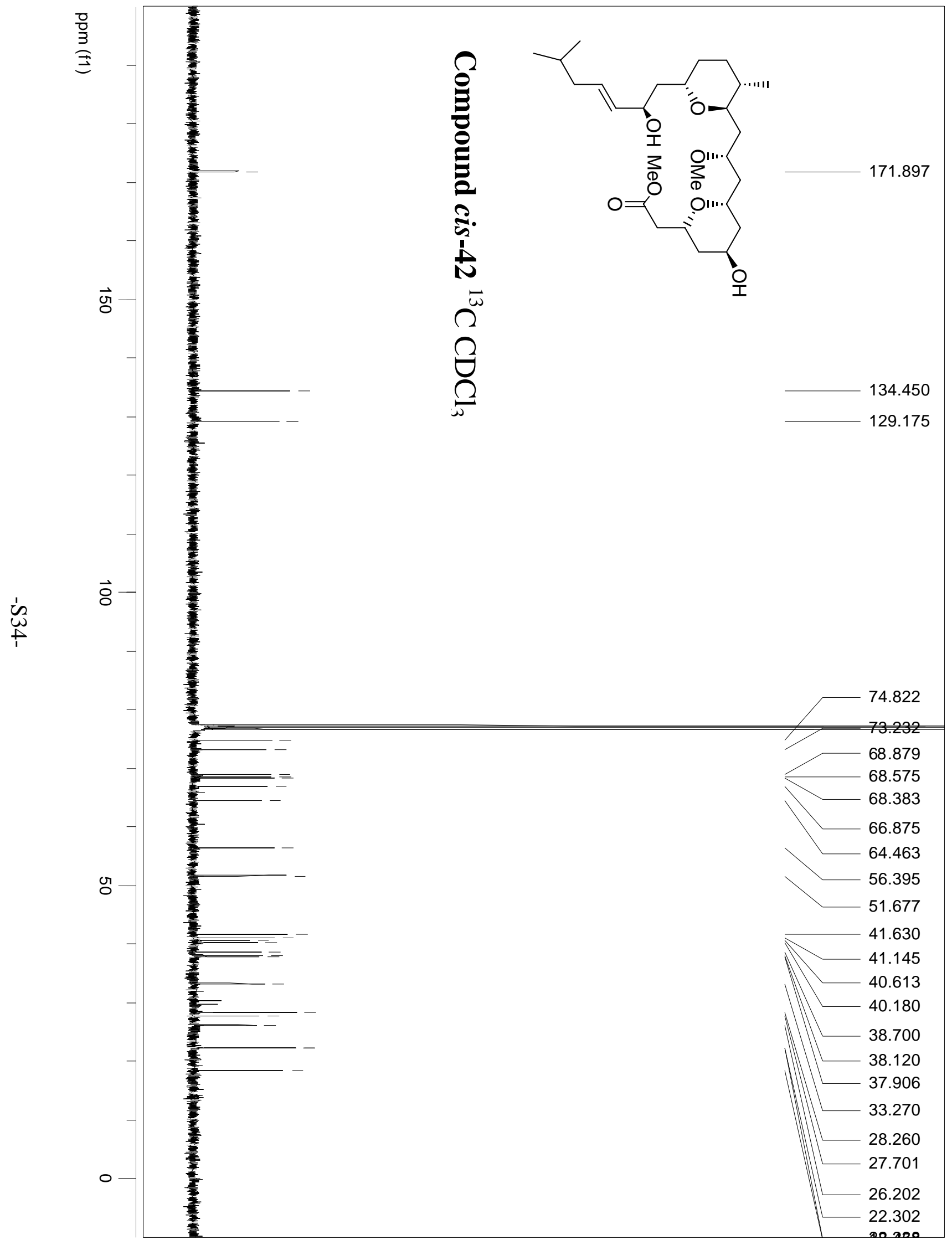




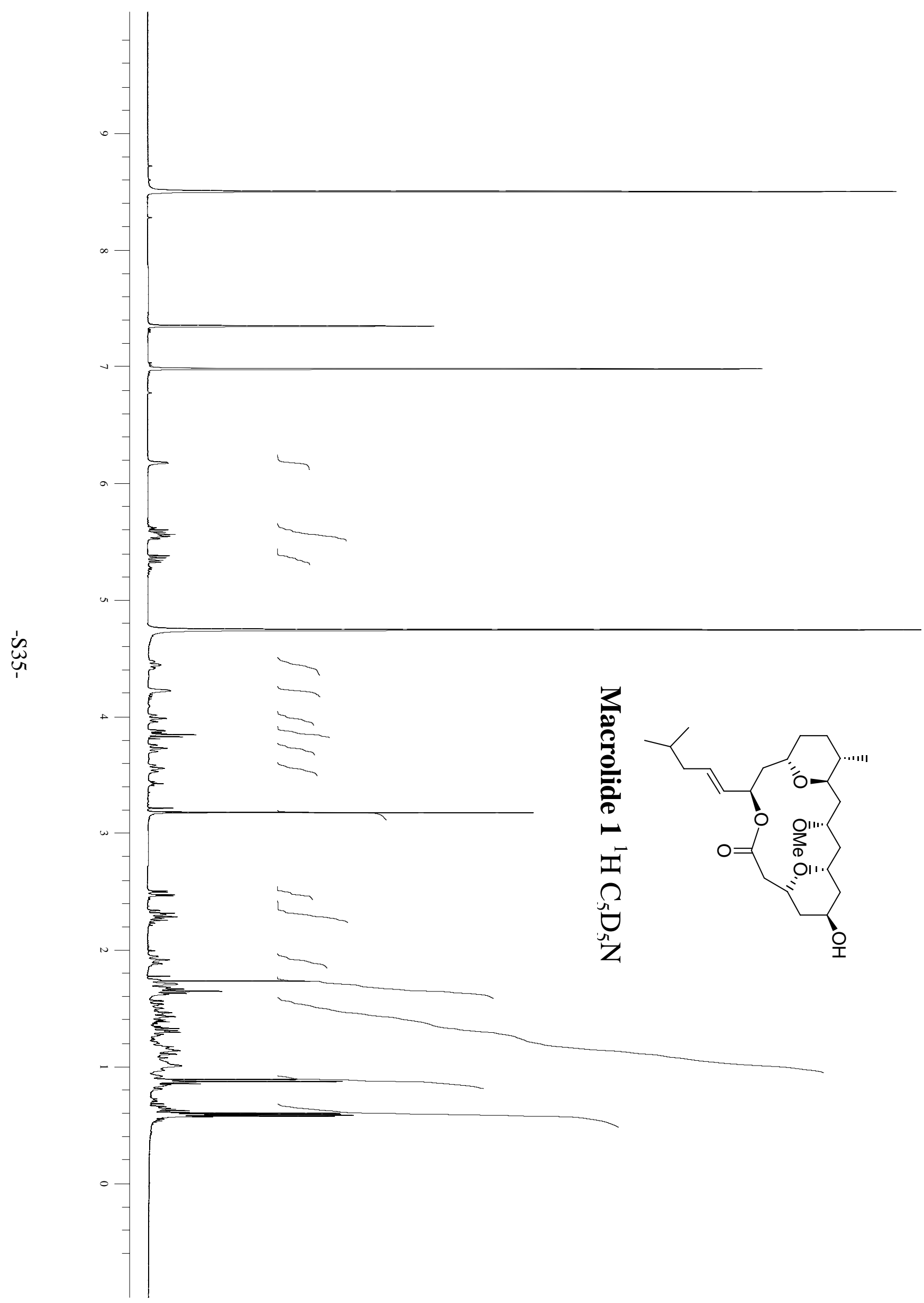




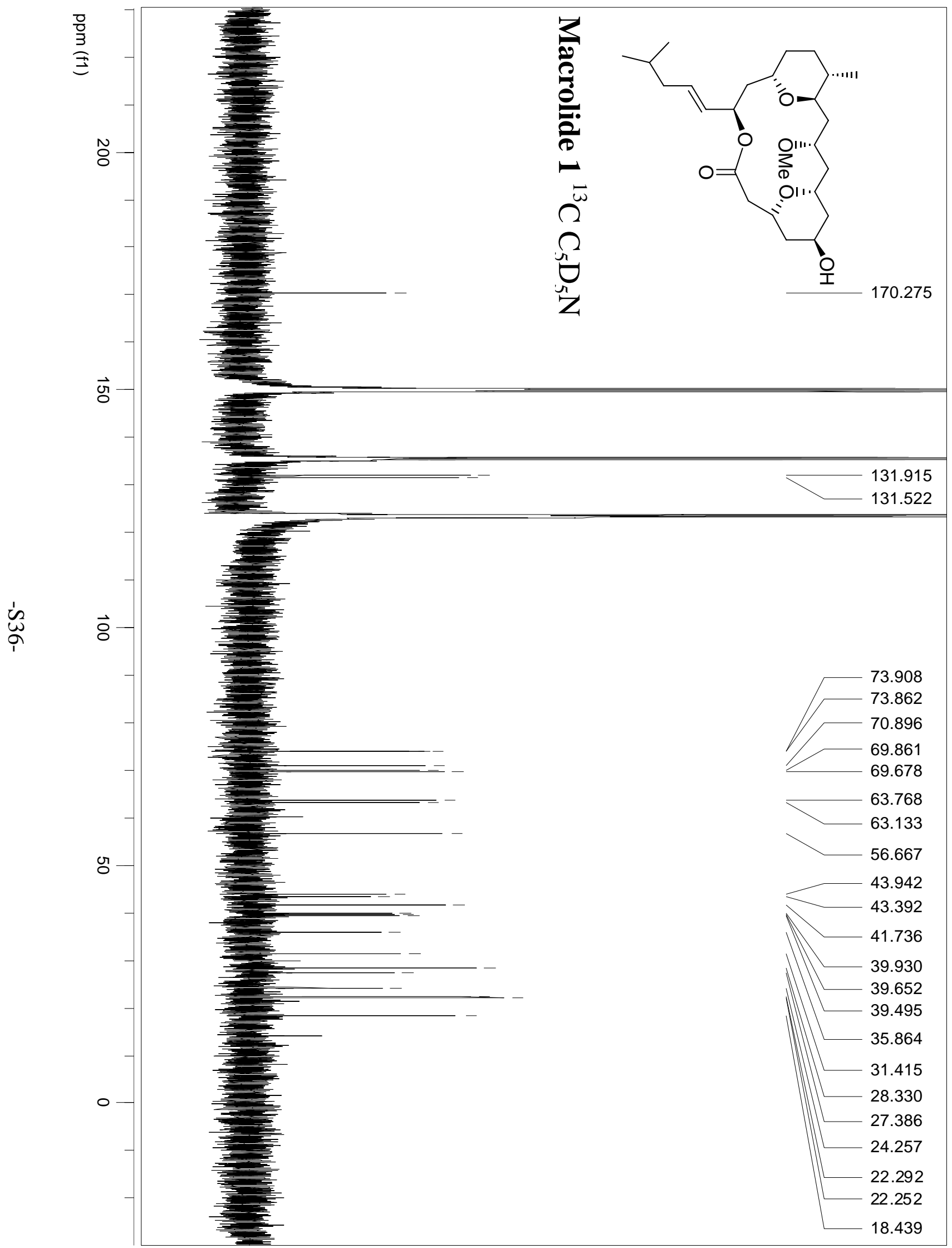




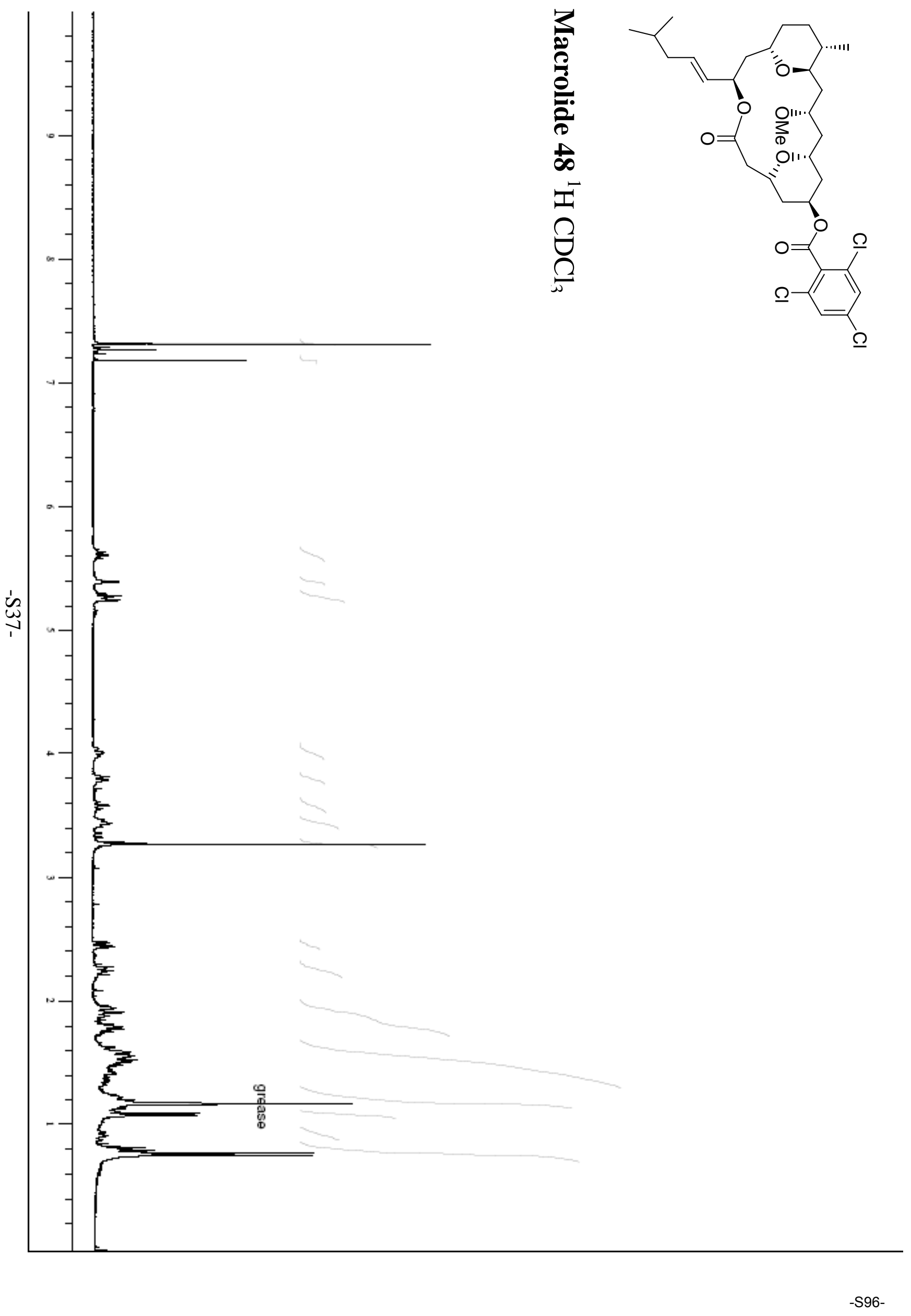




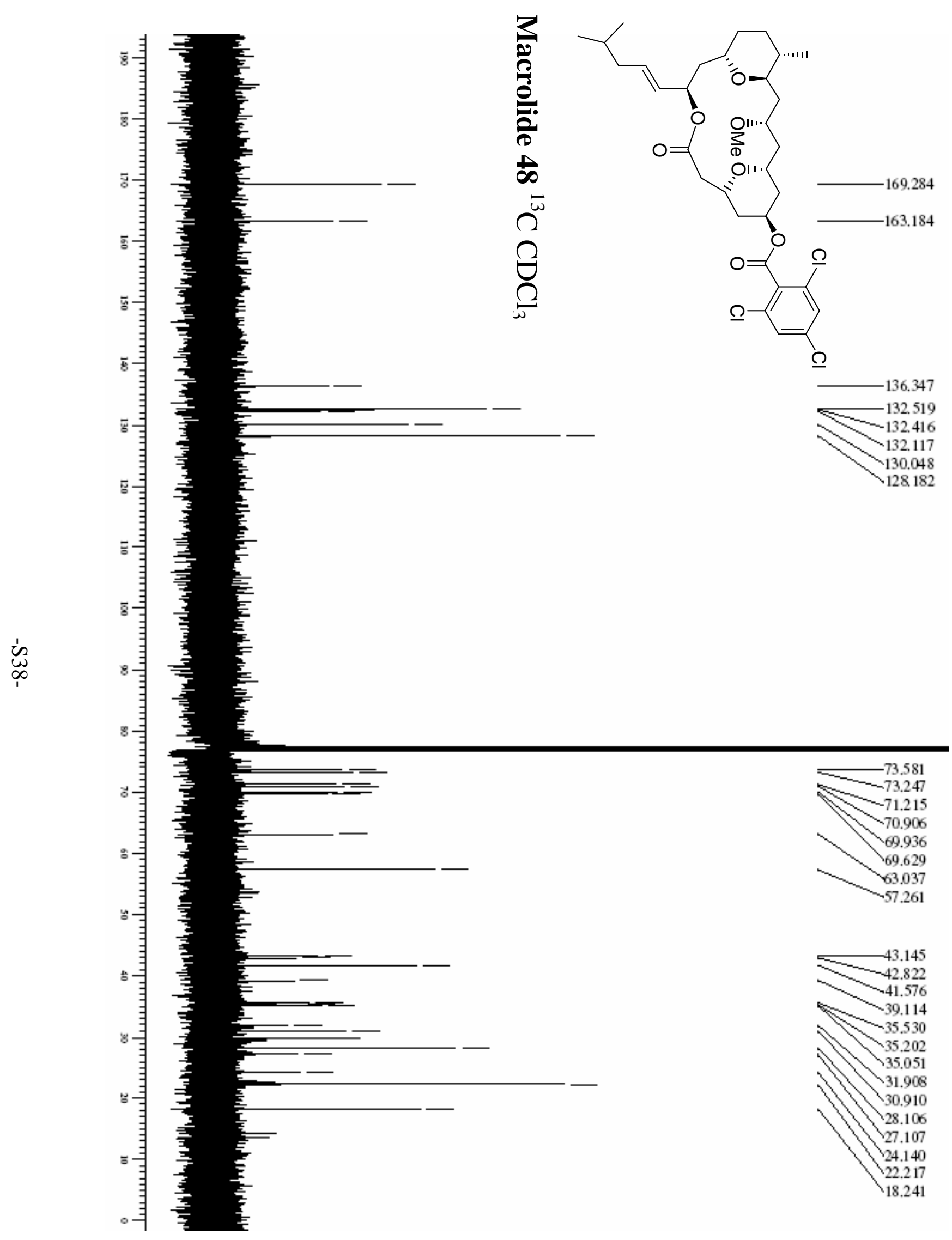

